\title{
Laser Drilling: Drilling with the Power of Light Phase 1: Feasibility Study
}

\author{
Topical Report
}

Reporting Period: September 29, 2000 - September 28, 2001

Cooperative Agreement No. DE-FC26-00NT40917

Brian C. Gahan and Richard A. Parker*

Gas Technology Institute

1700 S. Mount Prospect Road

Des Plaines, IL 60018

*Now at Parker Geoscience Consulting, LLC

Ramona Graves and Samih Batarseh**

Petroleum Engineering Department

Colorado School of Mines

Golden, CO 80401

**Now at Gas Technology Institute

Claude B. Reed and Zhiyue Xu

Argonne National Laboratory

9700 South Cass Ave.

Argonne, IL 60439-4815

Humberto Figueroa

Petroleos de Venezuela INTEVEP, S.A.

Caracas 1070A, Venezuela

Neal Skinner

Halliburton Energy Services

2601 Beltline Rd.

Carrollton, TX 75006

September 30, 2001 


\section{Disclaimer}

This report was prepared as an account of work sponsored by an agency of the United States Government. Neither the United States Government nor any agency thereof, nor any of their employees, makes any warranty, express or implied, or assumes any legal liability or responsibility for the accuracy, completeness, or usefulness of any information, apparatus, product, or process disclosed, or represents that its use would not infringe privately owned rights. Reference therein to any specific commercial product, process, or service by trade name, trademark, manufacturer, or otherwise does not necessarily constitute or imply its endorsement, recommendation, or favoring by the United States Government or any agency thereof. The views and opinions of authors expressed therein do not necessarily state or reflect those of the United States Government or any agency thereof. 


\section{Abstract}

A laser drilling research team was formed from members of academia, industry and national laboratory to explore the feasibility of using modern high-powered lasers to drill and complete oil and gas wells. The one-year Phase 1 study discussed in this report had the goals of quantifying the amount of pulsed infrared laser energy needed to spall and melt rock of varying lithologies and to investigate the possibility of accomplishing the same task in water under atmospheric conditions. Previous work by some members of this team determined that continuous wave lasers of varying wavelengths have more than enough power to cut, melt and vaporize rock.

Samples of sandstone, limestone, and shale were prepared for laser beam interaction with a $1.6 \mathrm{~kW}$ pulsed $\mathrm{Nd}$ :YAG laser beam to determine how the beam's size, power, repetition rate, pulse width, exposure time and energy can affect the amount of energy transferred to the rock for the purposes of spallation, melting and vaporization. The purpose of the laser rock interaction experiment was to determine the threshold parameters required to remove a maximum rock volume from the samples while minimizing energy input.

Absorption of radiant energy from the laser beam gives rise to the thermal energy transfer required for the destruction and removal of the rock matrix. Results from the tests indicate that each rock type has a set of optimal laser parameters to minimize specific energy (SE) values as observed in a set of linear track and spot tests. In addition, it was observed that the rates of heat diffusion in rocks are easily and quickly overrun by absorbed energy transfer rates from the laser beam to the rock. As absorbed energy outpaces heat diffusion by the rock matrix, local temperatures can rise to the melting points of the minerals and quickly increase observed SE values. The lowest SE values are obtained in the spalling zone just prior to the onset of mineral melt.

The current study determined that using pulsed lasers could accomplish removing material from rock more efficiently than continuous wave lasers. The study also determined that reducing the effect of secondary energy absorbing mechanisms resulted in lower energy requirements in shale and, to some extent, in sandstones. These secondary mechanisms are defined as physical processes that divert beam energy from directly removing rock, and may include thermally-induced phase behavior changes of rock minerals (i.e., melting, vaporization, and dissociation) and fractures created by thermal expansion. Limestone is spalled by a different mechanism and does not seem to be as affected by secondary mechanisms. It was also shown that the efficiency of the cutting mechanism improved by saturating porous rock samples with water, and that a laser beam injected directly through a water layer at a sandstone sample was able to spall and melt the sample. 


\section{Table of Contents}

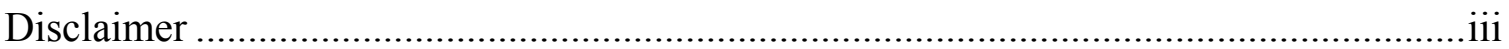

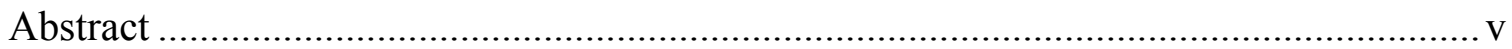

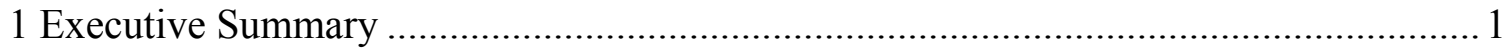

1.1 Legacy GRI Project, 1997-2000 ..................................................................... 1

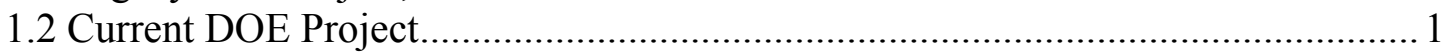

1.2.1 Experimental Approach ......................................................................... 1

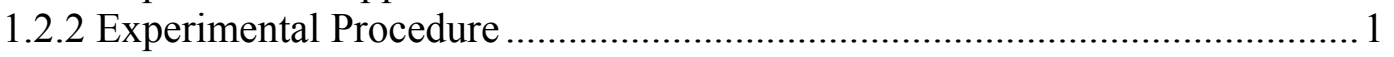

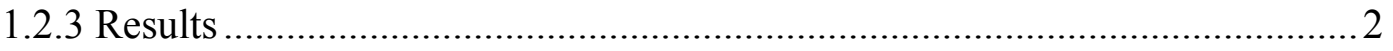

1.2.4 Conclusions and Recommendations ....................................................... 2

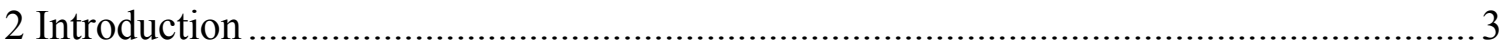

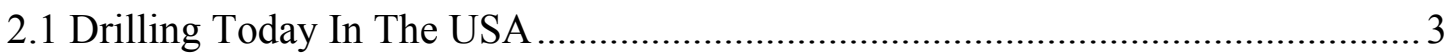

2.2 1997-2000 GRI Laser Drilling Research Project.................................................... 4

2.2.1 Phase One DOE Study ………….......................................................

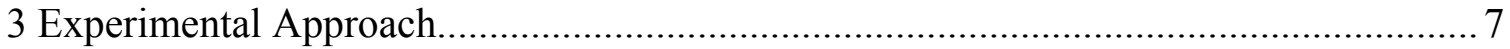

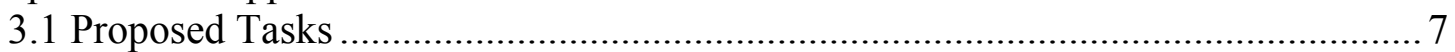

3.1.1 Determining “Absolute” Specific Energy .................................................

3.1.2 Determining the Value of Pulsed Lasers...................................................... 10

3.1.3 Saturated and Submerged Tests ............................................................... 12

3.2 The Rocks Used in the Phase 1 Feasibility Study ............................................... 13

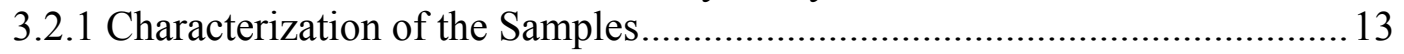

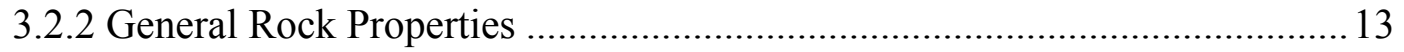

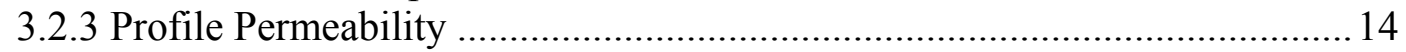

3.2.4 Factors to Consider in Using Samples ....................................................... 15

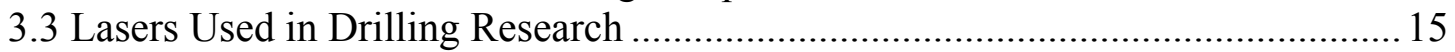

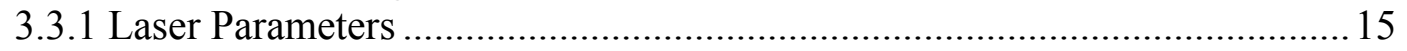

3.3.2 Characteristics Of The Lasers Used In This Study ....................................... 16

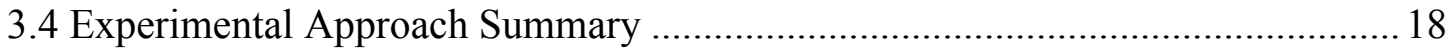

4 Experimental Procedures.................................................................................... 19

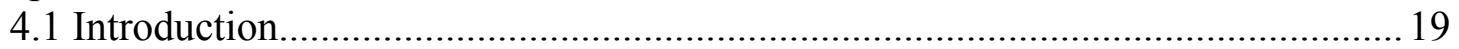

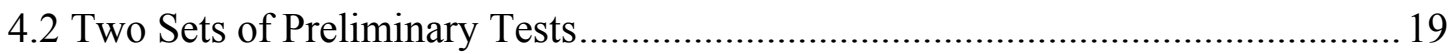

4.2.1 $\mathrm{CO}_{2}$ Disk Linear Tests .......................................................................... 19

4.2.2 Long Sample Linear Track Tests …………….......................................22

4.2.3 Fixed Laser Parameter Tests. ………………........................................2

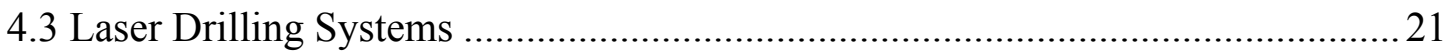

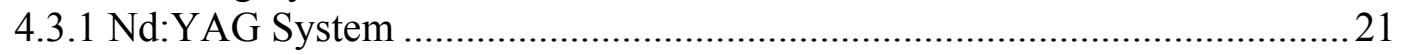

4.3.2 Nuvonyx Diode System ………………………....................................2 21

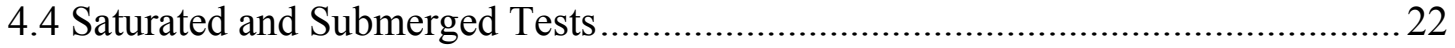

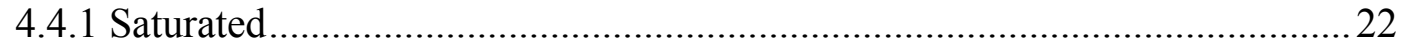

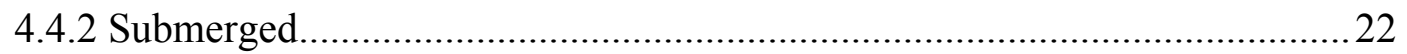

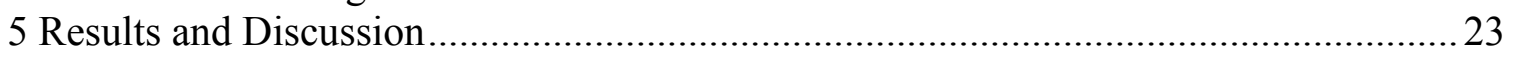

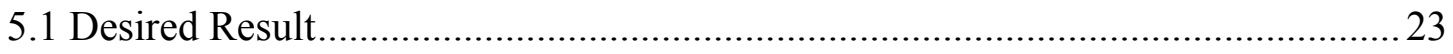

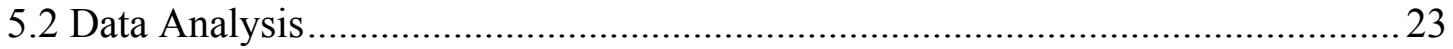

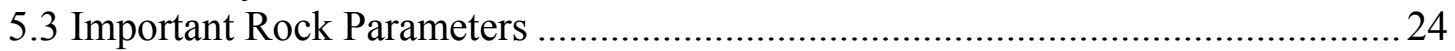

5.4 Spallation and Melting Zones Identified ........................................................ 24

5.5 Spallation Tests with Dry Samples................................................................2 


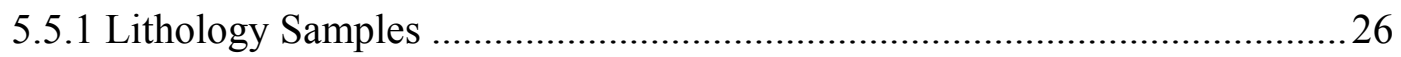

5.5.2 Specific Energy as Power Increases: Non-melt vs. Melt ...............................22

5.5.3 Effects of Pulse Width and Repetition Rate................................................28

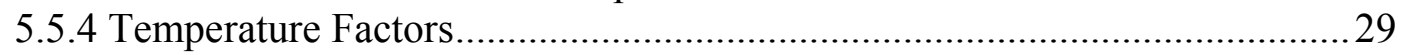

5.5.5 Spallation Tests with Saturated Samples …………....................................22

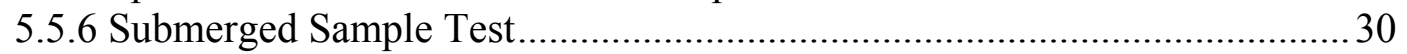

5.5.7 Diode Laser Tests with Dry Samples............................................................ 30

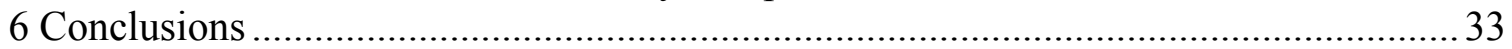

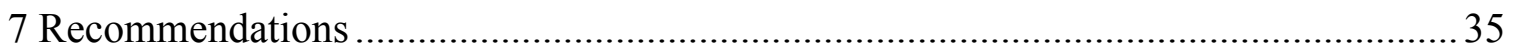

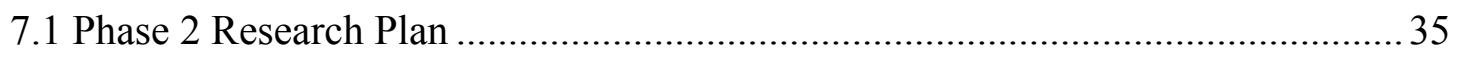

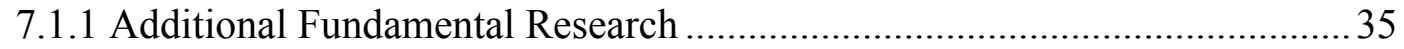

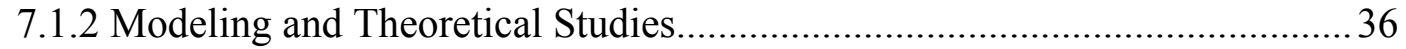

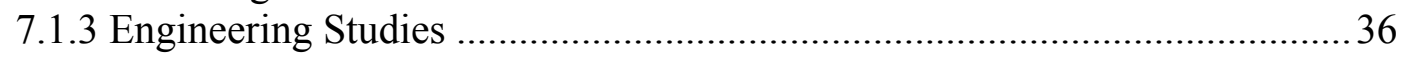

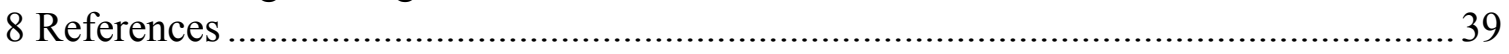

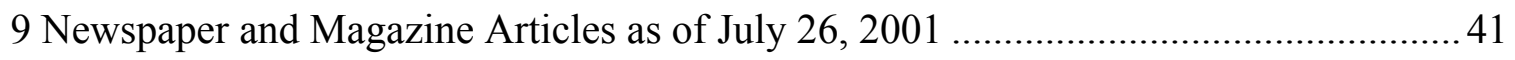

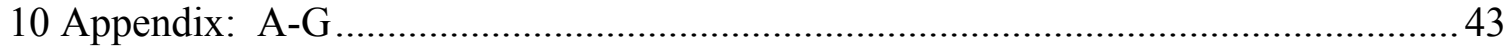

A: Test Sample Photographs: Fixed Parameters ………………………………….... 45

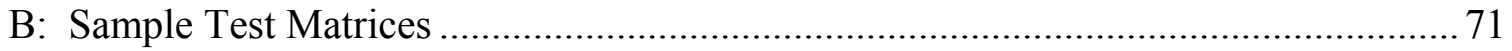

Dry Samples................................................................................................

Table B-1: Berea Gray Sandstone, dry ……………….................................... 73

Table B-2: Frontier Shale, dry .................................................................. 74

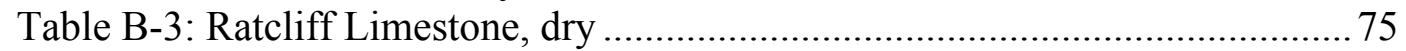

Saturated and Underwater Samples ..................................................................... 76

Table B-4: Berea Gray, Saturated Samples.......................................................... 76

Table B-5: Berea Gray, Underwater Samples ................................................... 76

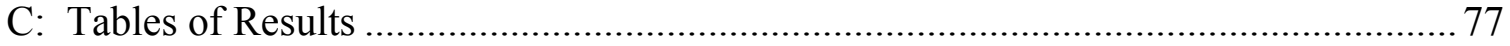

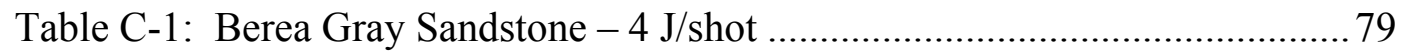

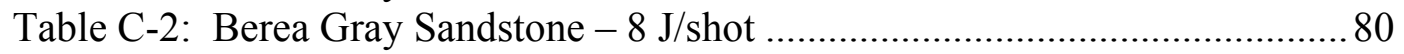

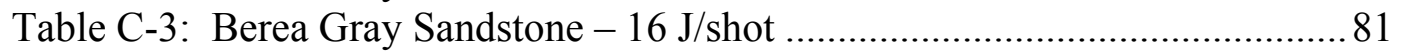

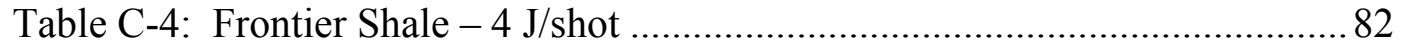

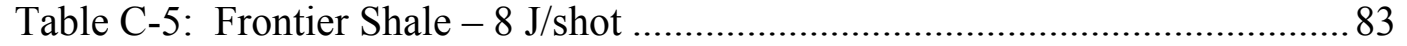

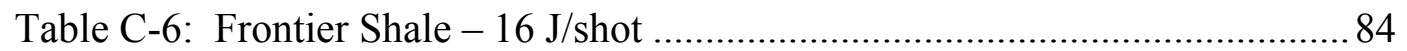

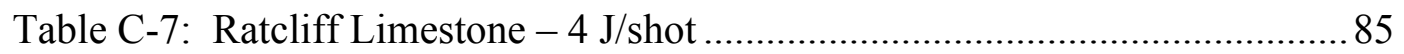

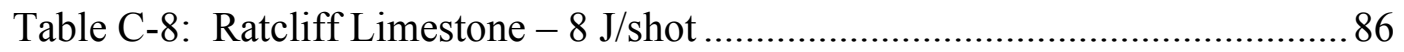

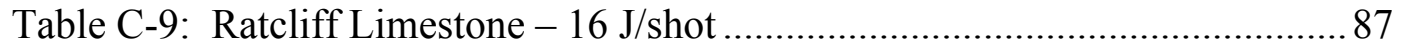

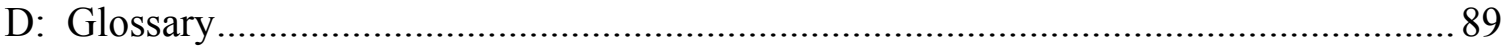

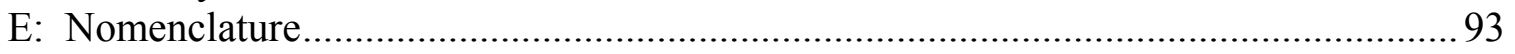

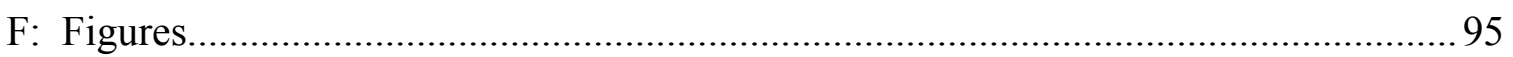

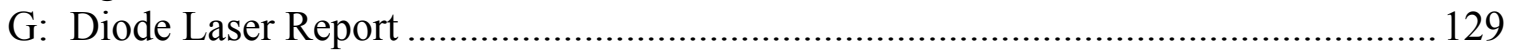




\section{Executive Summary}

\subsection{Legacy GRI Project, 1997-2000}

Three sandstones, three shales, three limestones, two granites, a salt and a concrete were subjected to energy from three lasers, including the MIRACL of the U.S Army and the COIL and $\mathrm{CO}_{2}$ lasers belonging to the U. S. Air Force. From the lasing and analysis of more than 240 samples, the following three main conclusions were drawn:

1. Present day lasers have more than enough power to spall, melt and vaporize rock.

2. Qualitatively, there is as much SE variability within as between lithologies.

3. Less power is needed to spall, melt or vaporize rock than calculated from basic principles in the 1960's by orders of magnitude.

\subsection{Current DOE Project}

\subsubsection{Experimental Approach}

A work plan was proposed to DOE to expand upon the GRI-funded work with additional wavelengths of laser power in environments other than air. It was felt necessary to demonstrate that laser parameters could be more carefully defined and to test the idea that pulsed lasers could cut more efficiently, as they do in metal work. Three objectives were defined:

1. Quantify GRI results,

2. Test effects of varying pulse parameters, and

3. Test laser/rock interaction under water.

\subsubsection{Experimental Procedure}

To accomplish objectives 1 and 2, it was felt necessary to:

1. Keep secondary mechanisms to a minimum,

2. Avoid melting and remelting of rock particles before they can get clear of the beam,

3. Properly purge the energy absorbing gas formed by heating the rock,

4. Keep energy below the levels that produce plasma,

5. Keep hole depth less than diameter, and

6. Complete several matrices of power/pulse width/pulse rate parameters to determine onset of spallation and melting and to find minimum SE for three representative lithologies: sandstone, limestone and shale.

To accomplish goal 3, samples were lased in stages:

1. Determine SE in water saturated samples to estimate effect of water in pores,

2. Measure energy absorbance in water, 
3. Adjust beam parameters, such as spot size and duration to account for absorbance losses, and

4. Inject beam into water directly from fiber to minimize reflective losses and simulate possible downhole configuration.

\subsubsection{Results}

1. Over 100 samples were processed according to the methods outlined. The results indicate that the GRI study did include significant energy loss to secondary effects. While it cannot be stated conclusively that the current work avoided all such effects, they were reduced considerably.

2. Removing the secondary effects allowed the determination that there are definable differences between lithologies. Shale, in particular, requires an order of magnitude less energy than sandstone or limestone. Limestone exhibited the least change in calculated SE than the other samples since no evidence of melting occurs, only thermal dissociation of the carbonate.

3. Pulsed lasers clearly cut faster with less energy than Continuous Wave lasers.

4. Wider pulse width and faster pulse repetition rates cut faster up to the point at which melting occurs.

5. Fluid saturated samples cut faster than dry samples. This is not totally understood as of yet. Possible mechanisms include suppression of melting by the more rapid heat transfer away from the cutting face, and an explosive expansion of the water into steam contributing to spallation.

\subsubsection{Conclusions and Recommendations}

While some fundamental measurements are still necessary, the minimum energy requirements are much better understood and ideas for system designs are now possible. The Laser Drilling Team has concluded that the feasibility of using lasers for drilling deep wells into the earth has been shown to the point that engineering and design studies can be started.

A work plan for a Phase 2 study includes the following tasks:

1. Continue laser tests under water until the laser/rock interaction is understood as well as it is now for dry and saturated rock.

2. Perform additional underwater SE tests in a simulated downhole environment with the development of a vessel that allows a laser beam injection into a pressurized environment with the sample under at least uniaxial stress.

3. Perform modeling and engineering design studies to develop and refine possible downhole assembly configurations.

It is projected that a Phase 3 study will be necessary to refine the system designs and perform tests targeted at particular system components. 


\section{Introduction}

\subsection{Drilling Today In The USA}

Rock destruction and removal is a significant issue in the process of oil and gas development. Over the years, billions of cubic feet of rock have been removed, with tremendous capital investment. In 1999, approximately 20,000 wells (oil, gas and dry) were drilled onshore in the United States, averaging about 6,000 feet deep, at a cost of nearly $\$ 15$ billion (Figure 1$)^{1}$. This is equivalent to approximately 23,000 miles, or nearly three times the diameter of the earth $(7,926$ miles).

According to a GRI study conducted in $1990,48 \%$ of the drilling time of a typical well is spent on making hole, $27 \%$ of the time spent changing bits or putting steel tubular casing in place, and $25 \%$ of the time spent measuring well and formation characteristics $^{2}$. Major reductions in drilling costs can be obtained by drilling faster and reducing requirements for drill string removal, bit replacement and setting casing.

The 2001 report of the National Energy Policy Development Group, headed by Vice President Dick Cheney titled "Reliable, Affordable, and Environmentally Sound Energy for America's Future" has a primary recommendation for action "to increase domestic production." Under this recommendation is a call for the Departments of Energy and Interior to promote enhanced oil and gas recovery from existing wells through new technology. Characteristics of the laser drilling system make it friendlier to the environment than current state-of-the-art drilling systems and it has the potential to tap known U.S. resources which are currently uneconomical to develop. Drilling is faster so the system is on location for a shorter period of time, thus minimizing interruptions to the natural ecosystems and reducing drilling objections for local residents. It is envisioned that the laser system would have a smaller environmental footprint and the use of hazardous chemicals would be greatly reduced.

Some of the concerns in drilling operations include: rock destruction and removal; drilling time and cost; rig size and transportation; hole shape and deviation; fishing for stuck pipe; and tripping and drilling in hard formations including granite. In well completion operations, perforating with a shaped charge gun causes reduced production by damaging the formation around the perforated tunnel. Depending on the rock type, drilling rates can be significantly reduced using lasers when compared to conventional drilling rates. For example, drilling

\footnotetext{
${ }^{1}$ DeGolyer and MacNaughton, 2000

${ }^{2}$ Andersen, et al., 1990.
} 
in hard rocks, such as granite, is extremely difficult or impossible. This research has shown that lasers penetrate hard rock at about the same rate as for soft rocks.

Reducing these costs and eliminating problems would have a significant positive impact on the oil and gas industry. New technologies and tools operate using basic rock destruction mechanisms like thermal spalling, fusion and vaporization, mechanical stresses and chemical reactions ${ }^{3}$. All of these destruction mechanisms can be achieved using lasers. For example, at low laser power, spalling (chipping) can be obtained. Increase in the laser power, with a fixed beam diameter, results in phase changes and reactions in the rock, like dehydration of clays, releasing of gases and inducing thermal stresses. At a certain power, the rock will melt (fuse) and at higher power the rock will vaporize.

Laser technology applied to drilling and completion operations has the potential to reduce drilling time, eliminate the necessity to remove and dispose of drilling cuttings and improve well performance through improved perforation operations.

\subsection{7-2000 GRI Laser Drilling Research Project}

Because reducing drilling costs in an environmentally sensitive manner is critical, in 1997 the Gas Research Institute (now Gas Technology Institute) initiated a two-year research program directed towards revolutionizing drilling. The specific objective of the research was to determine the feasibility of using high power lasers (1 kW and higher) for drilling and completing oil and natural gas wells. A 1994 congressional mandate to transfer cold war military defense technologies to American industry opened the door to begin an investigation of applying "Star War" laser technology to drill and complete oil and natural gas wells.

Two types of military lasers were included in this investigation: the Chemical Oxygen Iodine Laser (COIL) and the Mid-Infrared Advanced Chemical Laser (MIRACL). The COIL was developed at the U.S. Air Force Research Laboratory, Kirtland Air Force Base in Albuquerque, New Mexico. The size of the COIL has been reduced and optimized as part of the Airborne Laser (ABL) research project. Because of its tactical capabilities, it will be placed onboard a Boeing 747 aircraft and used to track and destroy missiles. The MIRACL is located at the U.S. Army's High Energy Laser Systems Test Facility in White Sands, New Mexico. The MIRACL was tested first because it is the most powerful laser in the Western Hemisphere. It has an output power that can exceed $1200 \mathrm{~kW}$. The initial tests determined that less power could be used for rock destruction so the remaining tests were conducted using the Air Force's $6.8 \mathrm{~kW}$ COIL.

\footnotetext{
${ }^{3}$ Maurer, 1968, 1980
} 
High power lasers were being developed in the former Soviet Union independent of the development in the U.S. A comprehensive literature review of Russian laser technology and experiment research using a $\mathrm{CO}$ and $\mathrm{CO}_{2}$ was conducted by the P.N. Lebedev Radiophysics Institute in Moscow, Russia. Some preliminary testing using a $\mathrm{CO}_{2}$ laser was also done at the U.S. Air Force Laser Hardening Material Experimental Laboratory in Dayton, Ohio.

\subsubsection{Phase One DOE Study}

The GRI project to demonstrate the feasibility of using high power lasers for oil and gas applications was very successful. Building on this, the U.S. Department of Energy (DOE) funded the next phase to more fully investigate the basic scientific principles that can bring this laser drilling and completions concept within reach of an industry-supported prototype development. Consortium partners in this research with DOE are Gas Technology Institute, Halliburton Energy Services, and the research facility within the Venezuelan National Oil Company, Petroleos de Venezuela - INTEVEP, S.A.(INTEVEP).

The experimental research was conducted at Argonne National Laboratory in Chicago, IL and in the Petroleum Engineering Department at the Colorado School of Mines, Golden, CO under the direction of the Gas Technology Institute. A very preliminary study of the Nuvonyx diode laser was performed at NA Tech, a small metallurgical company in Golden, Colorado.

The National Academy of Science published a report in 2001 "Energy Research at DOE: Was It Worth It?" This report concluded that DOE funded research has yielded economic returns of an estimated $\$ 40$ billion from an investment of $\$ 13$ billion since 1978. Laser drilling and completions research has the potential to continue and improve this return on DOE investment. Additional work is required to investigate scientific-engineering problems such as drilling under reservoir conditions of stress, pore pressure and saturation. Methods for rock removal from wells drilled by laser radiation, methods of delivering laser radiation, the economics, portability, reliability, durability, safety and environmental considerations should be taken into account. 


\section{Experimental Approach}

\subsection{Proposed Tasks}

The 1997-2000 GRI Laser Drilling Project consisted of fundamental research testing the feasibility of using the modern generation of lasers for hard rock drilling. The work attempted to measure the specific energy (SE, defined below) needed to cut and melt different lithologies, but found that secondary mechanisms prevented a "true" or "absolute" SE from being measured. The GRI work focused on continuous wave lasers, with little experiment time available for testing pulse efficiencies. The research team was very aware of industry's need to use pressure controlling weighted (and therefore opaque) drilling fluids, but rigid testing of this environment was not part of the research plan. Time was allotted for one test using the COIL, which showed that even through several inches of opaque drilling mud, a hole could be produced in a block of sandstone.

The research program reported in this document had the purpose of building on and adding to the GRI work in determining the feasibility of using high-power lasers in drilling and completing oil and natural gas wells by quantifying what was only qualitative measurements. The Phase 1 work required a better experiment design that minimized energy losses, while providing greater confidence in the SE calculations. Three tasks were identified:

Task 1.1 Energy Assessment Series -- GTI shall conduct laser cutting energy assessment series to determine the SE values of five (5) lithologies, of which includes a sandstone and a shale.

Task 1.2 Conduct Studies of Variable Pulse Laser Effects -- Using a $\mathrm{CO}_{2}$ laser, GTI shall perform series of tests on identical sandstone samples to determine the pulse, width and repetition rate that spalls the rock matrix most efficiently, then repeat the test using an Nd:YAG laser to determine wavelength effect. The test will be repeated with identical shale samples.

Task 1.3 Conduct Lasing through Liquids -- GTI shall design and conduct analytical studies to evaluate the optimum placement for the initial laser beam/liquid interface.

\subsubsection{Determining "Absolute" Specific Energy}

The absolute SE of a given rock sample is an intrinsic physical property of the rock, much like porosity and permeability, and should not change regardless of the rock removal techniques employed. There can be any number of measured values of SE, however, based upon the parameters of any given rock removal technique. These values can approach the absolute $\mathrm{SE}$ as the rock removal techniques become more efficient with respect to the responding primary and secondary mechanisms of the rock itself. Since SE is determined as the beam's 
power density (irradiance) for a given time duration per volume of rock removed, an accurate means must be available to measure these factors.

For purposes of pre- and post-laser rock property measurements, it is important to avoid edge effects, such as micro fractures, that affect the physical properties of the rock, but don't contribute to determining the SE, therefore, no laser spot edges were preformed closer than $2 \mathrm{~cm}$ from edge or each other.

\subsubsection{Material Removal}

The goal of the experiments was to remove a measurable amount of material with each use of the laser. There was quite a bit of discussion about what the minimum of removed material should be relative to the total mass of the sample. This was complicated by the need for a robust balance to handle the total weight of the sample, and could reduce the number of significant digits for a given sample weight. If the weight of material removed in a single hole was a few milligrams, would it be insignificant relative to the total mass of the rock or be within the error of the balance? The balance available was capable of weighing a maximum of a 160 gram sample with 4 digits to the right of the decimal point, which was sufficient for the experiments. If a particular test removed any material at all, it was in the 10's to 100 's of milligrams.

\subsubsection{Secondary Mechanisms}

Several details of the test plan were intended to reduce, if not eliminate, the secondary mechanisms recognized in the GRI study. The hole depth was kept less than the diameter to reduce the amount of spalled material that was melted and vaporized before escaping from the beam; and to reduce the amount of time that exsolved gases were in the beam before being dispersed by the purge gas. A coaxial purge vent was used to provide more efficient material removal.

Critics of the use of lasers in rock drilling point out the deleterious effect of plasmas, formed by the ionizing effect of the laser beam on gas molecules, on the absorption of the beam before reaching the sample. Calculations done by Humberto Figueroa, a member of the team from INTEVEP, indicated that the energy being used in these tests was well below that required for plasma formation.

\subsubsection{Specific Energy Calculations}

In order to break rock by mechanically or thermally induced stresses, sufficient power must be applied to the rock such that the induced stresses exceed the rock's strength. Similarly, when fusing rock, sufficient heat must be generated to produce local temperatures that exceed the melting temperature of the rock. Once these threshold values of power and energy are exceeded, the amount of energy required to break or remove a unit volume of rock remains nearly constant. This energy parameter, which is a measure of the efficiency of the rock destruction 
technique, is defined as SE. The term SE is associated with various definitions and is commonly used by the drilling industry in discussions of the efficiency of mechanical drilling, particularly in measuring effectiveness of new bit designs. SE is defined in this experimental work as the amount of energy required to remove a unit volume of rock and is relationally represented as follows:

$\mathrm{SE}(\mathrm{J} / \mathrm{cc})=$ Energy input $/$ volume removed

\subsection{Parameters Affecting SE Measurements.}

There are three basic phenomena evident in the process of radiant energy transfer to solids: reflection, scattering and absorption of radiation. The flow of energy of an incident electromagnetic wave $\left(\mathrm{E}_{\text {inc }}\right)$ is divided into these parts:

$E_{\text {inc }}=E_{\text {refl }}+E_{s c}+E_{\text {abs }}$

Where $\mathrm{E}_{\text {refl }}, \mathrm{E}_{\mathrm{sc}}$, and $\mathrm{E}_{\mathrm{abs}}$ are reflected, scattered and absorbed fractions of the energy flow of the incident wave, respectively.

If a surface is a planar one, like a mirror, then much of the energy is reflected. Rough surfaces mainly scatter the incident radiation. The reflectivity is determined by the composition of the solid, while the scattering of radiation is determined by wavelength, $\lambda$. It is the absorbed energy that gives rise to the rock heating and destruction. Reflection and scattering represent energy losses that occur apart from the absorbed energy. Minimizing fractions of reflected and scattered energy losses will, consequently, maximize the energy available for transfer to a rock for destruction.

There are factors that affect the amount of absorbed energy transferred to the rock samples, known as secondary effects, and include the creation of melted materials, beam absorbing exsolved gases in the lased hole and induced fractures in the surrounding rock. When applying high power lasers on rocks, the laser can spall, melt, or vaporize the rock as the energy transferred to the rock raises its temperature locally. Mineral melt begins to occur when the rate of heat dissipation by the rock is exceeded by the rate of energy absorbed by the rock. As time increases, energy accumulates in the form of heat, raising the local temperature of the minerals to their melting points, forming a glassy melt.

The amount of melt is a function of the mineralogy of the rock and the intergranular space of the rock matrix. The closer the grains are to one another, the more heat will be transferred, resulting in more melt in the rocks. However, for tightly packed grains, the heat conductivity could reach higher values dissipating the heat at a faster rate, reducing the amount of melted material. Also, some minerals decompose and produce gas. As a result, the melt and gases 
require part of the laser energy for their creation, so a smaller percentage of the total laser energy is transmitted to rock.

Fractures that form in the samples also have an impact on SE. It may be that fractures extending out from the laser created hole are beneficial to the removal process. However, it is our conclusion that the fractures seen in the tests are an artifact of the sample size and do not represent what will occur in the subsurface under in situ conditions.

For the purposes of this study, fractures represent losses of energy, which result in higher SE values. Fractures are classified as macro- and micro- fractures. The behavior of fractures is different from one rock type to another. This difference depends on intrinsic factors such as mineralogy, thermal properties of the rocks, volume of void space, dimension of the sample and the amount of stress applied. Mineralogy also affects fracture formation. Clays contain water and by subjecting the clays to higher temperatures, water will escape in the form of vapor. This increases the volume and pressure in the pore and can cause fractures. Sandstones and shales have high thermal conductivities and contain clays. Limestones, on the other hand, have low thermal conductivity and have low amounts of clay and quartz. Therefore, fractures are expected in sandstones and shales, but not in limestones.

Rocks having a high thermal conductivity transfer heat more efficiently and the temperature is more uniform within the rock. Therefore, for this type of rock, cooling occurs gradually along the core sample. For example, fractures in sandstones developed regularly, not randomly. High temperatures resulting from the energy of the laser beam causes quartz grains to expand. At $600^{\circ} \mathrm{C}$ quartz grains expand by $1.75 \%$ of the original size. In the case of full grain contact (low void space), grains have less space to expand and fractures develop ${ }^{4}$.

The dimensions of the sample can affect the behavior of the fractures. It has been observed from the previous tests ${ }^{5}$ that the $2.54-\mathrm{cm}$ diameter cores are highly fractured around the hole, while the $3.09-\mathrm{cm}$ diameter cores are less fractured. Finally, stress applied to the core minimizes the macro fractures, while the micro fractures will still remain.

\subsubsection{Determining the Value of Pulsed Lasers}

\subsubsection{What Is A Pulsed Laser?}

The discharge of a pulsed laser is characterized by a train of pulses of similar characteristics generated at a fixed time interval as shown in Equation 3.

\footnotetext{
${ }^{4}$ W.H. Somerton, 1992.

${ }^{5}$ R.M. Graves and D.G. O'Brien, 1998
} 
$\mathrm{P}_{\mathrm{av}}=\mathrm{P}_{\mathrm{p}} \times \mathrm{W}_{\mathrm{p}} \times \mathrm{R}$

In this equation, $\mathrm{P}_{\mathrm{p}}$ refers to the maximum power in a single pulse, $\mathrm{W}_{\mathrm{p}}$ is the width of each pulse in units of time, and $\mathrm{P}_{\mathrm{av}}$ is the output power averaged over time (Figure 2). An important parameter in pulsed discharges is the pulse repetition rate $\mathrm{R}$, or number of pulses per unit time, defined as the inverse of time, $\mathrm{T}: \mathrm{R}=1 / \mathrm{T}$. Also, the average power and the energy $\mathrm{E}$ in each pulse are related to the other laser parameters through the relationship shown in equation 4 .

$\mathrm{E}=\mathrm{P}_{\mathrm{p}} \times \mathrm{W}_{\mathrm{p}}$

This type of discharge allows for a better control of the laser effects on the rocks than the continuous discharge, since each parameter affects the rock differently. For example, long pulses ( $\mathrm{W}_{\mathrm{p}}$ on the order of milliseconds) and high repetition rates favor melting, whereas short pulses $\left(\right.$ small $\left._{\mathrm{p}}\right)$ and low repetition rate favor creation of microfractures. This type of beam manipulation is not possible in the case of the continuous wave $\mathrm{CO}_{2}$ laser discharge.

For experiments where the laser beam diameter (spot size) is varied, it is best to define the laser intensity, I (also called power density), as the peak power divided by the beam spot size represented by Equation 5 .

$\mathrm{I}\left(\mathrm{W} / \mathrm{cm}^{2}\right)=\mathrm{P}_{\mathrm{p}}(\mathrm{W}) /$ spot size $\left(\mathrm{cm}^{2}\right)$

This wide range of parameter values allows for the determination of their effects on SE within that range. Lasers utilize three methods of rock destruction; spallation, melting, and vaporizing; and can be controlled to the extent of the application of these parameters. In this phase of the research, the experiments were carried out using lower powers and less exposure time than in the COIL experiments of the previous GRI laser study ${ }^{6}$.

\subsubsection{Using a Pulsed Laser on Rock Samples}

The purpose of the laser rock interaction experiments is to determine laser and rock threshold parameters required to remove the maximum rock volume from the samples with a minimum amount of energy. This was performed first with dry rock samples, followed by saturated and submerged samples. All of the experiments were conducted at atmospheric pressure.

\footnotetext{
${ }^{6}$ R.M. Graves and D.G. O'Brien, 1998
} 
A change in experiment design following the GRI study was to keep the hole depth less than the hole diameter. Previous results determined that the material liberated from the rock remained in the hole as the hole got deeper and was melted and vaporized, absorbing energy from the beam that should have been used for breaking new rock. Also, the deep holes trapped the gases exsolving from the rock, absorbing even more of the beam energy. Except for the limestones, all of the samples had some amount of melt attached to the rock. A power/time range where the rock was spalled and not melted was postulated, but not observed. The large expanse of clean rock evident from the very high power MIRACL laser was attributed to vaporization rather than spalling.

The power density of the laser beams and total power exposed to the rock was known for the continuous wave (CW) work, so some initial estimates were made for the pulse parameters to be used in this study. These estimates were determined from preliminary linear tests described in the next chapter, where a spalling zone was observed on the sandstones for the first time. From this information, several test matrices were created with various combinations of pulse width, repetition rate and duration, in an attempt to determine the specifications for each lithology (Appendix B). It was determined that the calculated average power $\left(E^{*} L^{*} R\right)$ would be kept at the maximum for the $1.6 \mathrm{~kW} \mathrm{Nd:YAG} \mathrm{laser.}$ Real average power, as measured for each set of parameters, was always somewhat less than calculated because of the limitations of the laser system.

\subsubsection{Saturated and Submerged Tests}

\subsubsection{Saturated}

The team was interested in determining the behavior of water in the pores of the sandstones. Two possible outcomes were theorized: the water would convert into steam, aiding in the breakage of the rock, or the presence of water would alter the heat conductivity of the system, and allow heat to leave the immediate area quickly enough that reduce or avoid fractures. There could also be some combination of the two. A series of tests were devised to expand the dry rock matrices to investigate the behavior of the wet samples.

\subsubsection{Submerged}

The drilling industry has made it clear during our discussions with them that to claim success, this research program will have to demonstrate that laser drilling can take place in the presence of water and other fluids in the borehole. The full analysis is beyond the scope of this feasibility study, however an initial test could provide valuable qualitative information. In addition to the saturated sample tests described above, a series of experiments were undertaken to explore the possibility of injecting the laser beam into water and have it impinge on and cut into a rock sample. A full set of test matrices were not envisioned or accomplished, but enough work was done to show the possibilities and give the team a direction forward. 


\subsection{The Rocks Used in the Phase 1 Feasibility Study}

\subsubsection{Characterization of the Samples}

Tests were conducted on sandstone, limestone and shale, with the majority of the tests being sandstone. Berea sandstone, a standard quarry rock used in the petroleum industry for laboratory testing, a Ratcliff limestone from a cored well at a depth of 6,000 ft and a Frontier shale from 13,200 ft were the test rocks. These rock types were selected because they have very consistent and uniform properties. Also, they had been used in the Chemical Oxygen Iodine Laser (COIL) experiments that were conducted as part of the previous GRI funded research "Revolutionary Technology for Gas Wells (GRI contract number 5097260-3968).

\subsubsection{General Rock Properties}

The rocks were initially characterized during the GRI funded research and are discussed in detail in the related GRI reports. ${ }^{7,8,9}$

Microscopic properties, such as mineralogy, clay content, and microfractures, were determined using a scanning electron microscope with the energy dispersive system (SEM-EDS), x-ray diffraction (XRD), and thin sections. Melting temperatures of these rocks were measured using differential thermal analysis (DTA).

Core properties, such as porosity and permeability, were measured on representative samples using the Core Measurement System-300 (CMS-300). The CMS-300 measures porosity, permeability, bulk modulus, Klinkenberg slip factor, and the non-Darcy flow coefficient (Forchheimer) up to 5,000 psi. For this study, the porosity and permeability data from the CMS-300 were used to ensure consistency of samples for comparison to other laser studies performed on these rock types. These general properties are summarized in Table 1.

The compressional and shear wave velocities through the cores were also measured and used to calculate the dynamic elastic rock properties. These properties include Young's modulus (E), shear modulus $(\mathrm{G})$, bulk modulus $\left(\mathrm{K}_{\mathrm{b}}\right)$, and Poisson's ratio ( $v$ ) (Table 2). These parameters are an indication of the rock's strength. They were measured with no imposed stress and the cores were dry; the same test conditions the rocks were under when lased.

\footnotetext{
${ }^{7}$ Graves and Batarseh, 2001a

${ }^{8}$ Graves and Batarseh, 2001b

${ }^{9}$ Graves and Batarseh, 2001c
} 


\subsubsection{Profile Permeability}

The Pressure Decay Profile Permeameter (PDPK) was used to characterize the rocks before and after lasing. The PDPK measures point permeability at ambient conditions, Klinkenberg slip factor and the non-Darcy flow coefficient (Forchheimer). The PDPK is reliable down to a permeability of $0.001 \mathrm{md}$ and experience has shown it to be repeatable and accurate. This non-destructive, unsteady-state test can measure permeability on irregular shapes, therefore, it an excellent tool to analyze before and after lasing permeability.

Even though Berea exhibits consistent properties when compared to reservoir rocks, and is considered the standard used by industry, the permeability variations along four-slabbed 2-inch diameter cores was measured. These were the same Berea used to investigate the correlation between the rock removal mechanisms and beam irradiance through the linear track method with simultaneous change of beam size on the surface. Eighty-eight permeability measurements were taken at one-half inch intervals along the length of the eight slabs in the pattern shown in Figure 1.

The results of one pair of twin slabs are shown in Figure 2. The data were taken three times and the average value is plotted. An example of the permeability variability along the length of the core can be seen in BG1 in Column 1, which is 0.32 inches in from the left edge of the sample. The maximum permeability is $444 \mathrm{md}$ at 2.0 inches. The permeability one-half inch above is $338 \mathrm{md}$ while the permeability one-half inch below is $379 \mathrm{md}$. The minimum permeability is 117 md at 8.5 inches. BG1 also shows considerable variation along the width of the core. The maximum variation is at 8.5 inches with permeabilities from $127 \mathrm{md}$ to $414 \mathrm{md}$.

In BG2, the data taken at 0.5 inches from the top edge demonstrate the potential error that can occur near the edges of the samples. This enhanced permeability could be due to microcracking during preparation or testing, however low-power microscopic inspection did not indicate cracks. Another possibility is that the PDPK might have had a leak in the probe seal because of the proximity to the edge. All measured permeability results taken before and after lasing were visually compared to the core so anomalous data would not be used.

The curves in BG2 have a more similar shape than the curves in BG1. Since they are from the same core, it was anticipated that the two slabs would have comparable curve shapes. The data were taken in a square grid pattern so the arithmetic average of the permeabilities was used. The average permeability for BG1 is $301 \mathrm{md}$ and for BG2 it is $337 \mathrm{md}$. Table 3 gives the maximum, minimum, and average values for the eight Berea slabs.

These permeability data demonstrate that even though Berea sandstone is considered to be an excellent sample for laboratory measurements, there is still 
variation within the rock. Great care was taken when cutting, cleaning, marking, and shipping the rocks to insure that the preparation did not affect the test results. Also, the PDPK data was taken several times at a given point and averaged. During the analysis, if any data did not follow an expected trend, the permeability was re-measured to confirm the reliability of the initial measurements.

\subsubsection{Factors to Consider in Using Samples}

\subsubsection{How close should the holes be placed?}

The GRI study shows clearly that the rock samples will crack due to thermal stress from the heat of the laser. What was not understood is how the formation of the cracks affects the SE. The analysis of the data indicated that cracking should be treated as an energy absorbing boundary affect and should be avoided. However, there were two reasons why the team wanted to have more than one hole per sample. The first was to reduce number of samples required, and the second was to determine the repeatability of the laser/rock interaction. For the sandstones and shales, it was decided to limit the tests to three holes per sample, placed so that their edges are no closer than $2 \mathrm{~cm}$ to the edge and spaced equidistant to one other. For the limestone, since cracking was not evident on any previous samples, the placement and number of the holes was much less ordered.

\subsection{Lasers Used in Drilling Research}

\subsubsection{Laser Parameters}

LASER is an acronym for Light Amplification by Stimulated Emission of Radiation. Albert Einstein predicted the possibility of stimulated emission (generation of photons or discrete bundles of energy via transitions between atomic or molecular energy levels) in 1917. Laser use in many applications such as medical, metallurgical, and military, is becoming well understood. The principle of the laser is transforming different kinds of energy (chemical, electrical, etc.) into intense electromagnetic beams of monochromatic and coherent waves. The wavelength of a laser beam $(\lambda)$ depends on laser's active medium, and ranges from 0.1 micrometers $(\mu \mathrm{m})$ to $103 \mu \mathrm{m}$, spanning the ultraviolet, visible, infrared and sub-millimeter ranges of the photonic spectrum ${ }^{10}$.

Laser drilling is a developing technology that has been applied to industrial uses such as creating small holes in metal and other materials. This research examines the possibility of expanding the use of lasers to remove rock for oil and gas exploration and production applications, including conventional and horizontal

${ }^{10}$ W.T. Silfvast, 1996 
drilling, cutting windows in steel casing and cement, and other completion techniques.

In rock drilling, the type of laser used plays a crucial role in the efficiency and quality of the cut. Laser properties, including discharge type (continuous or pulsed), wavelength, peak power, average power, intensity, repetition rate, and pulse width define the type of laser rock interaction obtained, and thus, affect the amount of energy transfer to the rock. The results of the previous experimental work show that lasers penetrate well through rocks, as they have a low reflectivity of electromagnetic waves, resulting in a good coupling with the laser radiation. Also, the low thermal conductivity of rocks allows for a rapid heating of the rock sample in the vicinity of the beam.

\subsubsection{Characteristics Of The Lasers Used In This Study}

Except for a small study of the capabilities of the Nuvonyx diode laser at Native American Technologies Company, in Golden, Colorado, the lasers available for this study were located at the Laser Applications Laboratory (LAL) of the Technology Development Division at Argonne National Laboratory (ANL). A 6 $\mathrm{kW}$ carbon dioxide gas-type laser capable of both continuous wave and superpulsed beams, and a $1.6 \mathrm{~kW}$ neodymium yttrium aluminum garnet (Nd:YAG) solid-state laser capable of a wide range of pulse widths and repetition rates were initially evaluated. Although ANL's $\mathrm{CO}_{2}$ laser had the capability of mimicking a pulsed beam in its super-pulsed mode, the initial testing showed this laser was incapable of providing the required range of control on the power delivery and repetition rate to the sample. As a result, it was determined to use only the Nd:YAG laser while varying beam diameter, duration, energy per shot, pulse width, and pulse repetition rate, and determine their respective influences on measured specific energy (SE) values. However, since some of the figures included in this report were done with the $\mathrm{CO}_{2}$ laser, the characteristics of that laser will be presented as well. The Nuvonyx diode laser, because of its compact size, has the exciting possibility of being used downhole, so a few samples were exposed to various intensities of this laser.

\subsubsection{Characteristics Of The Nd:YAG Laser}

The Nd:YAG laser is a flash-lamp excited solid state laser. The model used at ANL is a four-stage version that has excellent power and beam characteristics, including a wide range of pulse modes. The Nd:YAG is already coupled to an optical fiber, so tests could be designed as if the system was configured for downhole work. The characteristics of the Nd:YAG laser are as follows: 
- Wavelength, $\lambda$

$1.06 \mu \mathrm{m}$

- Maximum Average Power, $\mathrm{P}_{\mathrm{av}}$

- Maximum Peak Power, $P_{p}$ $32 \mathrm{~kW}$

- Pulse Width Range, $\mathrm{W}_{\mathrm{p}}$

$0.1-10 \mathrm{~ms}$

- Repetition Rate Range, R

$25-800$ pulses/sec

- Maximum Energy, E

$100 \mathrm{~J} /$ pulse

\subsubsection{The $\mathrm{CO}_{2}$ Laser}

The $\mathrm{CO}_{2}$ laser is, in some ways, at the opposite end of the spectrum for infrared lasers. It is a radio frequency (RF) excited gas laser, where the $\mathrm{CO}_{2}$ is not used up, as the chemicals are in the COIL and MIRACL, but is replenished only when needed. The $\mathrm{CO}_{2}$ has the longest wavelength of the group studied to date. This long wavelength led to early and constant melting of any samples containing quartz, which is transparent to $\mathrm{Nd}: Y A G$ wavelength, but opaque to $\mathrm{CO}_{2}$ wavelength. This fact influenced our decision to cease additional tests using the $\mathrm{CO}_{2}$ after the first preliminary runs. The characteristics of the $\mathrm{CO}_{2}$ laser are as follows:

- Wavelength, $\lambda$

- Maximum CW Power, $\mathrm{P}_{\mathrm{av}}$

- Maximum Peak Power, $\mathrm{P}_{\mathrm{p}}$

- Pulse Width Range, $\mathrm{W}_{\mathrm{p}}$

- Pulse Frequency, R
$10.6 \mu \mathrm{m}$

$6.7 \mathrm{~kW}\left(\mathrm{TEM}_{20}\right)$ $1.8 \mathrm{~kW}\left(\mathrm{TEM}_{00}\right)$

(a) 4 times CW output

$50-500 \mu \mathrm{s}$

$0-25 \mathrm{kHz}$

\subsubsection{The Nuvonyx Diode Laser}

A diode laser of the power level necessary to cut rock is a relatively new development, but is becoming more common. The physical size of the laser is very attractive for field use, as is the ease of reconfiguring the shape and beam characteristics. In the Nuvonyx design, higher power can be obtained by merely adding more $1 \mathrm{~kW}$ modules. One big difference between the diode and the $\mathrm{Nd}$ :YAG lasers is that the power rating given for the diode laser is for average power in CW mode and peak power in pulsed mode, no multiplier is applied. The diode has two advantages over other systems, it is compact and easily moved; and it has a much higher efficiency than the other systems, greater than $50 \%$ compared to $10-25 \%$. The diode laser used for this research was manufactured by Nuvonyx and has the following characteristics: 
- Wavelength, $\lambda$

$0.8 \mu \mathrm{m}$

- Maximum CW Power, $\mathrm{P}_{\mathrm{av}}$ $4 \mathrm{~kW}$

- Maximum Peak Power, $\mathrm{P}_{\mathrm{p}}$ $4 \mathrm{~kW}$

- Pulse Width Range, $\mathrm{W}_{\mathrm{p}}$ $0-1000 \mathrm{msec}$

- Pulse Frequency, R

$0-1000 \mathrm{~Hz}$

\subsection{Experimental Approach Summary}

The team, through many discussions, made a series of test goals and developed test designs to accomplish them. Laser parameters of peak energy, pulse width and repetition rate were used such that the onset of breaking and of melting would be determined as separate events. The secondary mechanisms affecting the results of the GRI study would be avoided to obtain the best estimate of the "absolute" specific energy possible for each lithology tested: sandstone, shale and limestone.

Even though the single most drilled lithology is shale, and anything we develop in this project will have to work as well on shale as on sandstone, the majority of the tests were performed on the Berea gray sandstone, because of the consistency of the rock parameters. Interestingly, as will be discussed in the Results section, the techniques work better on shale than on sandstone, by an order of magnitude.

The lasers used for most of this study were the $\mathrm{CO}_{2}$ and Nd:YAG at Argonne National Laboratory. A small study was done using the Nuvonyx diode laser at Native American Technologies in Golden, Colorado. 


\section{Experimental Procedures}

\subsection{Introduction}

The research team all met three times during this phase of the study, in April, May and August. A first set of tests were designed to work with dry sandstone, shale and limestone samples, trying to get as close as possible to the "absolute" specific energy for each lithology. A second set was to extend this work and move on to testing sandstones saturated with water and sandstones submerged in water.

The lasers at the facility in Argonne National Lab were used for these tests. There was much preliminary work necessary to determine safety requirements while working with natural materials and to train the non-ANL members of the team to work safely during the tests.

\subsection{Two Sets of Preliminary Tests}

At ANL's request, several rock samples were supplied for preliminary laser/rock interaction tests. ANL had done ablation work on concrete, but had not used the lasers on natural materials. There was some concern about the safety aspect, such as stray reflections of the beam or possible explosions if the sample contained water or other fluids. It was also felt that test time would be more efficient while the team was together if starting points were determined beforehand. The samples supplied by Colorado School of Mines were used with a rough grid of tests to create test matrices that could be finished in the time available, which was less than a week in May and a week in August. The first set of samples indicated that the $\mathrm{CO}_{2}$ laser, in the super pulse mode, was not a suitable source of energy for this study, and the second showed that a zone of spallation could be seen as a separate entity, which had not been seen before in sandstones.

\subsection{1 $\mathrm{CO}_{2}$ Disk Linear Tests}

A series of initial preliminary tests were designed to observe the laser/rock interactions for both the $\mathrm{CO}_{2}$ and $\mathrm{Nd}$ :YAG lasers with each of the rock lithologies. The purpose of these initial tests was to identify possible laser-rock interaction phenomenon and the corresponding laser processing parameters. Initial laser/rock interactions were observed on prepared rock samples of Berea gray and Berea yellow sandstones, Frontier shale, Ratcliff limestone and a prepared concrete slab using various power settings and focal distances from Argonne's $6 \mathrm{~kW} \mathrm{CO}_{2}$ laser in continuous wave (CW) and super-pulsed modes.

The samples were exposed to the laser beam for predetermined periods of time to determine the dependence of the laser parameters on SE. Initial observations of 
each rock type exhibited different physical changes induced under a given matrix of laser parameters, particularly with respect to microfractures, mineral melting and dissociation (Figures 3a-d). Since we could not identify a zone of spallation using the $\mathrm{CO}_{2}$ laser, it was decided to use the Nd:YAG exclusively for the rest of the tests.

\subsubsection{Long Sample Linear Track Tests}

The rock samples used were Berea gray sandstone, Frontier shale, and Ratcliff limestone. The tests had two purposes: to determine if a separate spallation zone could be isolated; and to reduce the range of processing parameters such as beam spot size, laser parameter schedule (ELR), and beam exposure time needed to create the test matrices.

The linear tests were carried out by moving the slab at a constant speed while the laser lens was raised from 0.5 to $20 \mathrm{~cm}$ above the sample, resulting in a changing beam spot size from $0.5 \mathrm{~mm}$ to $22 \mathrm{~mm}$. A wide ranges of laser parameters were tested. Energy per pulse varied from 2 to $32 \mathrm{~J}$; repetition rate from 50 to $800 \mathrm{1} / \mathrm{s}$; peak power from 4 to $16 \mathrm{~kW}$; and pulse width from 0.5 to $2 \mathrm{~ms}$. The calculated average power was fixed at $1600 \mathrm{~W}$ for each test, while the actual delivered (measured) power ranged from 686 to $1310 \mathrm{~W}$. The difference is due mainly to losses in the fiber optic delivery system and the fact that at low energies/pulse (as low as $2 \mathrm{~J} /$ pulse) the laser does not deliver power as efficiently as at high energy per pulse. The different laser-rock reaction zones for each rock type are shown in Figures $6 \mathrm{a}-\mathrm{c}$. The zones are identified by regions of similar physical reactions observed in the rock, ranging from intense melting to merely scorching.

\subsubsection{Fixed Laser Parameter Tests.}

Round rock samples were prepared with dimensions of approximately $1.27 \mathrm{~cm}$ in thickness and $7.62 \mathrm{~cm}$ in diameter. The samples were exposed to the laser beam for predetermined periods of time to determine the dependence of SE on the laser parameters.

The average beam power ranged between $204 \mathrm{~W}$ and $1204 \mathrm{~W}$. The lasing or exposure time was $0.5,1.0$, or 1.5 seconds. The pulse width was either 1 or $2 \mathrm{~ms}$, whereas the repetition rate varied between 50 and 400 pulses/sec. Typical beam diameters were 1.27 and $0.95 \mathrm{~cm}$. Full test matrices can be seen in Appendix B.

Compressed nitrogen was used as purging gas to blow ejected gases and debris from the rock surface and to clean the hole. Purging is an important process to obtain accurate SE measurements, reducing gas condensation or debris in the hole, and minimizing melted material adhering to the surface. By reducing these secondary effects through the use of a purge gas, a more accurate SE value can be measured for each rock sample. In this set of experiments, purging was successful 
at removing unwanted residues, since the holes created were shallow, with depths on the order of a few millimeters. This was not the case in the earlier COIL experiments, where the holes were much deeper and melted deposits were formed in almost every instance ${ }^{11}$.

\subsection{Laser Drilling Systems}

\subsubsection{Nd:YAG System}

Most of the tests reported here were conducted with a laser drilling system that consisted of a $1.6 \mathrm{~kW}$ pulsed Nd:YAG laser with fiber-optic beam delivery, fiveaxis CNC workstation and coaxial purging gas unit (Figure 7). The fact that the beam is delivered by an optical fiber is particularly attractive because of its inherent flexibility and the possibility that this will be the method used to deliver and aim the high power beam down in a well. A $12.5-\mathrm{cm}$ transmissive focusing lens was used producing a collimated beam diameter of $985 \mu \mathrm{m}$. A constant nitrogen flow of 189 liter/min $\left(400 \mathrm{ft}^{3} /\right.$ hour $)$ was coaxially delivered to the rock by a nozzle $6 \mathrm{~cm}$ in diameter.

The Nd:YAG laser is attractive for this work not only because of the optical fiber delivery system, but because the wavelength is in the range where water is very nearly transparent and minimal power is lost during transmission through water. Also, the system is relatively compact and portable. Disadvantages include the low efficiency of the laser generation system, about 10 percent.

New developments are taking place in Nd:YAG technology, with higher power lasers now available. Lumonics, a laser manufacturer has a $4 \mathrm{~kW}$ average power laser in their development laboratory.

\subsubsection{Nuvonyx Diode System}

The diode laser at NA Technologies is used primarily for metal-forming research. It has few of the advanced sample handling capabilities of the ANL facility, such as the programmable movable stage and the coaxial gas purge nozzle. The system consists of the laser head, which is roughly an 8 " cube, the electronic control console, and the cooling water chiller, both of which are about two feet by two feet by three feet high.

The samples were placed on a hand cranked machinist stage (Figure 8) and the purge gas was directed across the sample. The test matrix was modified from that used for the Nd:YAG after a few preliminary samples were tried.

\footnotetext{
${ }^{11}$ R.M. Graves and D.G. O'Brien, 1998.
} 


\subsection{Saturated and Submerged Tests}

\subsubsection{Saturated}

Due to the difficulty of saturating the dense limestone and shale samples available for these tests, the saturated tests were done exclusively on Berea Gray samples. At the end of the May tests, samples resting in water-filled dishes with only the top surface exposed were exposed to the laser. The purge gas disturbed the water, and reliable results were not possible. It was decided to saturate the sandstone samples and set the wet samples on the stage with all other parameters (purge and lens distance, for instance). The disks were kept in water up to the moment of the tests, so very little was lost to evaporation.

\subsubsection{Submerged}

To truly test the behavior of the laser through water or other fluid and onto a sample would require the design and fabrication of a system beyond the scope of this feasibility study. A series of tests were undertaken to prepare for such a study, to be part of Phase Two. The first problem is to inject the laser beam into the water directly, so that surface instability and reflections could be avoided. Since the Nd:YAG beam is conveyed by an optical fiber, the end of the fiber could be placed, unprotected, into the water without damaging any of the optics. Zach Xu calculated that beam dispersion out of the fiber would be about 4 degrees, which was within the range needed to get a good beam diameter without having excessive distance between the fiber end and the sample.

First task was to confirm experimentally the value given in the literature of about 3 per cent energy absorption per centimeter of water thickness. A container was modified so that the bottom consisted of a glass disk as is used in the Nd:YAG optical system. A known thickness of water was placed in the container and the average power measuring instrument was placed below it. The power measured was close to what was expected, and it could be seen visually (from the heated spot) that the beam was a good shape and quite consistant across the area covered. The sample was then placed in a container and the fiber placed into the water above it. 


\section{Results and Discussion}

\subsection{Desired Result}

What the team would like to have seen resulting from these tests can be summarized in the schematic graph of Figure 9. The axes could be any number of things, such as SE versus time, or total energy versus spot size. The data is very complex, but some conclusions can be reached from the analysis done to date. A more formal study will be proposed as part of the Phase 2 work plan, including modeling of the data to date and the development of a theoretical explanation of the results to date.

\subsection{Data Analysis}

The data from all of the tests are contained in Excel spreadsheets, which are included as appendices to this report and as Acrobat Reader files.

For each sample, the laser parameters and the change in weight before and after lasing were recorded. The raw data model has the following headings:

- Sample no. (rock, speciman and spot numbers)

- Laser "Schedule" (ERL shorthand)

- Measured average power $\left(\mathrm{P}_{\mathrm{av}}\right)$

- Pulse width $\left(\mathrm{W}_{\mathrm{p}}\right)$

- Repetition rate $(\mathrm{R})$

- Time beam was on $(\mathrm{t})$

- $\quad$ Spot diameter (d)

- Weight before

- Weight after

Calculated fields include:

- Delta weight

- $\quad$ Spot area (A)

- Total Energy $\left(\mathrm{TE}, \mathrm{P}_{\mathrm{av}}{ }^{*} \mathrm{t}\right)$

- Total Energy Density (TE/A)

- Specific Energy $\left(\mathrm{SE},\left(\mathrm{P}_{\mathrm{av}} * \mathrm{t}\right) /(\mathrm{w} /\right.$ density $)$

The data has been plotted using the Excel graphing capability, primarily in the $x-y$ (scattered) type of graph. Symbols and colors of the data points in the graphs 
allow categorization of the data to examine any trends and relationships that may be present. Selected graphs are in the sections discussing particular tests, below.

\subsection{Important Rock Parameters}

At the beginning of the GRI study, it was felt that porosity would be an important factor in efficiency of cutting rock, as high porosity rocks would have narrower grain contacts to be broken. It was feared that shale, being non-granular, with no discernable porosity, would not cut well, or at all. The GRI study showed that the shale spalled in a manner similar to granular rocks. All lithologies were shown to have similar measured SE. The behavior of shale is important, as approximately 70 per cent of rock encountered in today's wells is shale.

Parameters that are probably important, and will be studied further, include:

- Thermal conductivity

- Reflectance

- Color (Albedo)

The physical characteristics of the rocks undoubtedly have a role in how they are affected by laser energy, such as:

- Porosity

- Permeability

- Mineralogy

- Degree of Cementation

- Compressive Strength

- Tensile Strength

Unfortunately, the size of the sample has been revealed to be a secondary effect. Often cracking from the hole to the edge was observed and, when present, affected the SE. Changes in the thickness of the sample also affected the SE. The mechanisms causing these changes are not known.

\subsection{Spallation and Melting Zones Identified}

For this series of tests, the aim was to identify the laser parameters in the spalling zone, and then identify the onset of melting. Conditions were identified under which the laser energy will break and remove rock without significantly melting, given the parameters used in this experiment for this set of samples.

The zone change of the rock depends on the laser parameters and the melting temperature of the minerals in the sample. The melting temperature of the rock 
sample increases with the percentage of quartz in the rock. As the melting temperature of the whole rock increases, rock destruction decreases. Applying this concept to SE, the higher the percentage of quartz, the higher the energy consumed in melting and vaporizing. That concept is particularly applicable when drilling "deep" holes (depth greater than width). In the case of shallow holes with a good purging system, other parameters compete with quartz concentration for control of onset of significant melting. Those parameters are surface roughness, color, grain cementation, vugs and fractures, in addition to the thermal properties like conductivity, heat capacity and diffusivity. The values of those parameters for sandstone, shale, and limestone test samples are listed in Table 4.

An example of zone changes as a function of rock type and SE is presented in Figure 10. The sample used was shale. The laser power was increased from 0.2 to $1.2 \mathrm{~kW}$. All other parameters remained the same for this series. In this plot there are two mechanisms clearly observed: the zone on the left is a spalling zone, which occurs at a lower average power, and a melting zone is on the right. A transition zone identifies a region between average powers of $0.534 \mathrm{~kW}$ and 0.62 $\mathrm{kW}$ where the spalling zone changes to a melting zone. We observed that the lowest specific energy is obtained in the spalling zone just prior to the onset of melting. A possible sequence is that at low laser powers, a considerable fraction of the energy is be consumed by thermal expansion, fracture formation and mineral and gas decomposition, leaving little energy left to effectively remove rock material. As the average power increases, heat transfer and additional reactions occur, removing material more effectively. As the average power increased further, the minerals begin to melt, energy is used for melting instead of removing material and higher SE values resulted. Once melting occurred, secondary effects began to consume additional energy, and SE values increased further.

Based on the linear track results, test parameter matrixes were selected for conditions that produced thermal spallation up to a slight melting zone. This is the area where the team expected to find the lowest SE values. The matrixes included three energy per pulse levels $(4,8$, and $16 \mathrm{~J} /$ pulse), each with specific pulse width and repetition rate. The pulse width was either 1 or $2 \mathrm{~ms}$, whereas the repetition rate varied between 50 and 400 pulse/second.

The test parameter matrix was performed on the samples. The beam diameters on the rock surface were 1.27 and $0.95 \mathrm{~cm}$. The beam exposure time was controlled at 0.5 and 1.0 or 1.5 seconds to only produce a shallow hole so that the secondary effects could be avoided. To determine the material removed by the laser, the rock sample was precisely weighed pre- and post-lasing using a Mettler AT 261 balance with maximum $205 \mathrm{~g} / 62 \mathrm{~g}$ and resolution $0.1 \mathrm{mg} / 0.01 \mathrm{mg}$. The removed volume was then calculated based on the rock bulk density. 


\subsection{Spallation Tests with Dry Samples}

As a result of the long sample linear tests described in the Experimental Procedures section, a matrix for each lithology, sandstone, shale and limestone, was created (Appendix B). The parameters identified above were varied in a preplanned manner, according to how difficult it was to set up new parameters. In general, for each matrix, the E, $\mathrm{L}, \mathrm{R}$ and $\mathrm{t}$ values were set, then the focusing lens distance (spot size). One or more samples would be exposed (three spots per sample for sandstones, one or more for shale and several for limestone, see pictures of the samples in Appendix A), then the distance changed and more samples tested. Then a new set of $\mathrm{E}, \mathrm{L}, \mathrm{R}$ and $\mathrm{t}$ values would be programmed and the procedure performed again. This was done for 30 sandstone samples, 24 shales and eight limestones at the Argonne laser facility and five sandstones, three shales and two limestones at Native American Technologies.

In general, specific energy values increased with the exposure time since, at the beginning of lasing, the laser radiation interacts with the surface only. At this time, the secondary effects, such as deposits of melted material are at a minimum. In this case, the laser beam can directly reach the solid rock and remove matter from it. However, as the exposure time increased the interaction region heats up, secondary effects including melted material begin to form consuming additional laser energy, but not removing material. Furthermore, this melt acts as a barrier, preventing the laser beam from fully interacting with the solid rock beneath. Also, longer laser beam exposure times mean more heat will be dissipated in the sample, and that heat will be used in thermal expansion, fracture formation and mineral decomposition. All these effects combined result in measured specific energy values increasing with longer exposure times. These results are in agreement with the CW COIL experiments, where a similar trend was observed for the specific energy values.

\subsubsection{Lithology Samples}

\subsubsection{Sandstone}

Most of the samples exposed to the laser were the Berea gray sandstone, because the physical properties of this quarry rock are so consistent, and it is readily available. However, the behavior of the rock is not straightforward. The long linear tests demonstrated that there are five discernable zones as power density increased:

1. Threshold scorching

2. Slight grain removal

3. Cutting with grain rounding but no grain-to-grain attachments

4. Light, loose melt

5. Heavy attached melting. 
These five zones were all demonstrated by the individual samples, with the added complication of cracking from the spot to the edge of the sample in some samples. Sometimes the crack developed after the first and sometimes after the second spot in a sample. Even if cracks are not visible to the naked eye, they can be detected by the separation of the individual spot data when plotted Total Energy Density vs Weight (Figure 11).

\subsubsection{Shale}

The long linear test identified three zones on the shale sample. Spallation started almost immediately and continued over a greater range of power density values before melting started. The shale samples gave the best indication that the secondary mechanisms had seriously affected the GRI deep hole samples. The SE calculation for the shale samples dropped by an order of magnitude from the GRI results. The shale samples also show a definite SE jump when the rock starts melting (Figure 10), and the gradient of the SE changes with power is different in the melting zone compared to the spallation zone.

\subsubsection{Limestone}

Limestone SE values were higher than shale, however we can only speculate at this time that it may be due to the relative reflective properties of the rocks. The lighter color of the limestone used in the present experiments may have reflected a larger percentage of the laser beam energy, resulting in less energy absorption and therefore, in weaker coupling efficiency. Another possible mechanism for limestone is that the laser energy disassociates the calcium carbonate in to calcium oxide and carbon dioxide, rather than melting or vaporizing the carbonate molecule. The energy required to do this could be more than the breaking energy of sandstone and shale spallation. However, there is something going on that is not yet understood. Figure 13 shows results of laser energy on dry limestone. The two curves are two different hole sizes, $1 / 8$ in and 5/16 in. There is no clearcut relationship with any other laser parameter, and the fact that the larger hole is exhibiting more efficient cutting indicates a change in mechanism between the two energy densities.

\subsubsection{Specific Energy as Power Increases: Non-melt vs. Melt}

Figure 10 shows the SE for shale samples as a function of laser power under fixed beam spot size of 0.5 inches and exposure time of 0.5 seconds. The SE results were grouped together by thermal spalling and melting identified by the physical reaction observed on the rock samples. Thermal spalling produced a clear hole, and melting left deposits in the hole. At very low beam power $(200 \mathrm{~W})$, the energy absorbed was only enough to heat up a small amount of rock and thermally fractured it; therefore, the SE value is very high. As the power was increased, a larger volume of rock heated up and fractured, resulting in smaller SE values. This trend continues until the melting of rock started at beam power over $600 \mathrm{~W}$. There is a sharp increase of SE (from 0.5 to $2.2 \mathrm{~kJ} / \mathrm{cm}^{3}$ ) when transition 
occurred from thermal spallation zone to melting zone. The SE decreased slightly in the melting zone as the laser power increased. This is due to a reduction of the viscosity of the melt at higher temperature induced by higher beam power, and the less viscous liquid was more easily removed from the hole by the purging gas.

\subsubsection{Effects of Pulse Width and Repetition Rate}

A second set of experiments studied the behavior of the pulse width on specific energy. The results obtained with the sandstone for pulse widths of 1 and $2 \mathrm{~ms}$ found that SE decreases as the pulse width increases for similar peak intensities. This behavior has been explained in terms of the amount of energy deposited in the sample per unit time and the length of the cooling time between pulses. At a given intensity, the amount of energy deposited on the rock per unit area doubles for pulse widths of $2 \mathrm{~ms}$ than for $1 \mathrm{~ms}$, therefore, putting more heat into the rock. Also, the longer the pulse, the less time there is for the rock to cool down and therefore the thermal stresses are reduced, as was previously discussed. These two effects combine to reduce SE when long pulse widths are used.

Another parameter that was explored was the effect of the repetition rate on SE. The repetition rate was varied from 50 to $400 \mathrm{pulses} / \mathrm{sec}$ while keeping the other laser parameters constant, resulting in a decrease in SE as the pulse repetition rate increases. This behavior was observed for different values of pulse width, exposure time, and peak intensity in each of the rock types. The result can be attributed to the fact that a pulsed discharge creates a cyclic heating and cooling of the rock sample, resulting in thermal stresses that can generate micro fissures. At a low repetition rate, the cooling time between pulses is long enough so that each new pulse generates a drastic change in temperature conducive to the formation of micro fissures. In the case of a high repetition rate, the time between pulses is short and the sample does not have time to cool as much, reducing the micro fissures. In this last case, the rock temperature increases more steadily.

Although Figure 12 indicates that the specific energy decreases with an increase in pulse repetition rate, these results are valid as long as the pulse width is kept constant or slightly varying. The effects of pulse width on the specific energy are dominant over the repetition rate. This property is shown when a pulse width of 2 ms was used, it lowers the specific energy regardless of the fact that the pulse repetition rate was increased from 50 to $400 \mathrm{pulses} / \mathrm{sec}$. It has been observed that the lowest specific energy was obtained from a pulse width of $2 \mathrm{~ms}$.

The effects of repetition rate and energy per pulse on SE values are shown in Figure 12. The group of $8 \mathrm{~J} /$ pulse contains the lowest $\mathrm{SE}$ values. With a high energy per pulse (e.g. $16 \mathrm{~J} /$ pulse) the minerals in the rock melted, and therefore a higher SE value was observed. With a low energy per pulse (e.g., $4 \mathrm{~J} /$ pulse), a small volume of rock was removed through spallation, also leading to a high SE value. By holding energy per pulse constant at either 4 or $8 \mathrm{~J} /$ pulse, an increase in 
repetition rate reduced the SE values first in thermal spallation zone, then increased the SE was observed as the local mineral temperatures increased above their respective melting points. After melting started, the SE value decreased slightly as repetition rate increased.

It is very interesting to note that the SE data produced at a constant calculated laser power of $1.6 \mathrm{~kW}$, as shown by the point SH13, SH2 and SH15 in Figure 12, were the same with the following combinations of energy per pulse and repetition rate: high energy per pulse and low repetition rate (SH13, $16 \mathrm{~J} /$ pulse, $100 \mathrm{1} / \mathrm{s})$; medium energy per pulse and repetition rate (SH2, $8 \mathrm{~J} /$ pulse, $2001 / \mathrm{s})$; and low energy per pulse and high repetition rate (SH15, $4 \mathrm{~J} /$ pulse, $400 \mathrm{1} / \mathrm{s})$. In other words, the same penetration rate could be achieved by differing these laser parameter combinations under the same average power.

\subsubsection{Temperature Factors}

Two major factors that control the material removal rate are the maximum temperature (Tmax) and temperature cycling frequency (Tf) in the thermal spalling dominant zone. Tmax, largely controlled by the applied energy per pulse, determines the temperature difference $(\Delta T)$ in the rock, which in turn determines the thermal stress in the rock that is proportional to $\Delta \mathrm{T}$. When the thermal stress reached the static rupture strength of the rock, fracture of rock occurred.

Fracture of rock could also occur at a stress that is lower than the rupture strength of the rock, but cyclic from tension to compression. Increase of repetition rate of the laser beam would increase the cyclic frequency of the thermal stress and enhance the fracture. When overall effect of Tmax and Tf was constant, the same $\mathrm{SE}$ results were expected. More systematic studies need to be done in the future to quantitatively characterize the laser-induced temperature and thermal stress field in the rock.

Another contributor to the material removal is the laser-driven shock wave, which was detected by many researchers ${ }^{12,13}$ and also by the current study. By increasing the repetition rate, a resulting increase in the intensity of the shock wave was induced, therefore, causing a reduction in the observed specific energy values.

\subsubsection{Spallation Tests with Saturated Samples}

The saturated samples were processed after a saturated linear test was done, similar to those done for the dry samples. It was decided that only the sandstone

\footnotetext{
12 A.H. Clauer, B.P. Fairand, and J. Holbrook, 1981.

${ }^{13}$ Y. Sano, M. Mukai, K. Okazaki, and M. Obata, 1997.
} 
would be used, as the shale and limestone are not nearly as porous and saturation could not be ensured. After the linear test was done, a matrix was created and samples were exposed to the laser (Figures 15, 16, 17)

The results are very encouraging, if not totally understood. Having water in the pores could potentially have had two possible effects. The first was that the water would explosively turn to steam, helping the breaking process. The other was that the increased thermal conductivity would cause the heat to flow away from the working face and the cutting action would be diminished.

The results are positive, for a combination of reasons, if our understanding is correct. There were no obvious steam explosions, although there was steam. The thermal conductivity increase may have actually helped decrease the SE by delaying the onset of melting, allowing more energy to be put into the rock and increasing the cutting action.

\subsubsection{Submerged Sample Test}

The submerged sample test demonstrated that the mechanisms inherent within these experiments are not totally understood (Figure 18). The preliminary tests described in the Experimental Procedures section showed that about 3 per cent of the beam energy was lost per centimeter of water over the sample and that the beam coming directly out of the raw fiber spread by the predicted 4 degrees. When the experiment was set up to get the desired spot size and the power parameters set on the laser, no material was removed from the sample. The laser obviously reached the sample surface, but was not able to put enough energy into the rock to spall it. The water probably carried off the heat too quickly.

When the fiber was moved much closer to the sample, decreasing the spot size and increasing the power density, the energy put into the sample went directly into the melting zone. The positive result is that a hole was put into the sample (Figure 19). Unfortunately, trying to repeat the experiment and find out more about this process resulted in the fiber end being damaged, and it was decided that the possibility of damaging the laser was too great to continue.

A table of the results can be seen in Appendix C.

\subsubsection{Diode Laser Tests with Dry Samples}

While the team was assembled at ANL for the May tests, a representative from Nuvonyx, a diode laser manufacturer, presented the team with information on a new diode laser. The specifications of this laser can be seen in the Experimental Procedures section. The laser is small, portable and capable of many configurations. A company near CSM was identified, Native American 
Technologies Company, in Golden, Colorado, that uses a $4 \mathrm{~kW}$ Nuvonyx laser for metal reforming.

NA Tech was very cooperative in allowing the team to test the laser on several rock samples. The results are very encouraging, but the beam configuration (being a rectangle) needs work. Figure 14 shows a shale sample that exhibits the characteristic beam profile of the diode laser. The four bars that together create the $4 \mathrm{~kW}$ of power each cut a line in the sample. The combination of the four lines creates a sizable hole.

A table of the results can be seen in Appendix F. 


\section{Conclusions}

The results of this study are an extension of the GRI-funded work in two ways:

1. The test plan was developed to measure the amount of energy required to remove material under various laser conditions, and not how quickly a hole could be made into a rock sample (penetration rate). Focus is on trying to minimize the secondary effects that absorb so much of the laser power.

2. By focusing on establishing an absolute specific energy for each sample, it became clear that there is a measurable difference in this value for the different lithologies, sometimes by an order of magnitude. The GRI study did not show this difference conclusively.

Instead of making deep, narrow holes in the samples, the hole diameters created by the laser beam were larger than the depth. This, in combination with a coaxial purge gas nozzle, meant that the exsolved gases and spalled particles, the cause of much of the energy robbing secondary effects, were removed quickly enough such that the laser beam was continuously hitting newly exposed rock surface. The results may not provide perfect measures of the absolute specific energy, but we are confident that the SE's determined in this study are very close to the intrinsic SE for each sample.

The plan for this study included a series of tests with CW laser beams to determine the absolute SE under the same conditions of the GRI study. It became clear that the $\mathrm{CO}_{2}$ laser at Argonne National Laboratory, under CW conditions, went from merely scorching the rock to melting it without a discernable spalling zone. Based on these preliminary tests, the experiment plan was modified to focus on the pulsing capabilities of the ND:YAG laser. A series of linear tests were done where the power density was changed along the length of the sample. The tests were performed on the Berea gray sandstone, a shale and a limestone. For each combination of peak power, pulse width and repetition rate, a spallingonly zone was clearly visible. The power density of that zone was used as the starting point of the test matrix developed for each lithology.

Limestone is the only lithology the absolute SE of which is practically the same as the $\mathrm{SE}$ range determined in the GRI study $(20-50 \mathrm{~kJ} / \mathrm{cc})$. It appears that the hole is made by thermal degradation $\left(\mathrm{CaCO}_{3}\right.$ to $\mathrm{CaO}$ and $\left.\mathrm{CO}_{2}\right)$ instead of breaking bonds between grains or within mineral crystals as is seen in sands and shales, so there is no melting and no secondary effects to cloud the results.

Reservoir rocks can be removed using a high power laser beam through thermal spalling, melting, or vaporizing. Thermal spallation is the most efficient rock removal mechanism requireing the lowest specific energy. The laser beam 
irradiance required for producing the thermal spallation zones are around 920 $\mathrm{W} / \mathrm{cm}^{2}$ for Berea gray sandstone and $784 \mathrm{~W} / \mathrm{cm}^{2}$ for shale.

The absolute SE required for laser removal of rock material was obtained in this study by carefully controlling the laser beam irradiance and exposure time and avoiding most of the secondary effects. As laser power increased, two rock removal zones, spallation and melting, were identified. In the sample data the lowest SE occurred at the point just prior to melting.

Increasing beam repetition rate within the same material removal mechanism zone would increase the material removal rate due to an increase of the maximum temperature, thermal cycling frequency, and intensity of laser-driven shock wave within the rock.

In this paper we have presented studies of the effects of the various Nd:YAG laser parameters on the specific energy for samples of shale, limestone, and sandstone. The major observation can be stated as follows:

- Measured SE increases very quickly with the beam exposure time indicating the effects of energy consuming secondary processes.

- Shale samples recorded the lowest specific energy values as compared with limestone and sandstone samples.

- As both pulse repetition rate and pulse width increase, the specific energy decreases, however, pulse width is a more dominant mechanism for reducing the specific energy than the pulse repetition rate.

- Two rock removal zones, spallation and melting, were identified in the shale sample data with the least required SE occurring at the point prior to melting.

- Each rock type has a set of optimal laser parameters to minimize SE as observed in the linear track tests.

- Rates of heat diffusion in rocks are easily and quickly overrun by absorbed energy transfer rates from the laser beam to the rock. As absorbed energy outpaces heat diffusion by the rock matrix, local temperatures rise to the minerals' melting points and quickly increase SE values.

- Sandstones saturated with water cut faster with more power able to be applied before melting commenced.

- The laser is able to spall and melt rock through water. 


\section{Recommendations}

\subsection{Phase 2 Research Plan}

\subsubsection{Additional Fundamental Research}

To continue this work, the end has to be defined. The goal for the three-year period originally proposed was to have the design for a field prototype completed, ready to be constructed and tested. This implies many steps that have to be undertaken. The prototype equipment can be separated into systems, each of which has design specifications to be created, potential problems identified and solutions worked out. In this section, the systems will be identified and a work plan outlined.

1. More detailed determination of the spallation/melting zone interfaces should be identified in sandstone, shale and limestone samples to determine their respective minimum SE values. The existence of such a boundary was demonstrated by this study, but its position can be determined with more accuracy.

2. The GRI study, as recorded in S. Batarseh's dissertation, gave strong indication that the rock immediately around the lased hole exhibits increased permeability due to the formation of micro-fractures and the destruction of grain-grain contacts. A follow-up analysis should be conducted to determine the effects of the laser rock interaction on permeability.

3. The shale results were quite surprising. The SE for this lithology is not only about an order of magnitude lower than the sandstone and limestone, but show a clear division between the spalling zone and the melting zone. The SE decreases rapidly to a minimum value, and then jumps up as melting starts. The gradient in the melting zone has a very different value than the gradient in the spalling zone. This result needs to be extended to other shales, since shale characteristics can be extremely varied.

4. One possible mechanism for applying the results of this work to the drilling of deep wells is to alternate the lasing of many spots to create a hole of the desired size. In order to estimate the number of spots required for a given hole, the amount of overlap necessary to create a smooth work face has to be determined. Also, the amount of "relaxation" time necessary to cool a given spot and prevent the accumulation of melted material needs to be measured.

\subsubsection{In-situ conditions}

The laser/rock interaction at atmospheric pressure in air, inert gas and water environments is fairly well understood, due to the GRI study and this Phase 1 DOE study. Mechanical methods of breaking rock are known to change behavior radically when the environment changes to the elevated pressures found at depth 
in wells. Phase 2 of the DOE study includes the development of a suitable pressure vessel that will simulate downhole confining stresses and pore pressures. The experiments will start using water as the fluid, and then will involve one or more common drilling fluids.

\subsubsection{Modeling and Theoretical Studies}

The empirical results from the GRI study and this phase of the DOE project have created a huge body of data. In order to understand and make the best use of this data, a theoretical understanding must be developed. In Phase 2, computer models will assist in creating a theoretical framework for the data.

\subsubsection{Engineering Studies}

\subsubsection{Cutting schemes}

The research team has discussed several possible designs for bottomhole assemblies. Most involve using optical fiber to bring the energy to the wellbore floor, but whether the energy will be combined into one beam or applied as a number of smaller beams, is yet to be determined. The work planned for fundamental portion of Phase 2 and the other engineering studies will help make this determination.

\subsubsection{Laser System}

The remaining fundamental work to be done in Phase 2 will have as one of its goals to determine the specific laser to be used for the prototype. Candidates at this time include the Nd:YAG, the COIL, a new diode laser and possibly the free electron laser. It should be noted that these lasers are all toward the shorter wavelengths within the infrared frequency band. The Nd:YAG is 1.06 microns, the COIL is 1.31 microns, the diode laser is 0.8 microns, and the free electron is tunable over a fairly wide wavelength range. In contrast, the MIRACL is 3.15 microns and the $\mathrm{CO}_{2}$ is 10.6 microns.

\subsubsection{Energy Delivery System}

Optical fibers seem to have the characteristics necessary for sending large amounts of power down a hole. However, the diode laser head is so small that, properly reconfigured, it may be possible lower the laser head down into the wellbore. As part of the Phase 2 work, a literature review and summary of optical fibers will be performed.

\subsubsection{Drill String and Bottom Hole Assembly Systems}

Laser drilling will differ from current technology in that no weight on bit is necessary; therefore there is no need for the tensile and compressive strength of steel in the drill string. Also, if optical fiber is used to send the energy down hole, sectional tubing will complicate the deployment of the fiber. A composite coiled tubing system seems like it would perform admirably, as long as pressure 
differentials between annulus and tubing interior do not exceed the tubing collapse strength.

Also, since there will be a minimum of abrasive activity around the drill head containing the fiber end effectors and fluid nozzles, there is no need for a heavy steel "bit". A composite matrix, easily shapeable and millable should work fine.

\subsubsection{Drilling Fluid and Solids Control Systems}

It is our vision that these systems will remain much the same as is being used for the rotary drilling rigs today. Some adaptation will be needed for use in composite tubing.

\subsubsection{Additional Systems}

At some time, a pressure control system will have to be adopted for deeper wells, but for the purposes of the prototype, will not be needed. 


\section{References}

1. DeGolyer and MacNaughton, One Energy Square, Dallas, Texas, 2000.

2. Andersen, et al, "Deep Drilling Basic Research: Volume 2 - Deep Drilling, " GRI 90/0265.2, June 1990, 78p.

3. W.C. Maurer, Novel Drilling Techniques, Pergamon Press, 1968.

4. W.C. Maurer, Advanced Drilling Techniques, Petroleum Publishing, 1980.

5. R.M. Graves and D.G. O'Brien, "Star Wars Laser Technology Applied to Drilling and Completing Gas wells," SPE 49259, 1998.

6. O’Brien, D. and R. Graves, “Targeted Literature Review: Determining the Benefits of StarWars Laser Technology for Drilling and Completing Natural Gas Wells," GRI Topical Report GRI-98/0163, 1998.

7. Batarseh, S., "Application of Laser Technology in the Oil and Gas Industry: An Analysis of High Power Laser-Rock Interaction and Its Effect on Altering Rock Properties and Behavior," PhD Thesis T-5492, Colorado School of Mines, Petroleum Engineering Department, 2001.

8. R.M. Graves and S. Batarseh, "Rock Parameters that Effect Laser-Rock Interaction: Determining the Benefits of Applying Star Wars Laser Technology for Drilling and Completing Oil and Natural Gas Wells," GRI Topical Report GRI-01/0080, 2001a.

9. R.M. Graves and S. Batarseh, "Laser Parameters that Effect Laser-Rock Interaction: Determining the Benefits of Applying Star Wars Laser Technology for Drilling and Completing Oil and Natural Gas Wells," GRI Topical Report GRI-01/0079

10. R.M. Graves and S. Batarseh, "Determining the Benefits of Applying Star Wars Laser Technology for Drilling and Completing Oil and Natural Gas Wells," GRI Final Report GRI-01/0078

11. B.C. Gahan, R. A. Parker, S. Batarseh, H. Figueroa, C.B. Reed and Z. Xu, " Laser Drilling: Determination of Energy Required to Remove Rock," SPE 71466, 2001.

12. J.F. Ready, D. F. Farson, LIA Handbook of Laser Materials Processing, Laser Institute of America, 2001.

13. W.T. Silfvast, Laser Fundamentals, Cambridge, 1996.

14. J. Hecht, The Laser Guidebook, McGraw-Hill, 1992.

15. W.H. Somerton, Thermal Properties and Temperature-related Behavior of Rock/Fluid System. University of California, Development in Petroleum Science. Elsevier, Amsterdam-London-New York-Tokyo, 1992.

16. B.V. Hunter, K.H. Leong, C.B. Miller, J.F. Golden, R.D. Glesias and P. J. Laverty, "Understanding high-power fiber-optic laser beam delivery," J. Laser Applications, 8, 1996: 307-16.

17. A. Kuhn, P. French, D.P. Hand, I.J. Blewett, M. Richmond, and J.D.C. Jones, "Preparation of fiber optics for the delivery of high-energy high-beam-quality Nd:YAG laser pulses," Applied Optics, vol. 39, No. 33, 20 November 200: 613643. 
18. Frank M. White, Fluid Mechanics, Third Edition, New York, McGraw-Hill, Inc., 1994:699.

19. A.H. Clauer, B.P. Fairand, and J. Holbrook, Shock Waves and High Strain Phenomena in Metals, vol. III, Plenum Press, New York, 1981:675-91.

20. Y. Sano, M. Mukai, K. Okazaki, and M. Obata, Nucl. Instr. And Meth. In Phys. Res. B, vol. 121, 1997:432-39.

21. J. Johnson, J. Am. Chem. Soc. 32 (1910), p.938.

22. J. Mitchell, J. Am. Chem. Soc. 123 (1923), p.1055.

23. Z. Brill, Anorg. Chem., 45 (1905), p. 279.

24. Z. Brill, Anorg. Chem., 57 (1907), p. 721.

25. K. W. Ray and F. C. Mathers, I. \& E. Chem. 20 (1928), pp. 415-419.

26. R. Doman, J. Barr and A. Alper, J. Am. Ceram. Soc., 46 (1963), p. 313. 


\section{Newspaper and Magazine Articles as of July 26, 2001}

1. News and Opportunities. GTI \& DOE Study Commercial Feasibility of Laser Drilling. GasTips, V 7, No. 1, Pg 44-45, Winter 2001.

2. Robinson, Rick. Lasers Developed for Drilling-Energy Producers Study Possibilities of Technology. The Oklahoman, February 21, 2001.

3. "Star Wars" Lasers May Assist Oil, Natural Gas Developments. Federal Technology Report, March 8, 2001, p9.

4. GTI \& DOE Study Commercial Feasibility of Laser Drilling. PR Newswire, February 23, 2001.

5. GTI Begins Study of Commercial Laser Drilling. Gas Daily, February 26, 2001.

6. The Commercial Viability of Using High-Powered Lasers to Drill for Oil and Natural Gas is Under Review. Inside Energy/with Federal Lands, February 26, 2001, p 6.

7. Parker, Richard A. High-Powered Lasers Hold Promise As Drilling/Completion Tools. Pipeline \& Gas Journal, January 1, 2001, p 28.

8. US DOE Launched a Research Effort to See if High-powered Lasers can be Adapted for Oil and Gas Drilling. Oil and Gas Journal, March 5, 2001, p8.

9. Journally Speaking; Interesting Times. Oil and Gas Journal, v 99, No. 16, p15, April 16, 2001.

10. DOE, GTI Study to Examine Use of Lasers for Drilling. OGJ Online, February 26, 2001.

11. NewsWell: Less Energy Needed for Laser-drilling, than once Speculated. Oil and Gas Investor, p 20-21, V 21, No. 5, May 2001.

12. Oil Industry Explores Laser Drills. Bakersfield Californian, March 15, 2001, p1.

13. Oil and Gas Industry Tests Lasers for Drilling. World News, Laser Focus World, June 2001.

14. Snyder, Robert E. What's Happening in Drilling. World Oil, V 222, No 4, P29, April 2001.

15. Perreault, Paul. Technology Watch: Lasers Join Hunt for Energy. Popular Mechanics, p16, June 2001.

16. Pitts, John Paul. New Study to Look at Laser Use for Drilling. Midland ReporterTelegram, May 27, 2001.

17. Perin, Monica. Drilling with Lasers: Energy Group Tests "Star Wars" Technology. Houston Business Journal, March 2, 2001.

18. Tech Transfer Track: GTI \& DOE Study Commercial Feasibility of Laser Drilling. PTTC Network News, V 7, No 1, p6, $1^{\text {st }}$ Quarter, March 2001.

19. Photonics Technology World: Lasers Could Simplify Drilling for Oil. Photonics Spectra, V 35, No 4, April 2001. 
10 Appendix: A-G 


\section{A: Test Sample Photographs: Fixed Parameters}




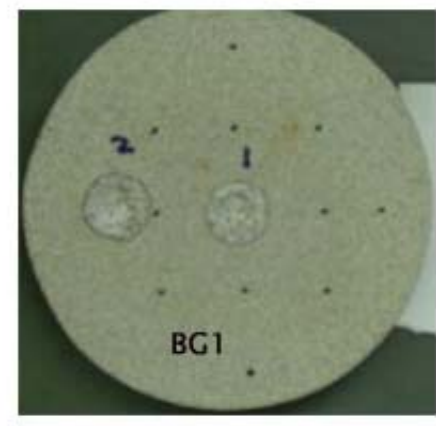

Figure A-1 Sample BG-1, shots 1 and 2 . Laser Parameters $E=8 \mathrm{~kW}$. $\mathrm{L}=2 \mathrm{msec}$, $R=100 /$ sec, $t=1.5$ secs, beam diameter $=0.375^{\prime \prime}$

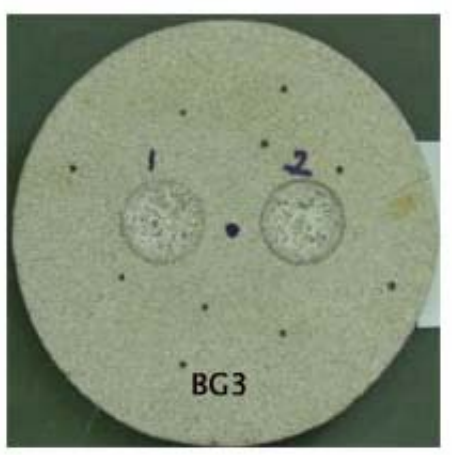

Figure A-3 Sample BG-3, shots 1 and 2. Laser Parameters $E=8 \mathrm{~kW}$. $\mathrm{L}=2 \mathrm{msec}$, $\mathrm{R}=100 / \mathrm{sec}, \mathrm{t}=1.5$ secs, beam diameter $=0.5$ "

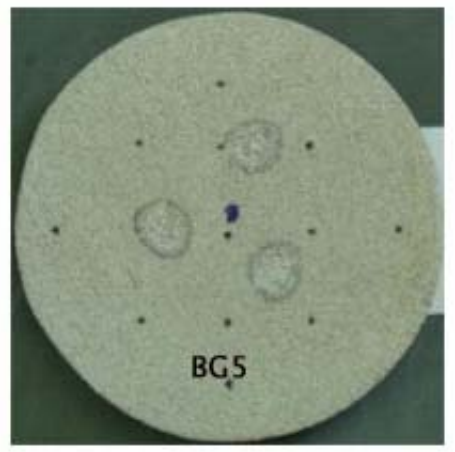

Figure A-5 Sample BG-5, shots 1, 2 and 3. Laser Parameters $E=8 \mathrm{~kW}$. $\mathrm{L}=2 \mathrm{msec}$, $\mathrm{R}=50 / \mathrm{sec}, \mathrm{t}=0.5 \mathrm{secs}$, beam diameter $=0.5^{\mathrm{n}}$

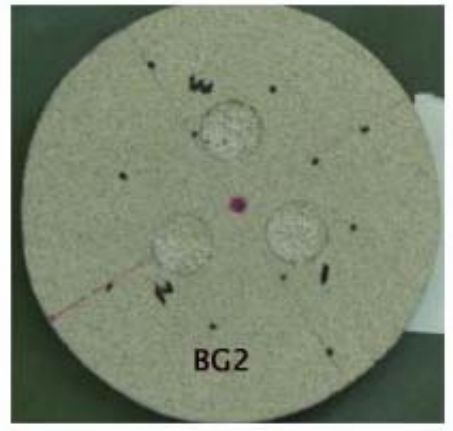

Figure A-2 Sample BG-2, shots 1, 2 and 3. Laser Parameters $E=8 \mathrm{~kW}$. $\mathrm{L}=2 \mathrm{msec}$,

$\mathrm{R}=100 / \mathrm{sec}, \mathrm{t}=0.5$ secs, beam diameter $=0.375^{\prime \prime}$

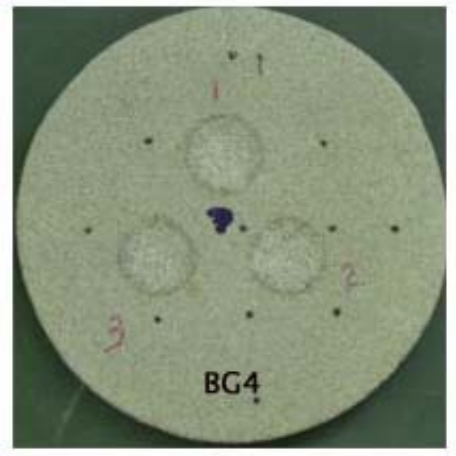

Figure A-4 Sample BG-4, shots 1, 2 and 3. Laser Parameters $E=8 \mathrm{~kW}$. $\mathrm{L}=2 \mathrm{msec}$,

$\mathrm{R}=100 / \mathrm{sec}, \mathrm{t}=0.5$ secs, beam diameter $=0.5$ "

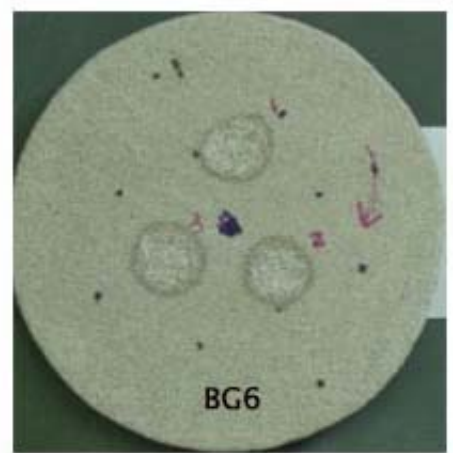

Figure A-6 Sample BG-6, shots 1, 2 and 3. Laser Parameters $E=8 \mathrm{~kW}$. $\mathrm{L}=2 \mathrm{msec}$, $\mathrm{R}=50 / \mathrm{sec}, \mathrm{t}=1.5$ secs, beam diameter $=0.5^{\mathrm{n}}$ 


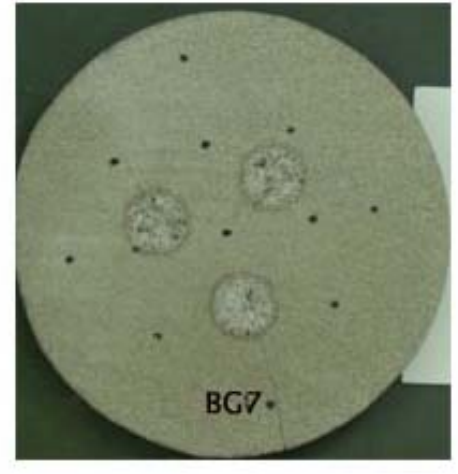

Figure A-7 Sample BG-7, shots 1, 2 and 3. Laser Parameters $E=4 \mathrm{~kW}$. L=1msec, $\mathrm{R}=400 / \mathrm{sec}, \mathrm{t}=1.5$ secs, beam diameter $=0.375^{\prime \prime}$

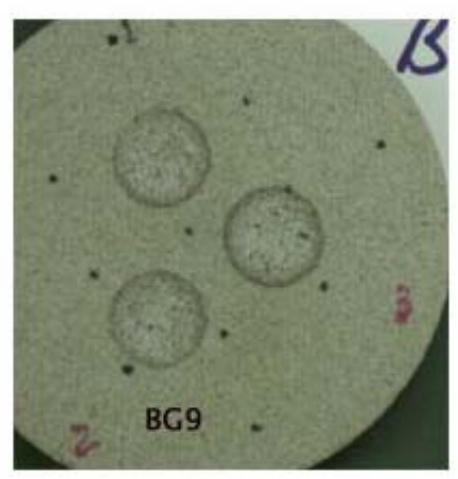

Figure A-9 Sample BG-9, shots 1, 2 and 3. Laser Parameters $E=4 \mathrm{~kW}$. $\mathrm{L}=1 \mathrm{msec}$, $\mathrm{R}=400 / \mathrm{sec}, \mathrm{t}=1.5 \mathrm{secs}$, beam diameter $=0.5^{\mathrm{n}}$

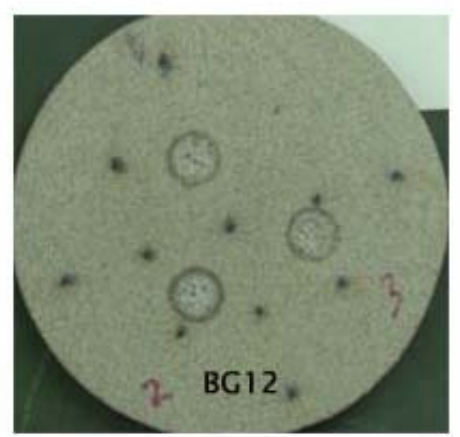

Figure A-11 Sample BG-12, shots 1, 2 and 3. Laser Parameters $E=4 \mathrm{~kW}$. $L=1 \mathrm{msec}$, $\mathrm{R}=200 / \mathrm{sec}, \mathrm{t}=1.5$ secs, beam diameter $=0.375^{\prime \prime}$

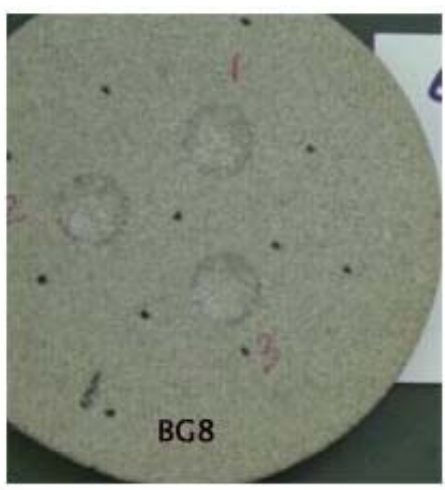

Figure A-8 Sample BG-8, shots 1, 2 and 3. Laser Parameters $E=4 \mathrm{~kW}$. L $=1 \mathrm{msec}$,

$\mathrm{R}=400 / \mathrm{sec}, \mathrm{t}=0.5$ secs, beam diameter $=0.375^{\prime \prime}$

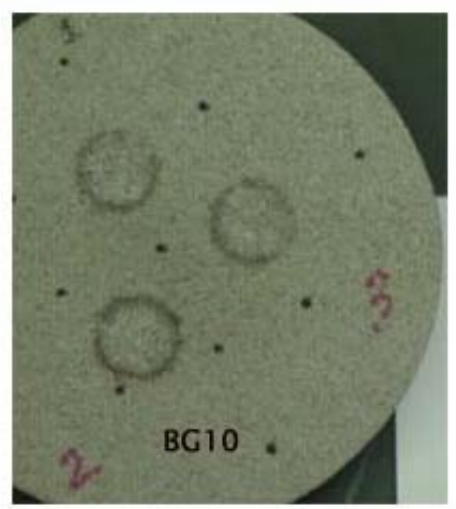

Figure A-10 Sample BG-10, shots 1, 2 and 3. Laser Parameters $E=4 \mathrm{~kW}$. L=1msec, $\mathrm{R}=400 / \mathrm{sec}, \mathrm{t}=0.5$ secs, beam diameter $=0.5^{\prime \prime}$

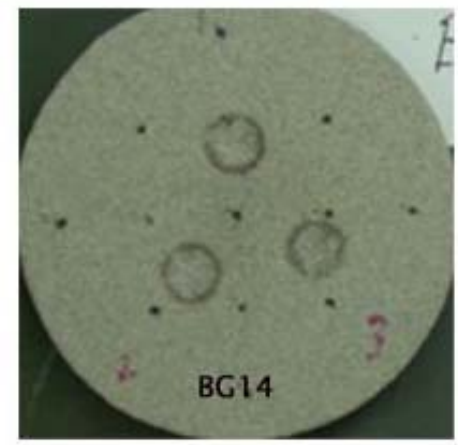

Figure A-12 Sample BG-14, shots 1, 2 and 3. Laser Parameters $E=4 \mathrm{~kW}$. L=1msec,

$R=200 /$ sec, $t=1.5$ secs, beam diameter $=0.5$ " 


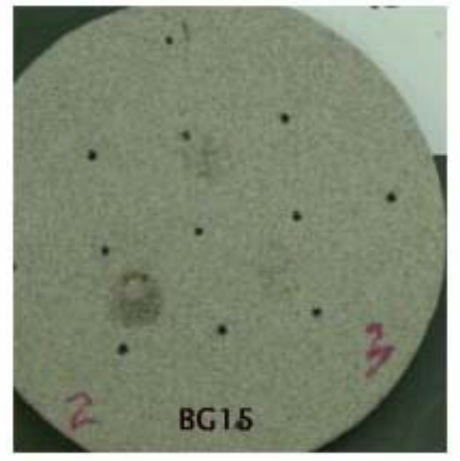

Figure A-13 Sample BG-15, shots 1, 2 and 3. Figure A-14 Sample BG-16, shots 1, 2 and 3. Laser Parameters $E=4 \mathrm{~kW}$. L=1msec, $\mathrm{R}=200 / \mathrm{sec}, \mathrm{t}=0.5$ secs, beam diameter $=0.5^{\prime \prime}$

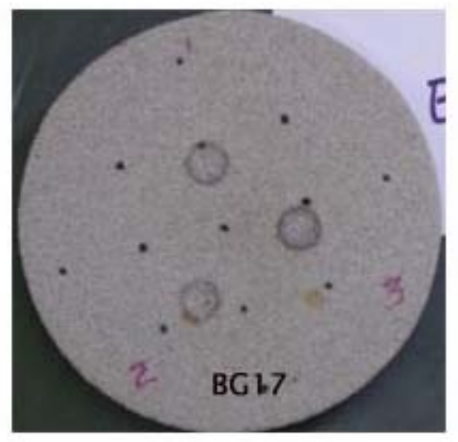

Figure A-15 Sample BG-17, shots 1, 2 and 3. Laser Parameters $E=4 \mathrm{~kW}$. L $=1 \mathrm{msec}$,

$\mathrm{R}=100 / \mathrm{sec}, \mathrm{t}=1.5$ secs, beam diameter $=0.375^{\prime \prime}$

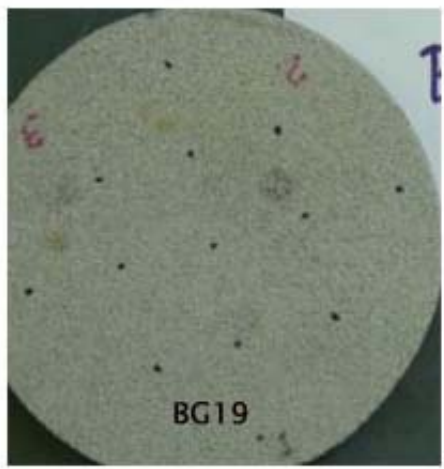

Figure A-17 Sample BG-19, shots 1, 2 and 3. Laser Parameters $E=4 \mathrm{~kW}$. L $=1 \mathrm{msec}$, $\mathrm{R}=100 / \mathrm{sec}, \mathrm{t}=0.5 \mathrm{secs}$, beam diameter $=0.375^{\prime \prime}$

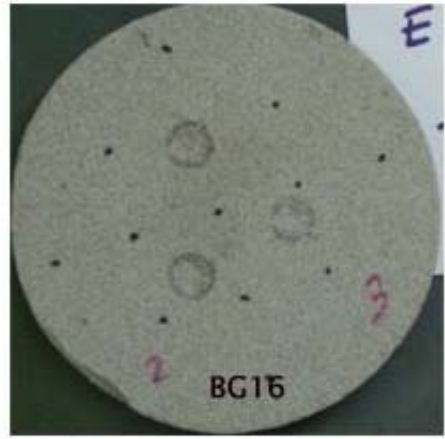
Laser Parameters $E=4 \mathrm{~kW}$. L=1msec, $\mathrm{R}=200 / \mathrm{sec}, \mathrm{t}=0.5$ secs, beam diameter $=0.375^{\prime \prime}$

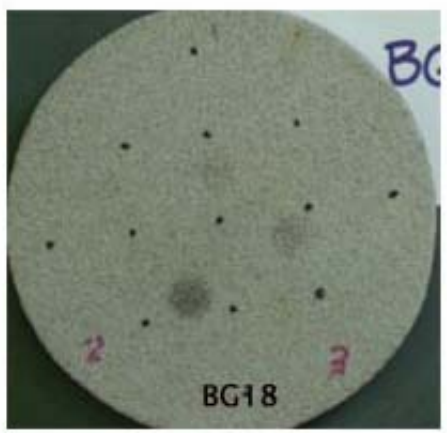

Figure A-16 Sample BG-18, shots 1, 2 and 3. Laser Parameters $E=4 \mathrm{~kW}$. $\mathrm{L}=1 \mathrm{msec}$,

$R=100 / \mathrm{sec}, t=1.5$ secs, beam diameter $=0.5^{\prime \prime}$

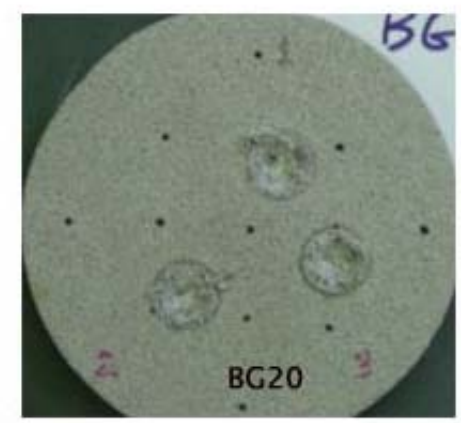

Figure A-18 Sample BG-20, shots 1, 2 and 3. Laser Parameters $E=8 \mathrm{~kW}$. $\mathrm{L}=1 \mathrm{msec}$,

$R=200 / \mathrm{sec}, t=1.5$ secs, beam diameter $=0.375^{\prime \prime}$ 


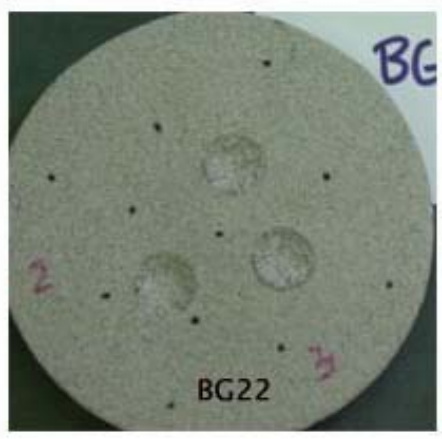

Figure A-19 Sample BG-22, shots 1, 2 and 3. Laser Parameters $E=8 \mathrm{~kW}$. $\mathrm{L}=1 \mathrm{msec}$,

$R=200 / \mathrm{sec}, \mathrm{t}=0.5$ secs, beam diameter $=0.375^{\prime \prime}$

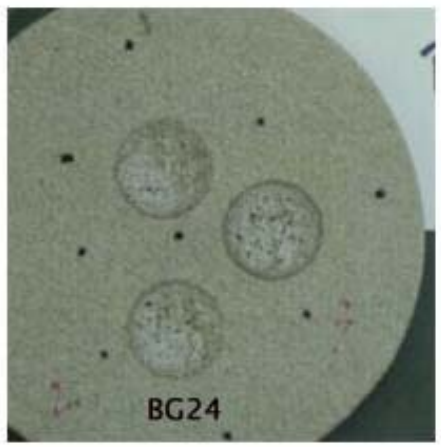

Figure A-21 Sample BG-24, shots 1, 2 and 3. Laser Parameters $E=8 \mathrm{~kW}$. L $=1 \mathrm{msec}$,

$R=200 / \mathrm{sec}, \mathrm{t}=1.5$ secs, beam diameter $=0.5^{\prime \prime}$

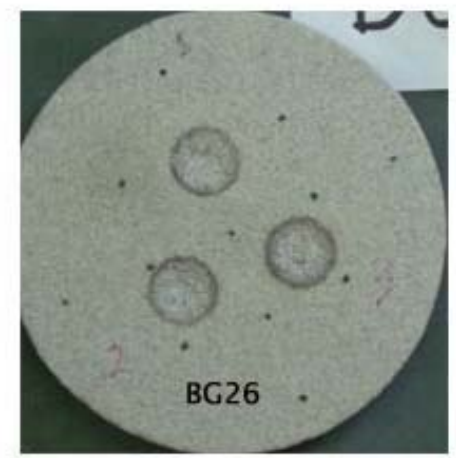

Figure A-23 Sample BG-26, shots 1, 2 and 3. Laser Parameters $E=8 \mathrm{~kW}$. L=1 $\mathrm{msec}$,

$R=100 / \mathrm{sec}, t=1.5$ secs, beam diameter $=0.5^{\prime \prime}$

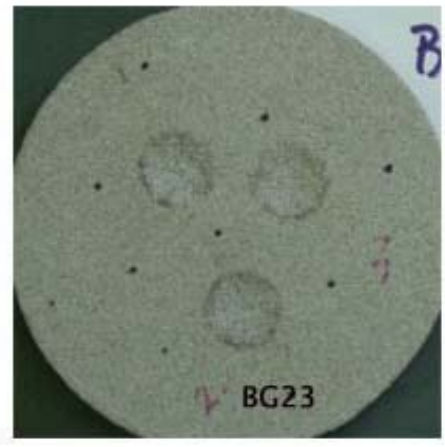

Figure A-20 Sample BG-23, shots 1, 2 and 3. Laser Parameters $E=8 \mathrm{~kW}$. L $=1 \mathrm{msec}$,

$R=200 / \mathrm{sec}, \mathrm{t}=0.5$ secs, beam diameter $=0.5^{\prime \prime}$

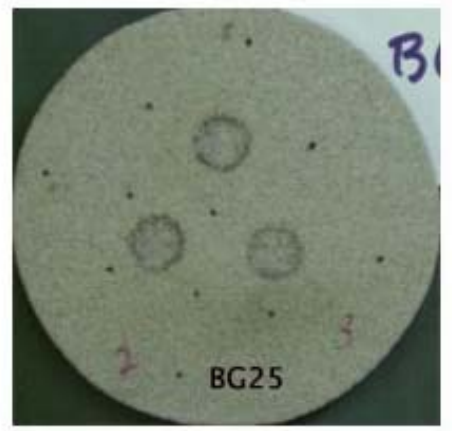

Figure A-22 Sample BG-25, shots 1, 2 and 3. Laser Parameters $E=8 \mathrm{~kW}$. $L=1 \mathrm{msec}$,

$R=100 / \mathrm{sec}, \mathrm{t}=0.5$ secs, beam diameter $=0.5^{\prime \prime}$

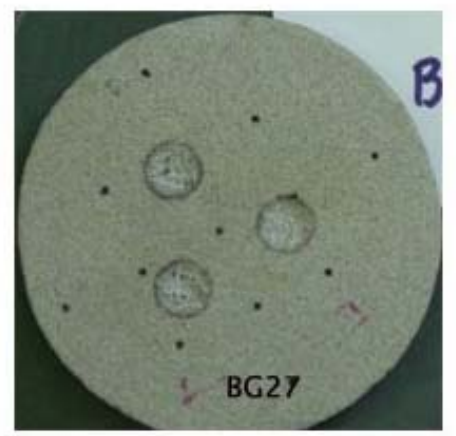

Figure A-24 Sample BG-27, shots 1, 2 and 3. Laser Parameters $E=8 \mathrm{~kW}$. $\mathrm{L}=1 \mathrm{msec}$,

$\mathrm{R}=100 / \mathrm{sec}, \mathrm{t}=1.5$ secs, beam diameter $=0.375^{\prime \prime}$ 


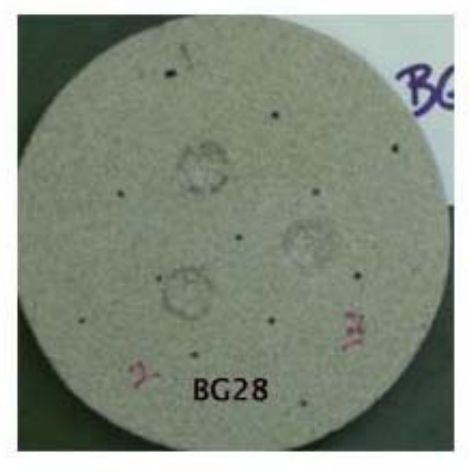

Figure A-25 Sample BG-28, shots 1, 2 and 3. Laser Parameters $E=8 \mathrm{~kW}$. L=1msec, $\mathrm{R}=100 / \mathrm{sec}, \mathrm{t}=0.5$ secs, beam diameter $=0.5^{\prime \prime}$

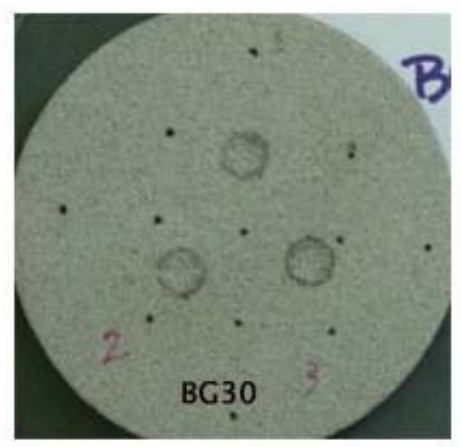

Figure A-27 Sample BG-30, shots 1, 2 and 3. Laser Parameters $E=8 \mathrm{~kW}$. L $=1 \mathrm{msec}$, $\mathrm{R}=50 / \mathrm{sec}, \mathrm{t}=1.5$ secs, beam diameter $=0.375^{\prime \prime}$

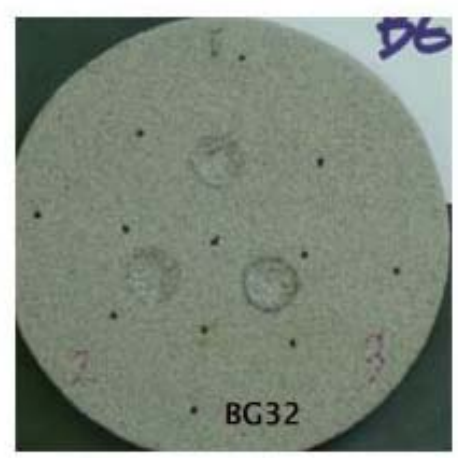

Figure A-29 Sample BG-32, shots 1, 2 and 3. Laser Parameters $E=8 \mathrm{~kW}$. $\mathrm{L}=2 \mathrm{msec}$,

$\mathrm{R}=50 / \mathrm{sec}, \mathrm{t}=1.5$ secs, beam diameter $=0.375^{\mathrm{N}}$

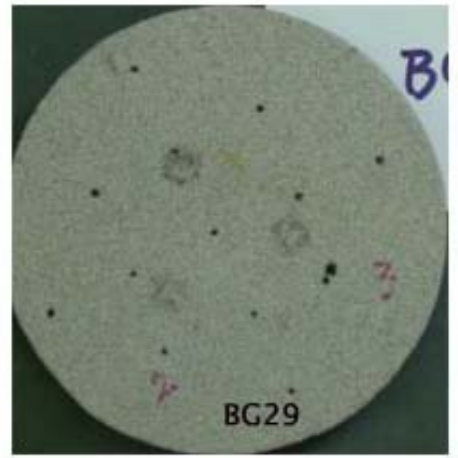

Figure A-26 Sample BG-29, shots 1, 2 and 3. Laser Parameters $E=8 \mathrm{~kW}$. $\mathrm{L}=1 \mathrm{msec}$,

$\mathrm{R}=50 / \mathrm{sec}, \mathrm{t}=0.5$ secs, beam diameter $=0.375^{\prime \prime}$

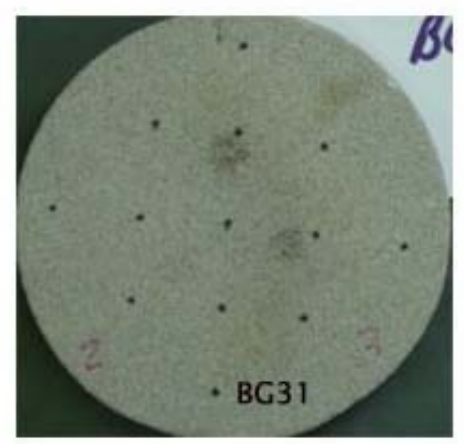

Figure A-28 Sample BG-31, shots 1, 2 and 3. Laser Parameters $E=8 \mathrm{~kW}$. L $=1 \mathrm{msec}$,

$\mathrm{R}=50 / \mathrm{sec}, \mathrm{t}=1.5$ secs, beam diameter $=0.5^{\prime \prime}$

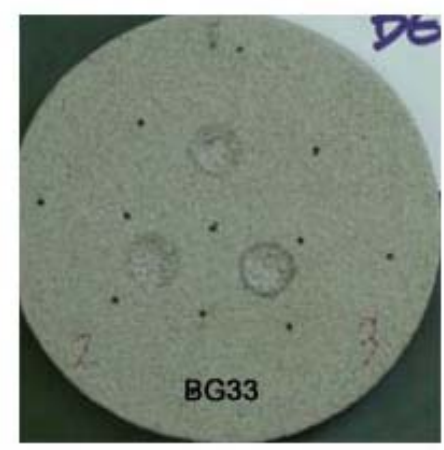

Figure A-30 Sample BG-33, shots 1, 2 and 3. Laser Parameters $E=8 \mathrm{~kW}$. $\mathrm{L}=2 \mathrm{msec}$,

$\mathrm{R}=50 / \mathrm{sec}, \mathrm{t}=0.5$ secs, beam diameter $=0.375^{\prime \prime}$ 


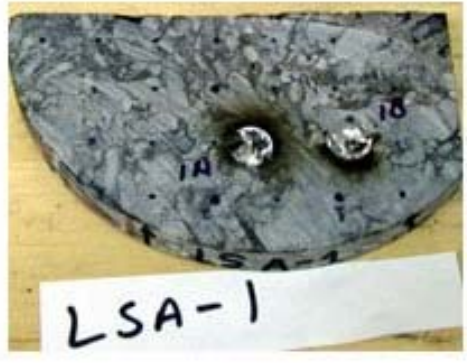

Figure A-31 Sample LSA-1 Laser Parameters: $E=8 \mathrm{~kW}$. $\mathrm{L}=1 \mathrm{msec}$, $\mathrm{R}=200 / \mathrm{sec}$, beam diameter $=0.375^{\prime \prime}$ Shot A: $t=0.5 \mathrm{sec}$, Shot B: $t=1.5 \mathrm{sec}$

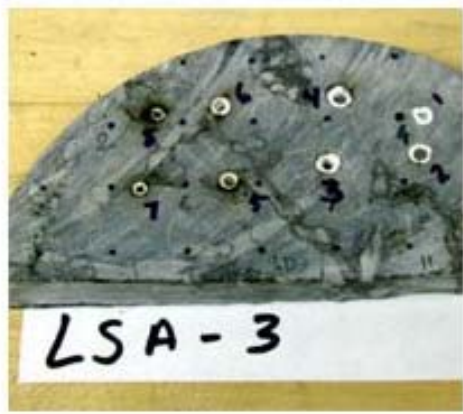

Figure A-33 Sample LSA-3, shots 1-8 Laser Parameters: $E=4 \mathrm{~kW} . \mathrm{L}=1 \mathrm{msec}$, Shots 1-6: $R=400 / \mathrm{sec}$

Shots 1 \& 2: $\mathrm{t}=0.5 \mathrm{sec}$, beam diameter $=0.125^{\prime \prime}$ Shot 3: $t=1.5 \mathrm{sec}$, beam diameter $=0.125 "$ Shot 4: $\mathrm{t}=1.0 \mathrm{sec}$, beam diameter $=0.125^{\prime \prime}$ Shot 5 : $t=0.5 \mathrm{sec}$, beam diameter $=0.063^{\prime \prime}$ Shot $6: \mathrm{t}=1.0 \mathrm{sec}$, beam diameter $=0.063$ Shots 7 \& 8: $R=200 / \mathrm{sec}$

Shot 7: $t=0.5 \mathrm{sec}$, beam diameter $=0.063$ Shot $8: t=1.0 \mathrm{sec}$, beam diameter $=0.063$

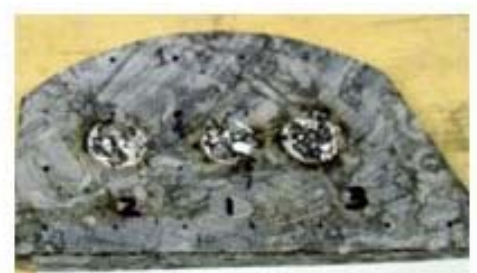

$$
\text { LSA- } 2
$$

Figure A-32 Sample LSA-2, shots 1 and 2 Laser Parameters: $E=8 \mathrm{~kW}$. L=1msec,

$\mathrm{R}=200 / \mathrm{sec}, \mathrm{t}=0.5 \mathrm{sec}$, beam diameter $=0.5^{\mathrm{n}}$

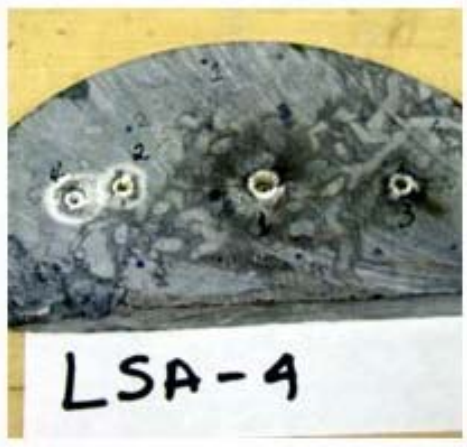

Figure A-34 Sample LSA-4, shots 1-4 Laser Parameters: $E=8 \mathrm{~kW}$. L2msec, $R=100 / \mathrm{sec}$

Shot 1: $t=1.5 \mathrm{sec}$, beam diameter $=0.125^{\prime \prime}$ Shot 2: $t=1.3 \mathrm{sec}$, beam diameter $=0.0625^{\prime \prime}$ Shot 3: $t=1.0 \mathrm{sec}$, beam diameter $=0.0625 "$ Shot 4: $t=1.25 \mathrm{sec}$, beam diameter $=0.0625 "$ 


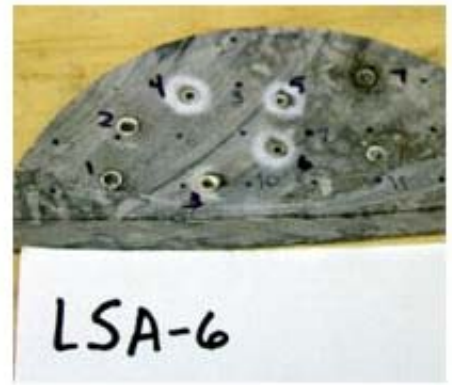

Figure A-35 Sample LSA-6, shots 1-8 Laser Parameters: $E=8 \mathrm{~kW}$. $\mathrm{L} 2 \mathrm{msec}$, Shots 1-4: $R=100 / \mathrm{sec}$

Shot 1: $\mathrm{t}=0.5 \mathrm{sec}$, beam diameter $=0.125^{\prime \prime}$

Shot 2: $t=1.0 \mathrm{sec}$, beam diameter $=0.125^{\prime \prime}$

Shot 3: $t=1.0 \mathrm{sec}$, beam diameter $=0.0625^{\prime \prime}$

Shot 4: $t=1.25 \mathrm{sec}$, beam diameter $=0.0625 "$

Shots 5-8: $\mathrm{R}=50 / \mathrm{sec}$

Shot 5: $t=1.0 \mathrm{sec}$, beam diameter $=0.0625^{\prime \prime}$

Shot 6: $t=0.5 \mathrm{sec}$, beam diameter $=0.063$

Shot 7: $\mathrm{t}=0.5 \mathrm{sec}$, beam diameter $=0.125$

Shot 8: $t=1.0 \mathrm{sec}$, beam diameter $=0.125$

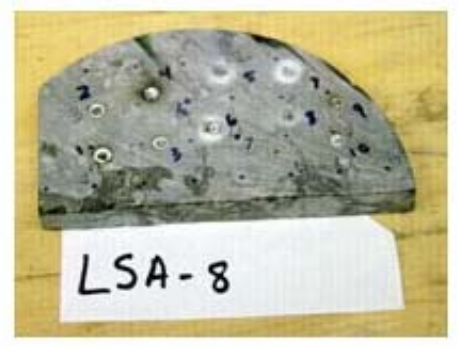

Figure A-37 Sample LSA-8, shots 1-10: Laser Parameters: $E=8 \mathrm{~kW}, \mathrm{~L}=1 \mathrm{msec}$

Shots 1and 2: $R=200 / \mathrm{sec}$

Shot 1: $t=1.0 \mathrm{sec}$, beam diameter $=0.125^{\prime \prime}$

Shot 2: $t=0.5 \mathrm{sec}$, beam diameter $=0.125^{\prime \prime}$

Shots $3-6: R=100 / \mathrm{sec}$

Shot 3: $t=1.0 \mathrm{sec}$, beam diameter $=0.125$ "

Shot 4: $t=0.5 \mathrm{sec}$, beam diameter $=0.125^{\prime \prime}$

Shot 5: $t=0.5 \mathrm{sec}$, beam diameter $=0.063^{\prime \prime}$

Shot 6: $t=1.0 \mathrm{sec}$, beam diameter $=0.063 "$

Shots 7-10: $\mathrm{R}=50 / \mathrm{sec}$

Shot 7: $t=1.0 \mathrm{sec}$, beam diameter $=0.063^{\prime \prime}$

Shot 8: $t=0.5 \mathrm{sec}$, beam diameter $=0.063^{\prime \prime}$

Shot 9: $t=0.5 \mathrm{sec}$, beam diameter $=0.125 "$

Shot 10: $t=1.0 \mathrm{sec}$, beam diameter $=0.125$

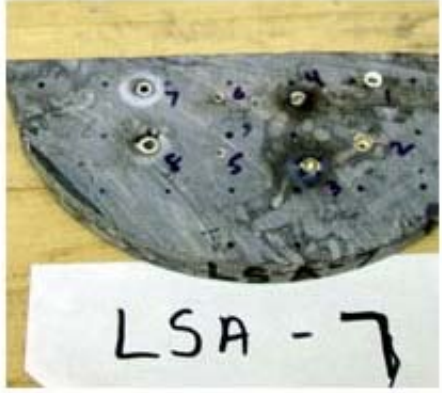

Figure A-36 Sample LSA-7, shots 1-8:

Shots 1-6: Laser Parameters: $E=8 \mathrm{~kW}, \mathrm{~L}=1 \mathrm{msec}$, Shots 1 \& 2: $R=200 / \mathrm{sec}$

Shot 1: $t=0.5 \mathrm{sec}$, beam diameter $=0.125$ "

Shot 2: $\mathrm{t}=1.0 \mathrm{sec}$, beam diameter $=0.125$ "

Shots 3-6: $R=100 / \mathrm{sec}$

Shot 3: $t=0.5 \mathrm{sec}$, beam diameter $=0.125^{\prime \prime}$

Shot 4: $t=1.0 \mathrm{sec}$, beam diameter $=0.125^{\prime \prime}$

Shot 5: $\mathrm{t}=0.5 \mathrm{sec}$, beam diameter $=0.063^{\prime \prime}$

Shot 6: $\mathrm{t}=1.0 \mathrm{sec}$, beam diameter $=0.063^{\prime \prime}$

Shots 7 \& 8: $E=8 \mathrm{~kW}, L=1 \mathrm{msec}, R=200 / \mathrm{sec}$

Shot 7: $t=0.5 \mathrm{sec}$, beam diameter $=0.063^{\prime \prime}$

Shot 8: $t=1.0 \mathrm{sec}$, beam diameter $=0.063 "$

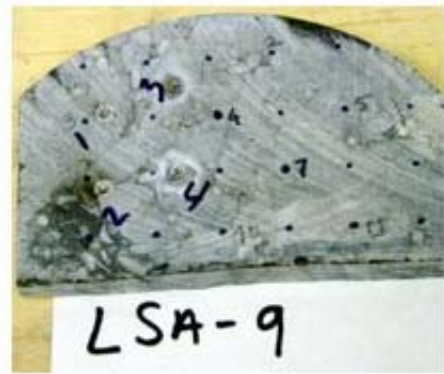

Figure A-38 Sample LSA-9, shots 1-14: Laser Parameters: $E=8 \mathrm{~kW}, \mathrm{~L}=2 \mathrm{msec}$, $\mathrm{R}=25 / \mathrm{sec}$

Shot 1: $t=1.0 \mathrm{sec}$, beam diameter $=0.125 "$ Shot 2: $t=0.5 \mathrm{sec}$, beam diameter $=0.125^{\prime \prime}$

Shot 3: $t=0.5 \mathrm{sec}$, beam diameter $=0.063^{\prime \prime}$

Shot 4: $t=1.0 \mathrm{sec}$, beam diameter $=0.063^{\prime \prime}$ 


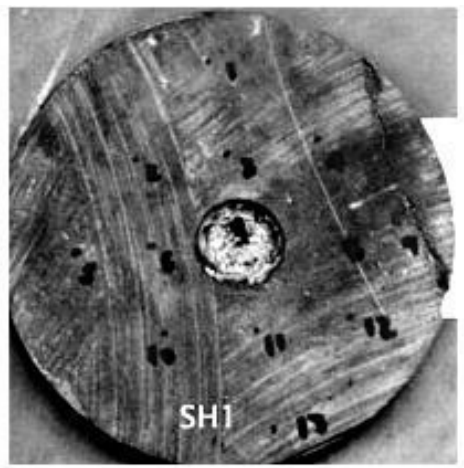

Figure A-39 Sample SH 1, shot 1:

Laser Parameters: $\mathrm{E}=8 \mathrm{~kW}, \mathrm{~L}=1 \mathrm{msec}$,

$\mathrm{R}=200 / \mathrm{sec}, \mathrm{t}=1.0 \mathrm{sec}$, beam diameter $=0.5^{\prime \prime}$

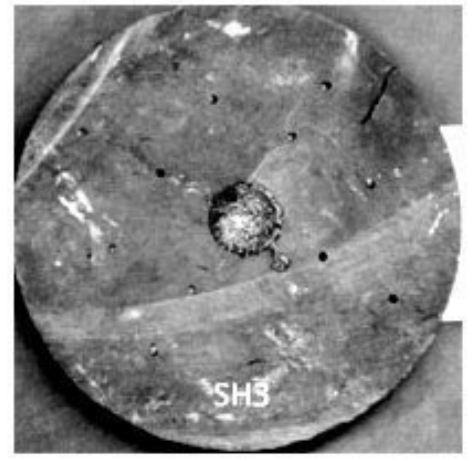

Figure A-41 Sample SH 3:

Laser Parameters: $E=8 \mathrm{~kW}, \mathrm{~L}=1 \mathrm{msec}$,

$\mathrm{R}=200 / \mathrm{sec}, \mathrm{t}=0.5 \mathrm{sec}$, beam diameter $=0.375^{\mathrm{N}}$

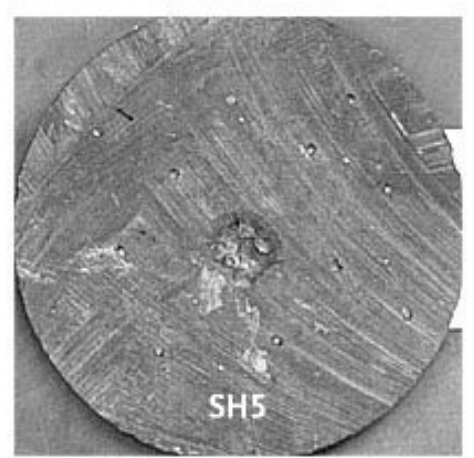

Figure A-43 Sample SH 5:

Laser Parameters: $E=8 \mathrm{~kW}, \mathrm{~L}=1 \mathrm{msec}$,

$\mathrm{R}=100 / \mathrm{sec}, \mathrm{t}=1.0 \mathrm{sec}$, beam diameter $=0.5^{\prime \prime}$

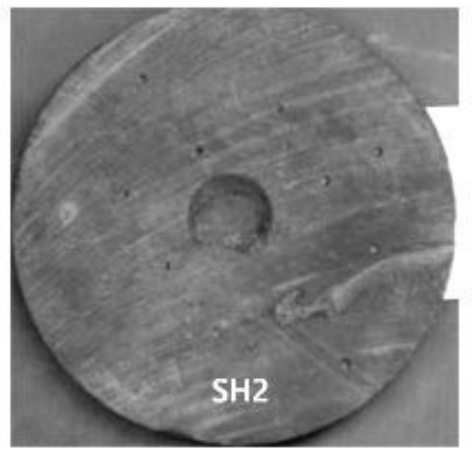

Figure A-40 Sample SH 2:

Laser Parameters: $E=8 \mathrm{~kW}, \mathrm{~L}=1 \mathrm{msec}$,

$\mathrm{R}=200 / \mathrm{sec}, \mathrm{t}=0.5 \mathrm{sec}$, beam diameter $=0.5^{\prime \prime}$

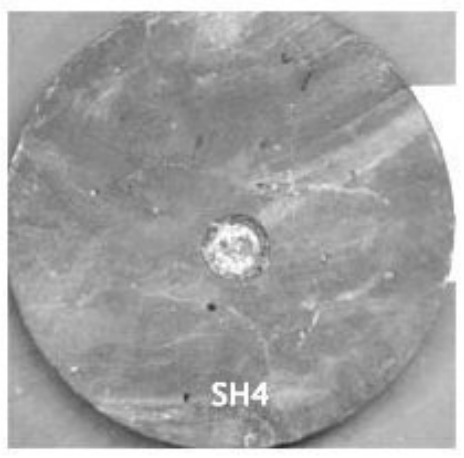

Figure A-42 Sample SH 4:

Laser Parameters: $E=8 \mathrm{~kW}, \mathrm{~L}=1 \mathrm{msec}$,

$\mathrm{R}=200 / \mathrm{sec}, \mathrm{t}=1.0 \mathrm{sec}$, beam diameter $=0.375^{\mathrm{N}}$

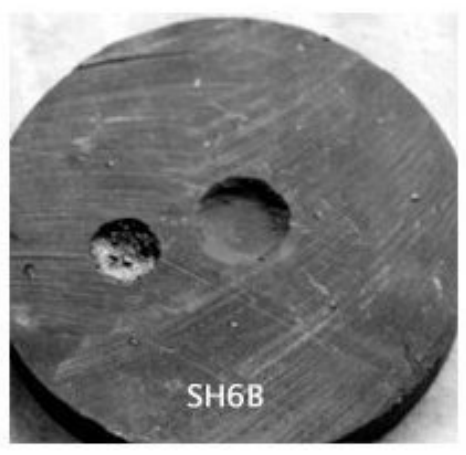

Figure A-44 Sample SH 6:

Laser Parameters: $E=8 \mathrm{~kW}, \mathrm{~L}=2 \mathrm{msec}$,

$\mathrm{R}=100 / \mathrm{sec}, \mathrm{t}=0.5 \mathrm{sec}$, Spot A: beam

diameter $=0.5$ ", Spot B: beam diameter $=0.375 "$ 


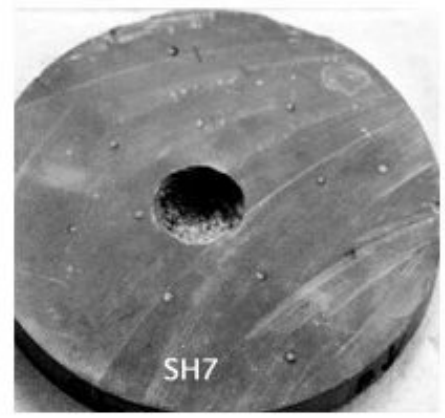

Figure A-45 Sample SH 7:

Laser Parameters: $E=8 \mathrm{~kW}, \mathrm{~L}=2 \mathrm{msec}$,

$\mathrm{R}=100 / \mathrm{sec}, \mathrm{t}=1.0 \mathrm{sec}$, beam diameter $=0.5^{\mathrm{n}}$

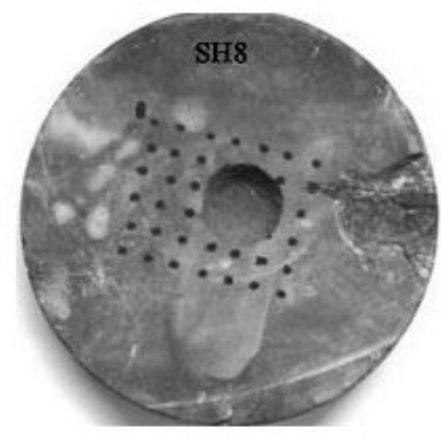

Figure A-47 Sample SH 8:

Laser Parameters: $E=8 \mathrm{~kW}, \mathrm{~L}=1 \mathrm{msec}$,

$\mathrm{R}=100 / \mathrm{sec}, \mathrm{t}=0.5 \mathrm{sec}$, beam diameter $=0.5^{\prime \prime}$

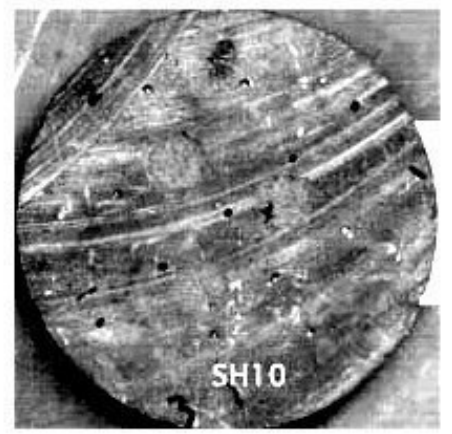

Figure A-49 Sample SH 10:

Laser Parameters: $E=8 \mathrm{~kW}, \mathrm{~L}=1 \mathrm{msec}$,

$\mathrm{R}=50 / \mathrm{sec}, \mathrm{t}=0.5 \mathrm{sec}$, beam diameter $=0.5 \mathrm{n}$

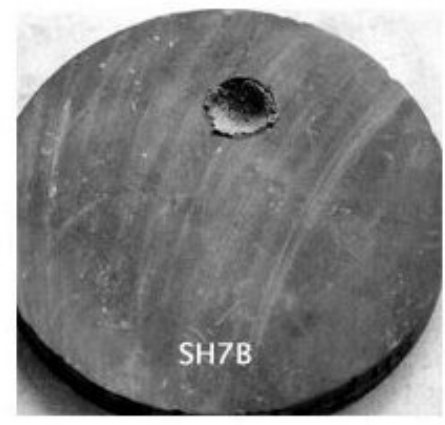

Figure A-46 Sample SH 7B:

Laser Parameters: $E=8 \mathrm{~kW}, \mathrm{~L}=2 \mathrm{msec}$,

$\mathrm{R}=100 / \mathrm{sec}, \mathrm{t}=1.0 \mathrm{sec}$, beam diameter $=0.375^{\prime \prime}$

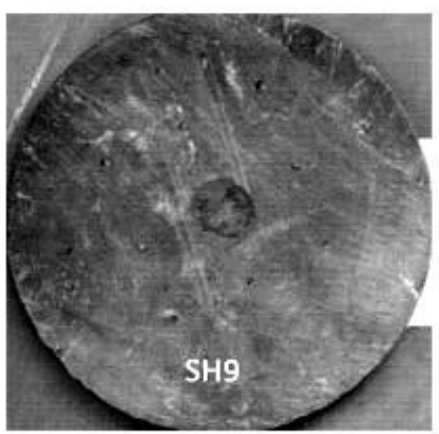

Figure A-48 Sample SH 9:

Laser Parameters: $E=8 \mathrm{~kW}, \mathrm{~L}=1 \mathrm{msec}$,

$\mathrm{R}=50 / \mathrm{sec}, \mathrm{t}=1.0 \mathrm{sec}$, beam diameter $=0.5^{\prime \prime}$

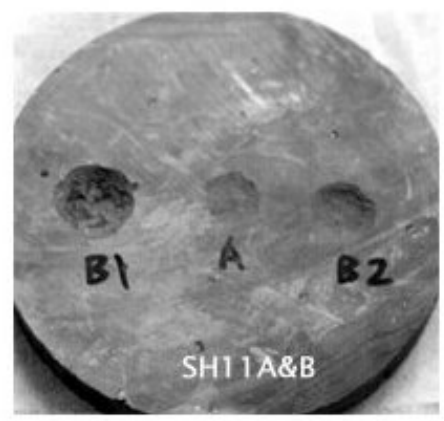

Figure A-50 Sample SH 11, shots A, B1 \& B2: Laser Parameters: $E=4 \mathrm{~kW}, \mathrm{~L}=1 \mathrm{msec}$,

Shot $A: R=100 / \mathrm{sec}, t=0.5 \mathrm{sec}$, beam diameter $=0.5 "$

Shot B1: $R=300 / \mathrm{sec}, \mathrm{t}=0.5 \mathrm{sec}$, beam diameter $=0.5^{\mathrm{N}}$

Shot B2: $R=150 / \mathrm{sec}, \mathrm{t}=0.5 \mathrm{sec}$, beam diameter $=0.5^{\prime \prime}$ 


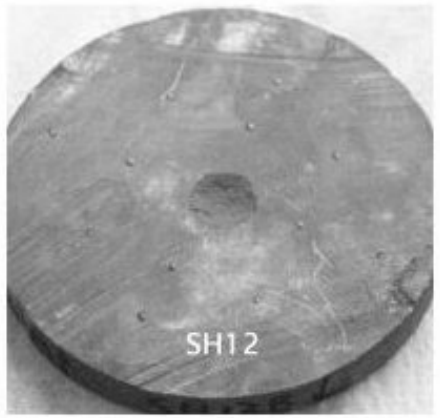

Figure A-51 Sample SH 12:

Laser Parameters: $E=4 \mathrm{~kW}, \mathrm{~L}=1 \mathrm{msec}$,

$\mathrm{R}=100 / \mathrm{sec}, \mathrm{t}=1.0 \mathrm{sec}$, beam diameter $=0.5^{\mathrm{n}}$

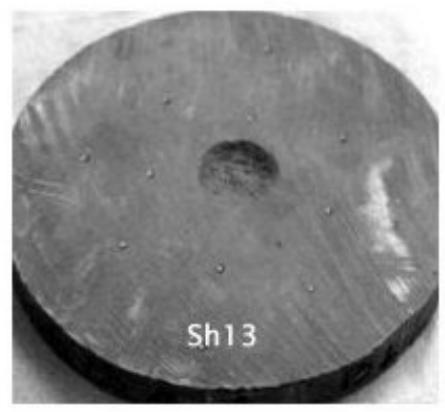

Figure A-53 Sample SH 13:

Laser Parameters: $E=8 \mathrm{~kW}, \mathrm{~L}=2 \mathrm{msec}$,

$\mathrm{R}=50 / \mathrm{sec}, \mathrm{t}=0.5 \mathrm{sec}$, beam diameter $=0.5^{\mathrm{n}}$

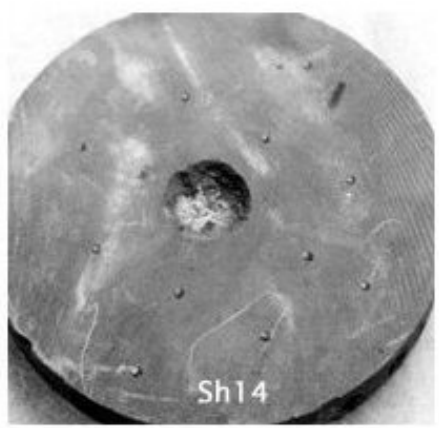

Figure A-55 Sample SH 14:

Laser Parameters: $E=8 \mathrm{~kW}, \mathrm{~L}=2 \mathrm{msec}$,

$R=50 / \mathrm{sec}, t=1.0 \mathrm{sec}$, beam diameter $=0.5^{\prime \prime}$

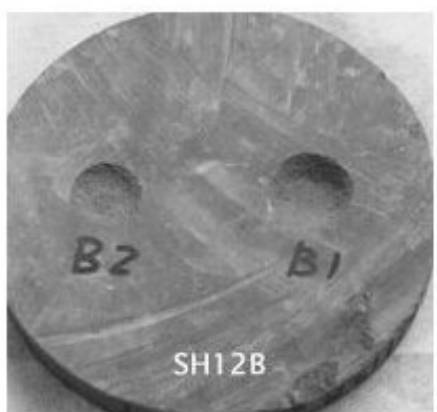

Figure A-52 Sample SH 12B, shots 1 \& 2:

Laser Parameters: $\mathrm{E}=8 \mathrm{~kW}, \mathrm{~L}=1 \mathrm{msec}$,

Shot 1: $R=150 / \mathrm{sec}, \mathrm{t}=0.5 \mathrm{sec}$, beam diameter $=0.5^{\prime \prime}$

Shot 2: $R=76 / \mathrm{sec}, \mathrm{t}=0.5 \mathrm{sec}$, beam diameter $=0.5^{\mathrm{n}}$

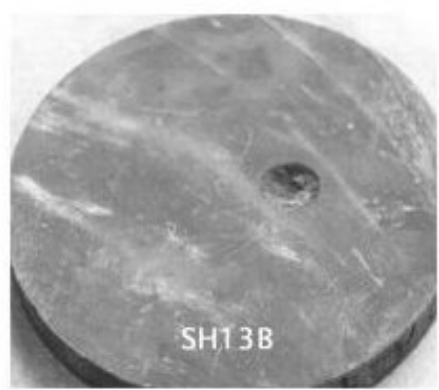

Figure A-54 Sample SH 13B:

Laser Parameters: $\mathrm{E}=8 \mathrm{~kW}, \mathrm{~L}=2 \mathrm{msec}$,

$\mathrm{R}=50 / \mathrm{sec}, \mathrm{t}=0.5 \mathrm{sec}$, beam diameter $=0.375^{\prime \prime}$

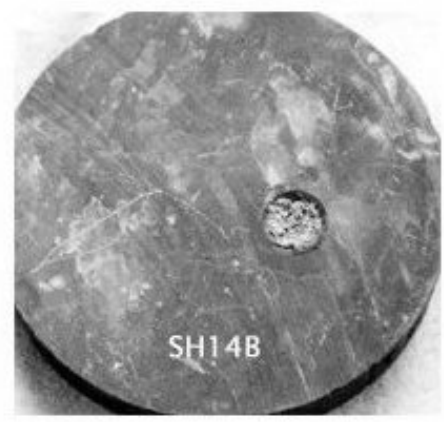

Figure A-56 Sample SH 14B:

Laser Parameters: $\mathrm{E}=8 \mathrm{~kW}, \mathrm{~L}=2 \mathrm{msec}$,

$\mathrm{R}=50 / \mathrm{sec}, \mathrm{t}=1.0 \mathrm{sec}$, beam diameter $=0.375^{\prime \prime}$ 


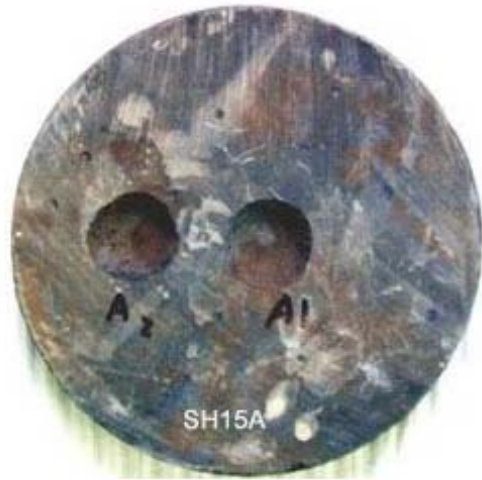

Figure A-57 Sample SH 15A1\&A2: Laser Parameters: $E=4 \mathrm{~kW}, \mathrm{~L}=1 \mathrm{msec}$, $\mathrm{R}=400 / \mathrm{sec}, \mathrm{t}=0.5 \mathrm{sec}$, beam diameter $=0.5 \mathrm{n}$

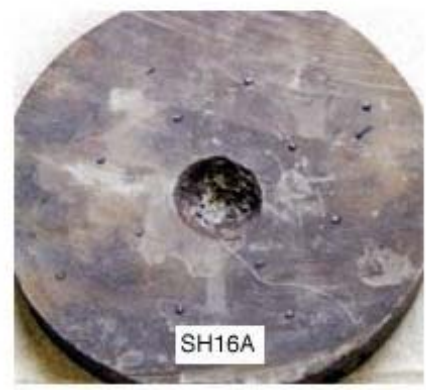

Figure A-59 Sample SH 16A: Laser Parameters: $E=4 \mathrm{~kW}, \mathrm{~L}=1 \mathrm{msec}$, $\mathrm{R}=400 / \mathrm{sec}, \mathrm{t}=0.5 \mathrm{sec}$, beam diameter $=0.5 \mathrm{"}$

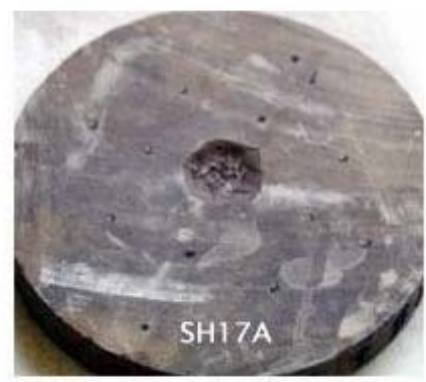

Figure A-61 Sample SH 17A: Laser Parameters: $E=4 \mathrm{~kW}, \mathrm{~L}=1 \mathrm{msec}$, $\mathrm{R}=200 / \mathrm{sec}, \mathrm{t}=1.0 \mathrm{sec}$, beam diameter $=0.5^{\mathrm{n}}$

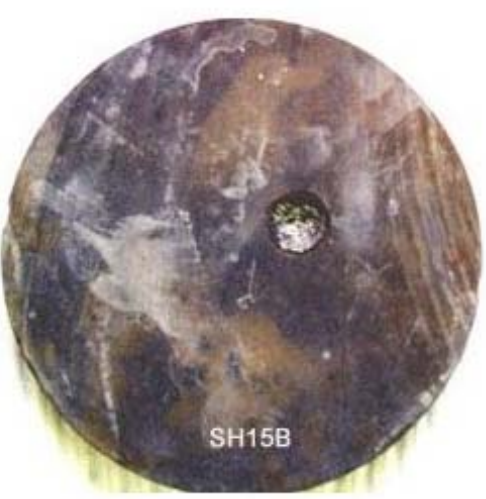

Figure A-58 Sample SH 15B:

Laser Parameters: $E=4 \mathrm{~kW}, \mathrm{~L}=1 \mathrm{msec}$,

$\mathrm{R}=400 / \mathrm{sec}, \mathrm{t}=0.5 \mathrm{sec}$, beam diameter $=0.375$ "

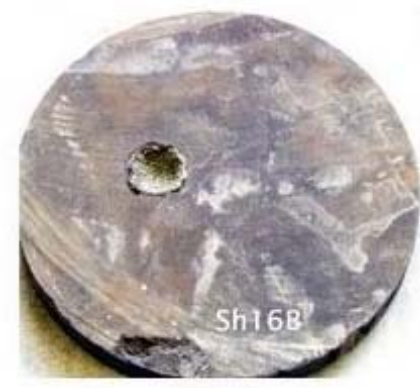

Figure A-60 Sample SH 16B: Laser Parameters: $E=4 \mathrm{~kW}, \mathrm{~L}=1 \mathrm{msec}$, $\mathrm{R}=400 / \mathrm{sec}, \mathrm{t}=1.0 \mathrm{sec}$, beam diameter $=0.375^{\prime \prime}$

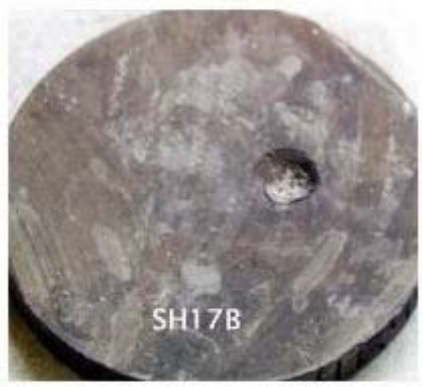

Figure A-62 Sample SH 17B:

Laser Parameters: $E=4 \mathrm{~kW}, \mathrm{~L}=1 \mathrm{msec}$, $R=200 / \mathrm{sec}, t=1.0 \mathrm{sec}$, beam diameter $=0.375^{\prime \prime}$ 


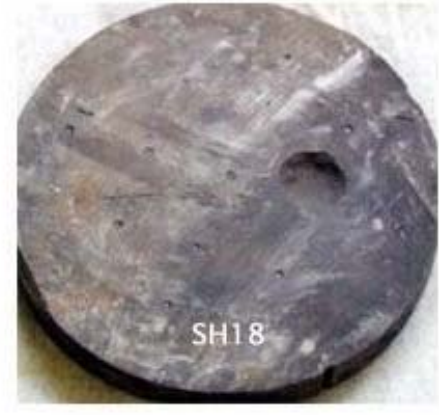

Figure A-60 Sample SH 18A:

Laser Parameters: $E=4 \mathrm{~kW}, \mathrm{~L}=1 \mathrm{msec}$,

$\mathrm{R}=200 / \mathrm{sec}, \mathrm{t}=0.5 \mathrm{sec}$, beam diameter $=0.5^{\mathrm{n}}$

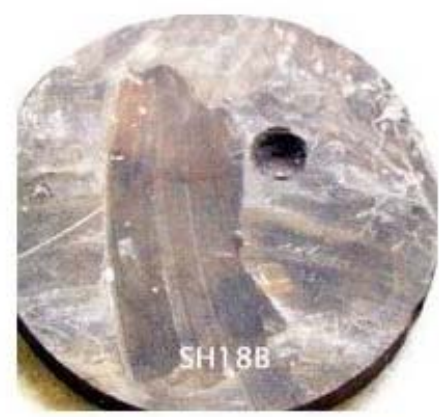

Figure A-61 Sample SH 18B:

Laser Parameters: $E=4 \mathrm{~kW}, \mathrm{~L}=1 \mathrm{msec}$,

$\mathrm{R}=200 / \mathrm{sec}, \mathrm{t}=0.5 \mathrm{sec}$, beam diameter $=0.375^{\prime \prime}$ 


\section{B: Sample Test Matrices}




\section{Dry Samples}

Table B-1: Berea Gray Sandstone, dry

\begin{tabular}{|c|c|c|c|c|c|}
\hline & Rep Rate & & $(\sec 0$ & & Beam Diam \\
\hline & per sec & 0.5 & 1 & 1.5 & inches \\
\hline Matrix 1 & 400 & BG8 & none & BG7 & 0.375 \\
\hline$E=4$ & & BG10 & none & BG9 & 0.500 \\
\hline$L=1$ & 200 & BG16 & none & BG12 & 0.375 \\
\hline $4 \mathrm{~J} / \mathrm{shot}$ & & BG15 & none & BG14 & 0.500 \\
\hline & 100 & BG19 & none & BG17 & 0.375 \\
\hline & & none & none & BG18 & 0.500 \\
\hline Matrix 2 & 200 & $\overline{B G 22}$ & none & BG20 & 0.375 \\
\hline$E=8$ & & BG23 & none & BG24 & 0.500 \\
\hline $\mathrm{L}=1$ & 100 & BG28 & none & BG27 & 0.375 \\
\hline $8 \mathrm{~J} / \mathrm{shot}$ & & BG25 & none & BG26 & 0.500 \\
\hline & 50 & BG29 & none & BG30 & 0.375 \\
\hline & & none & none & BG31 & 0.500 \\
\hline Matrix 3 & 100 & BG2 & none & $\overline{B G 1}$ & 0.375 \\
\hline$E=8$ & & BG4 & none & BG3 & 0.500 \\
\hline$L=2$ & 50 & BG33 & none & BG32 & 0.375 \\
\hline $16 \mathrm{~J} / \mathrm{shot}$ & & BG5 & none & BG6 & 0.500 \\
\hline & 25 & none & none & none & 0.375 \\
\hline & & none & none & none & 0.500 \\
\hline
\end{tabular}


Table B-2: Frontier Shale, dry

\begin{tabular}{|c|c|c|c|c|c|}
\hline \multirow[b]{3}{*}{$\begin{array}{l}\text { Matrix } 1 \\
E=4\end{array}$} & \multirow{2}{*}{$\begin{array}{c}\text { Rep Rate } \\
\text { per sec }\end{array}$} & \multicolumn{3}{|c|}{ Time (seconds) } & \multirow{2}{*}{$\begin{array}{c}\text { Beam Diam } \\
\text { inches }\end{array}$} \\
\hline & & 0.5 & 1 & 1.5 & \\
\hline & 400 & \multirow{2}{*}{$\begin{array}{c}\text { SH15B } \\
\text { SH15A1 } \\
\text { SH11B1 }\end{array}$} & $\begin{array}{c}\mathrm{SH} 16 \mathrm{~B} \\
\mathrm{SH} 16\end{array}$ & $\begin{array}{l}\text { none } \\
\text { none }\end{array}$ & $\begin{array}{l}0.375 \\
0.500\end{array}$ \\
\hline \multirow{5}{*}{$\begin{array}{l}\mathrm{L}=1 \\
4 \mathrm{~J} / \mathrm{shot}\end{array}$} & \multirow{2}{*}{200} & & SH17B & none & 0.500 \\
\hline & & \multirow{2}{*}{$\begin{array}{c}\text { SH18B } \\
\text { SH18 } \\
\text { SH11B2 }\end{array}$} & $\mathrm{SH} 17$ & none & 0.500 \\
\hline & \multirow{3}{*}{$\begin{array}{l}150 \\
100\end{array}$} & & & none & 0.500 \\
\hline & & & & none & 0.375 \\
\hline & & SH11 & SH12 & none & 0.500 \\
\hline \multirow{3}{*}{$\begin{array}{c}\text { Matrix } 2 \\
E=8\end{array}$} & \multirow[t]{2}{*}{200} & \multirow{3}{*}{$\begin{array}{c}\mathrm{SH} 3 \\
\mathrm{SH} 2 \\
\mathrm{SH} 12 \mathrm{~B} 1\end{array}$} & \multirow{2}{*}{$\begin{array}{l}\mathrm{SH} 4 \\
\mathrm{SH} 1\end{array}$} & \multirow{3}{*}{$\begin{array}{l}\text { none } \\
\text { none } \\
\text { none }\end{array}$} & 0.375 \\
\hline & & & & & 0.500 \\
\hline & \multirow{2}{*}{$\begin{array}{l}150 \\
100\end{array}$} & & & & 0.500 \\
\hline \multirow{5}{*}{$\begin{array}{l}L=1 \\
8 \mathrm{~J} / \mathrm{shot}\end{array}$} & & \multirow{4}{*}{$\begin{array}{c}\text { SH8 } \\
\text { SH12B2 }\end{array}$} & \multirow{3}{*}{ SH5 } & \multirow{5}{*}{$\begin{array}{l}\text { none } \\
\text { none } \\
\text { none } \\
\text { none } \\
\text { none }\end{array}$} & 0.375 \\
\hline & \multirow{4}{*}{$\begin{array}{l}76 \\
50\end{array}$} & & & & 0.500 \\
\hline & & & & & 0.500 \\
\hline & & & & & 0.375 \\
\hline & & SH10 & $\mathrm{SH} 9$ & & 0.500 \\
\hline \multirow{6}{*}{$\begin{array}{l}\text { Matrix } 3 \\
E=8 \\
L=2 \\
16 \mathrm{~J} / \mathrm{shot}\end{array}$} & \multirow[t]{2}{*}{100} & \multirow{6}{*}{$\begin{array}{l}\text { SH6B } \\
\text { SH6 } \\
\text { SH13B } \\
\text { SH13 }\end{array}$} & \multirow{6}{*}{$\begin{array}{c}\text { SH7B } \\
\text { SH7 } \\
\text { SH14B } \\
\text { SH14 }\end{array}$} & none & 0.375 \\
\hline & & & & none & 0.500 \\
\hline & \multirow[t]{2}{*}{50} & & & none & 0.375 \\
\hline & & & & none & 0.500 \\
\hline & \multirow[t]{2}{*}{25} & & & none & 0.375 \\
\hline & & & & & 0.500 \\
\hline
\end{tabular}


Table B-3: Ratcliff Limestone, dry

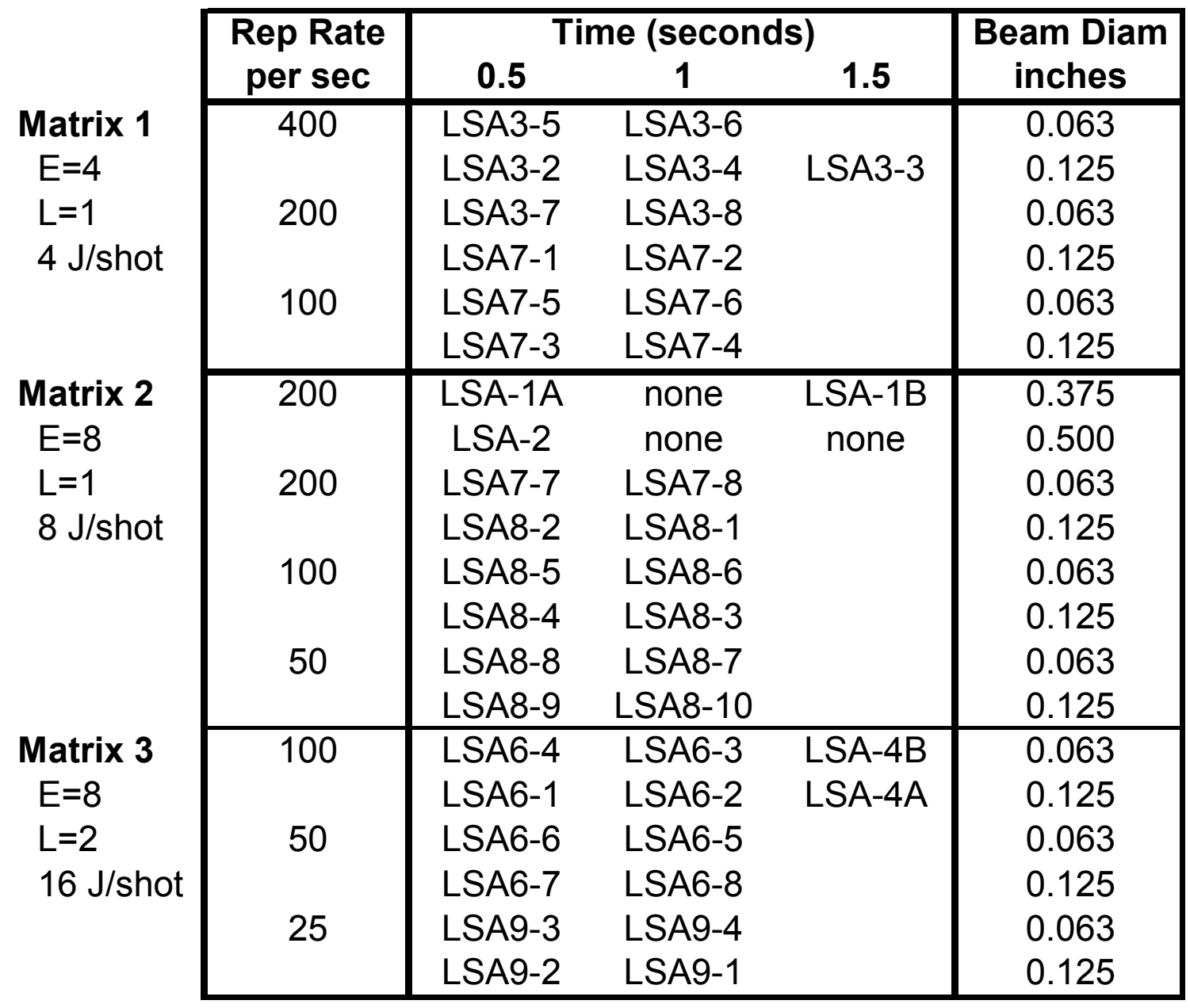




\section{Saturated and Underwater Samples}

Table B-4: Berea Gray, Saturated Samples

Saturated Sample Matrix: Time $=1$ Second and Beam Diameter $=0.5$ Inches

\begin{tabular}{|c|c|c|c|c|c|c|c|}
\hline \multirow{2}{*}{$\begin{array}{l}\text { Peak Power } \\
\text { (Schedule) }\end{array}$} & \multirow{2}{*}{$\begin{array}{l}\text { Pulse } \\
\text { Width } \\
\text { (ms) }\end{array}$} & \multirow{2}{*}{$\begin{array}{c}\text { Repetition } \\
\text { Rate } \\
\text { (1/sec) }\end{array}$} & \multicolumn{5}{|c|}{ Disk Thickness } \\
\hline & & & 0.5 & 1 & 1.5 & 2 & 2.5 \\
\hline$\overline{8}$ & & 200 & BG3as & BG1s & BG7s & $\overline{B G 9 s}$ & BG10s \\
\hline 16 & & 100 & BG2as & BG2s & & & \\
\hline 32 & $\begin{array}{r}0.5 \\
1 \\
2\end{array}$ & $\begin{array}{c}100 \\
50 \\
25\end{array}$ & $\begin{array}{l}\text { BG4as } \\
\text { BG1as } \\
\text { BG5as }\end{array}$ & $\begin{array}{l}\text { BG3s } \\
\text { BG4s } \\
\text { BG5s }\end{array}$ & & & \\
\hline
\end{tabular}

Table B-5: Berea Gray, Underwater Samples

\begin{tabular}{|c|c|c|c|c|c|}
\hline $\begin{array}{c}\text { Test } \\
\text { \# }\end{array}$ & $\begin{array}{c}\text { Laser } \\
\text { schedule }\end{array}$ & $\begin{array}{c}\text { Distance } \\
\text { btw fiber } \\
\text { and rock, } \\
\text { (inches) }\end{array}$ & $\begin{array}{c}\text { Exposure } \\
\text { time (s) }\end{array}$ & Shots & Notes \\
\hline 1 & E8L2R100 & 1.75 & 1 & 100 & No effect \\
\hline 2 & E8L2R100 & 1.1 & 5 & 500 & No effect, power check 1408 \\
\cline { 1 - 2 } W
\end{tabular}




\section{C: Tables of Results}




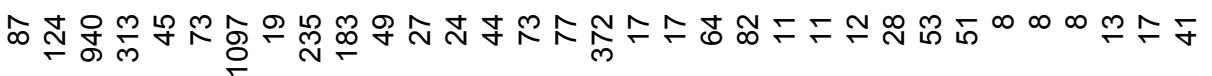
के

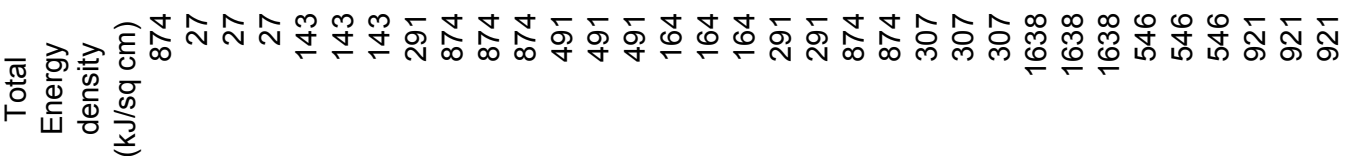

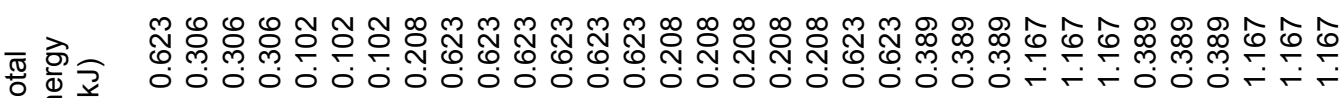

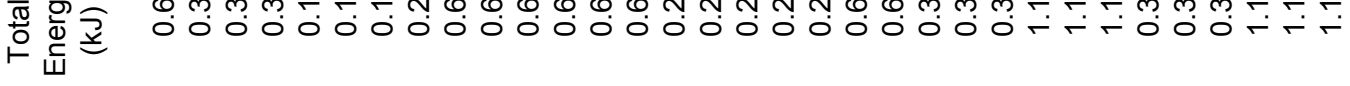

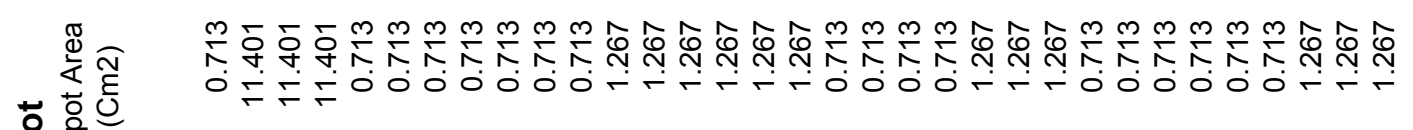

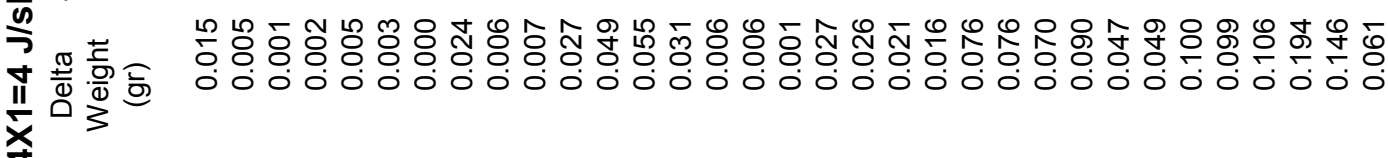

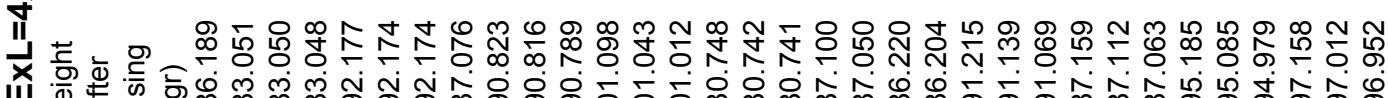

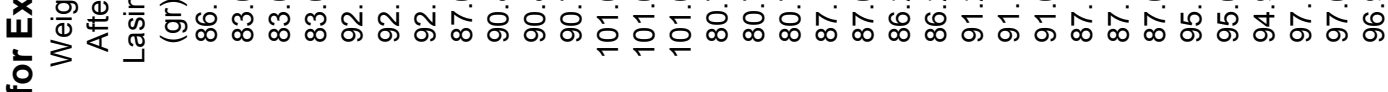

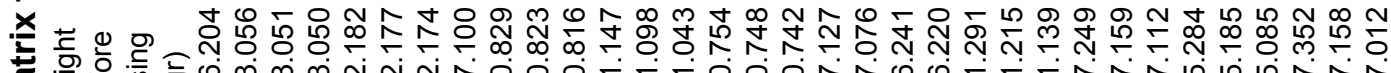

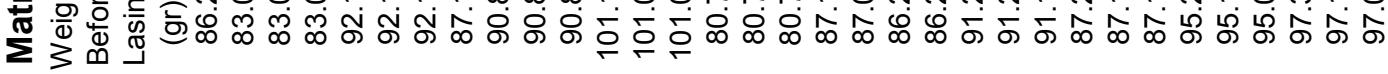
竞

(1) 嵌

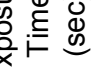

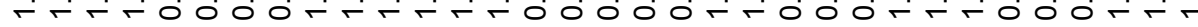

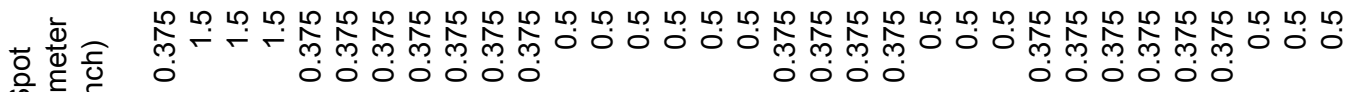
के $\frac{\pi}{0} \subseteq$

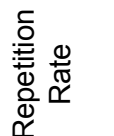

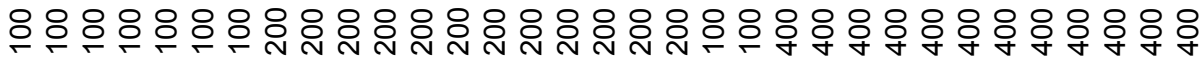
$\stackrel{\infty}{\frac{\infty}{5}} \underset{0}{\stackrel{5}{*}}$

ఠ。 至

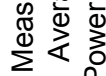

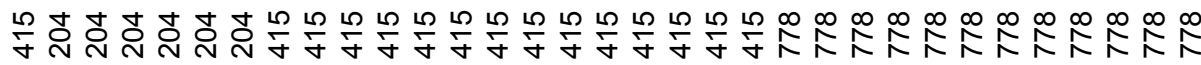

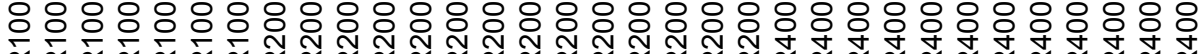

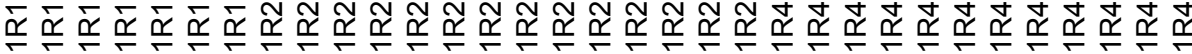

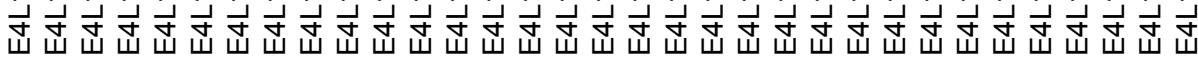
吕产

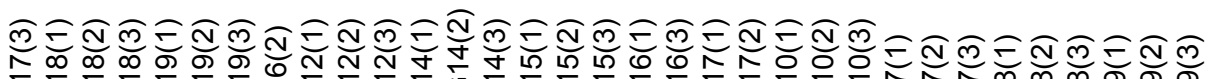

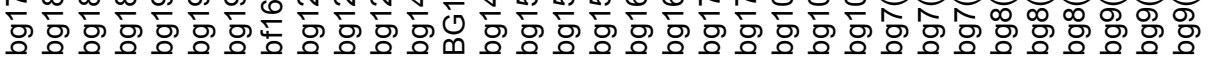


产

웜 늉 ஸे

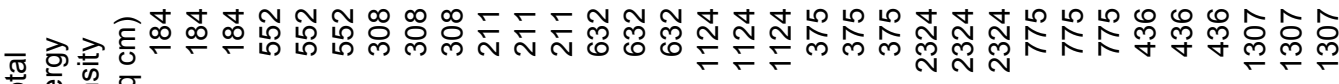

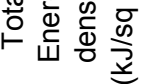

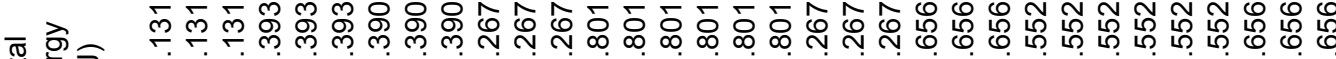

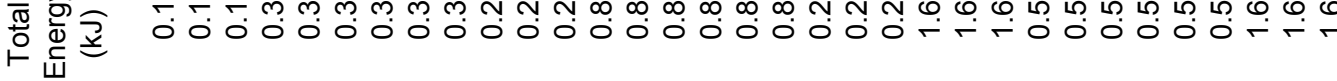

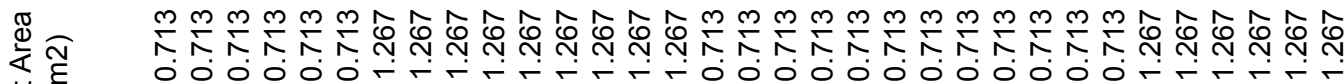
节范

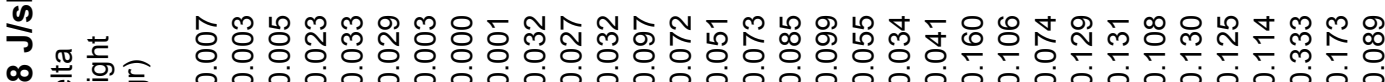

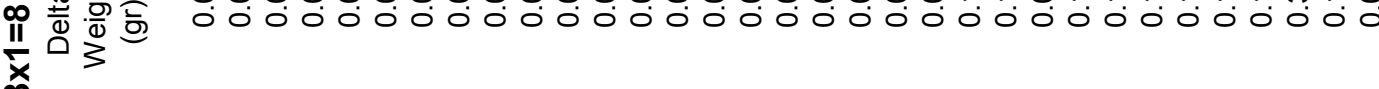

苟 茫

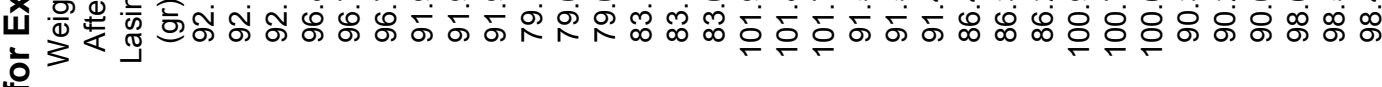

套

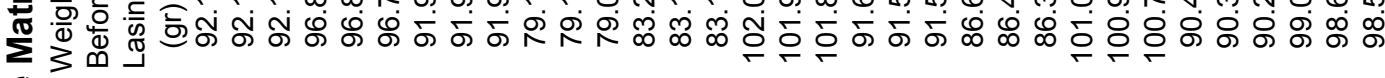
(1)

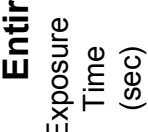

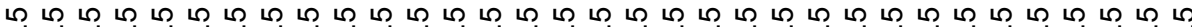

$\bar{\Phi}$

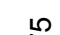

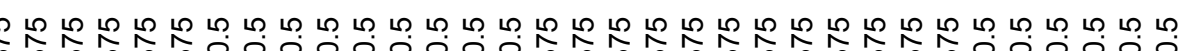

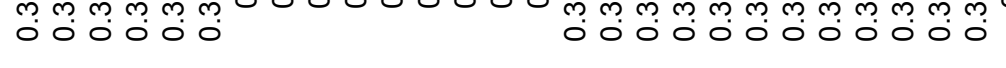

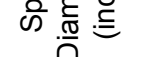

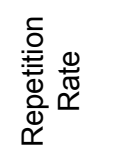

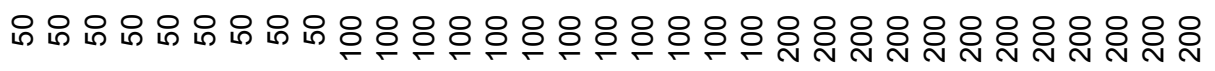

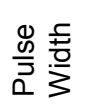

용

要要这

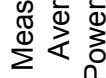

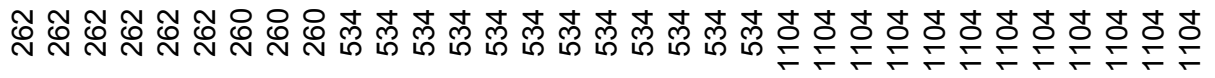

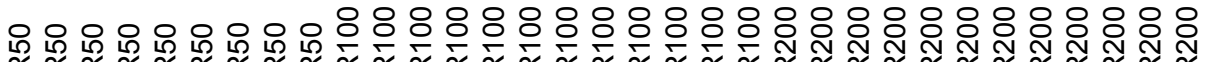

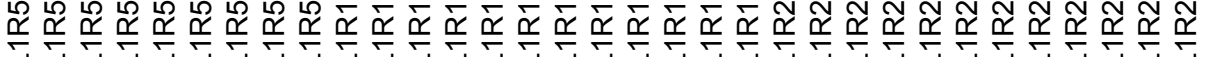

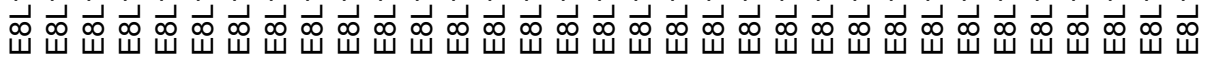
㐫

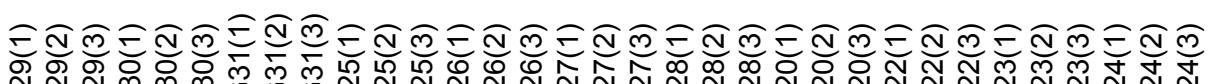

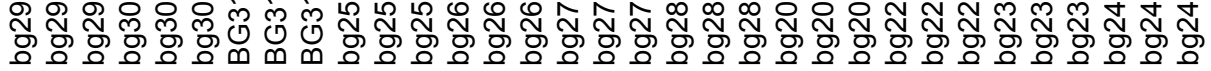




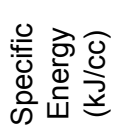

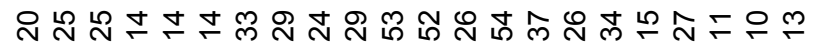

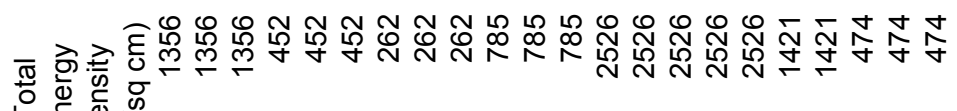

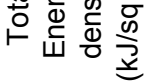

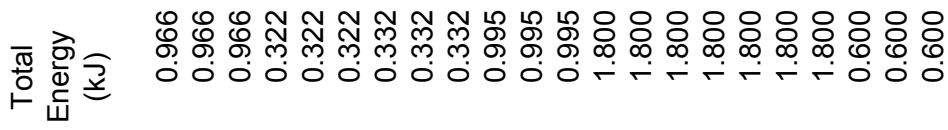

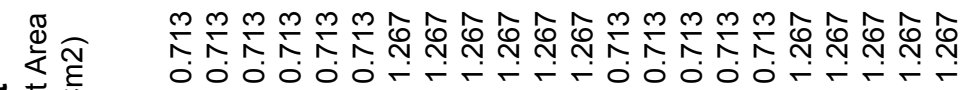
능

ज象

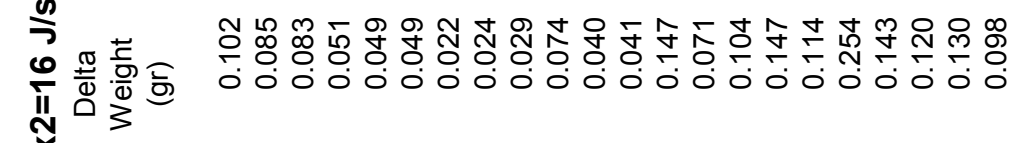

茪 志施

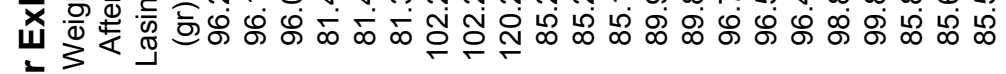
으

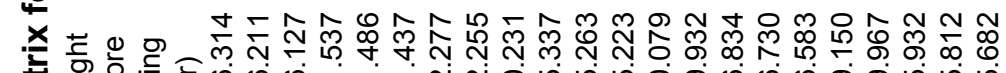
L

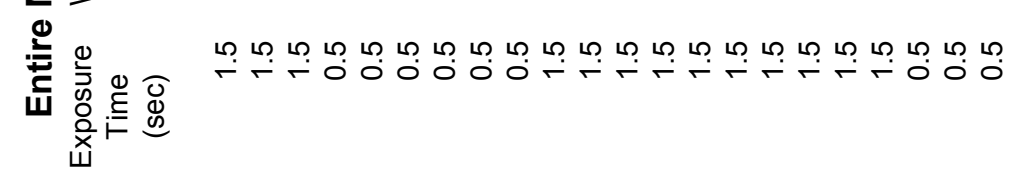

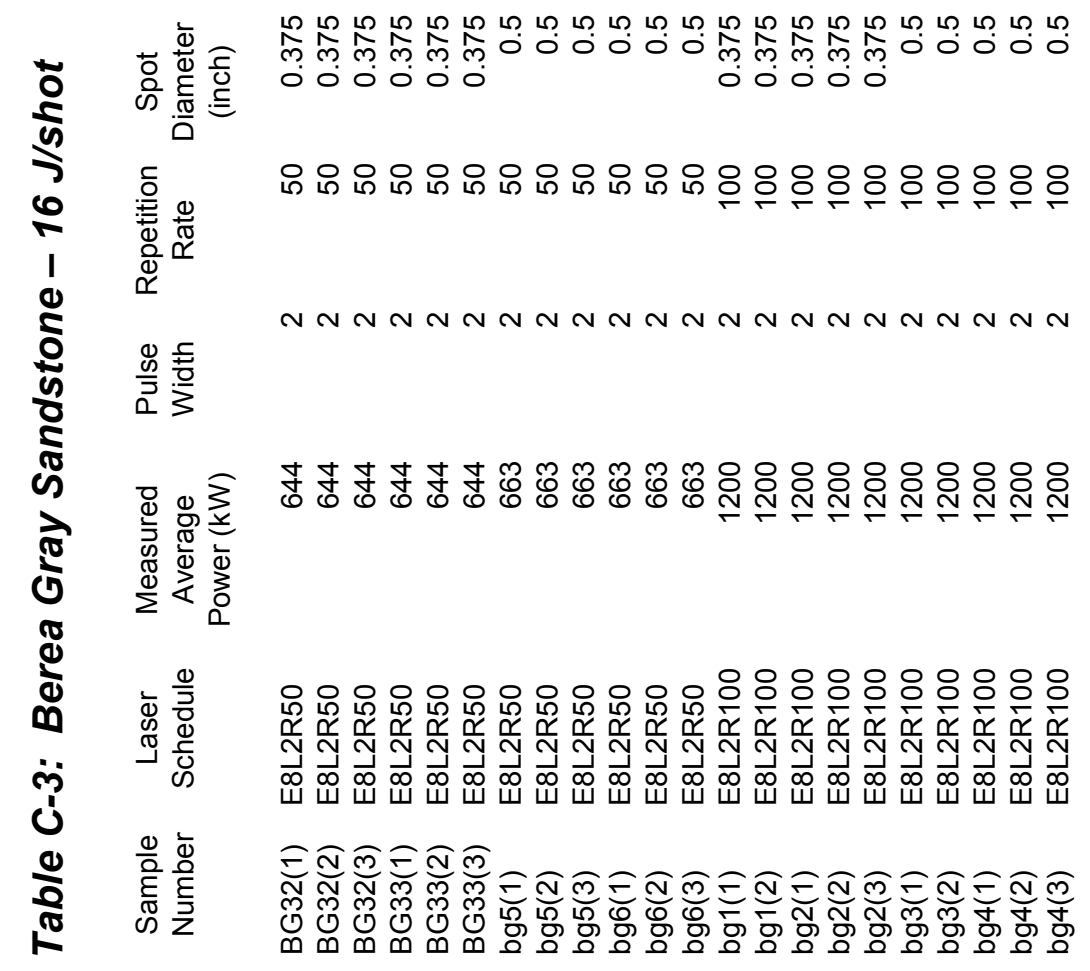




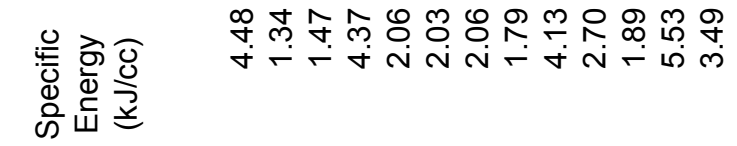

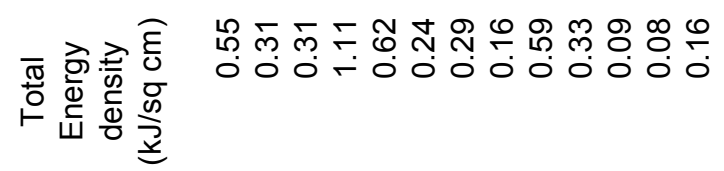

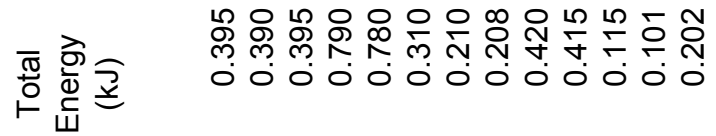

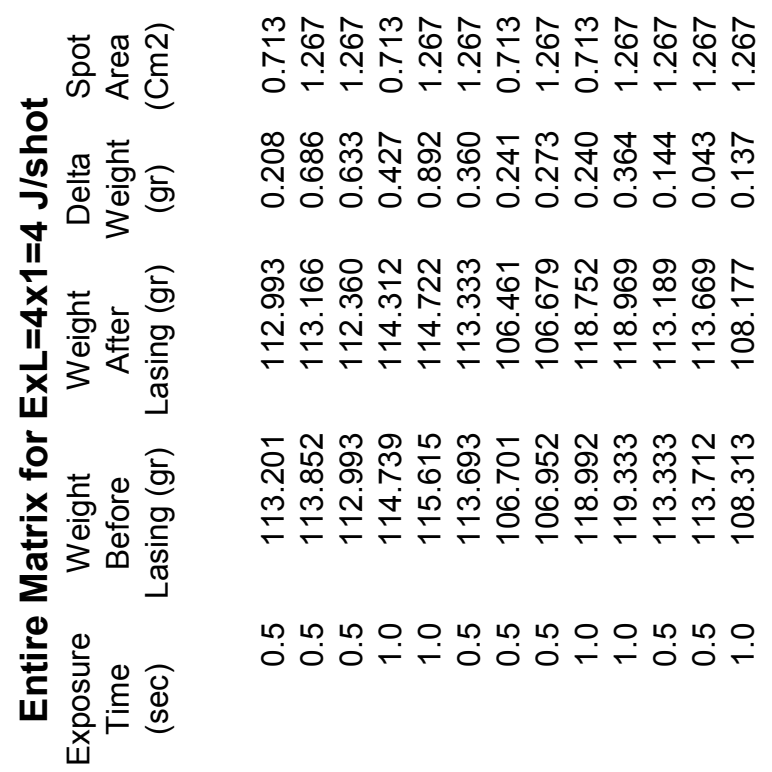

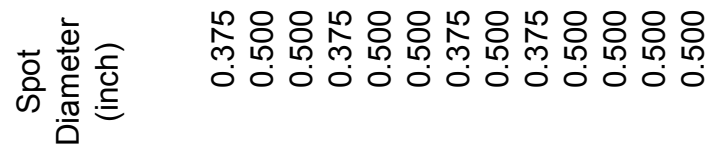
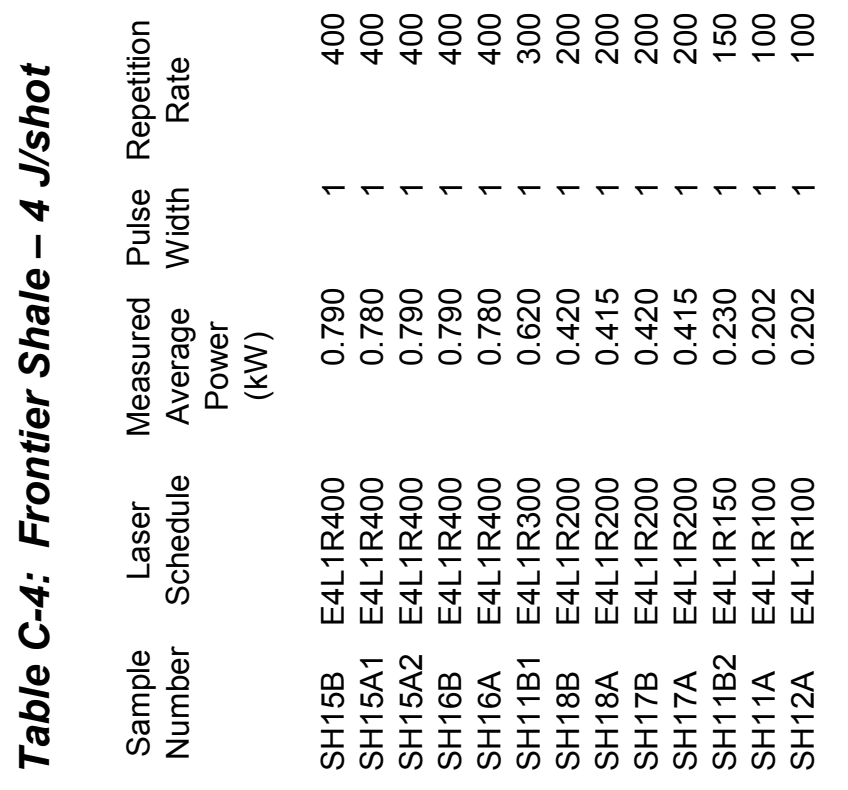


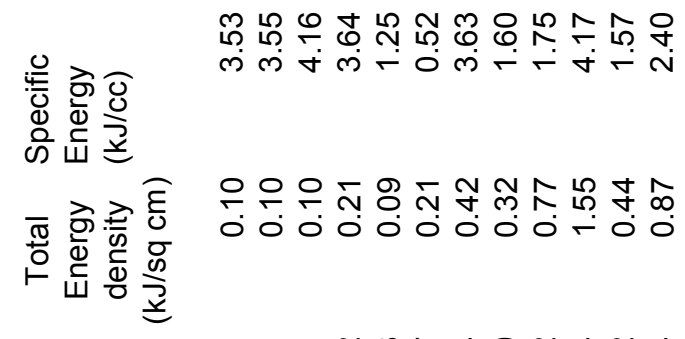

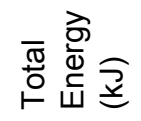

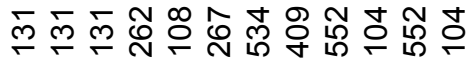
Бо

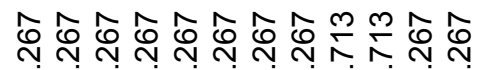

શั

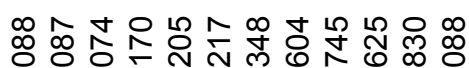

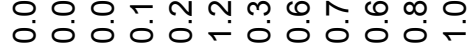

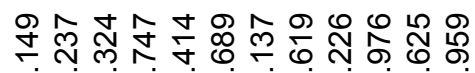

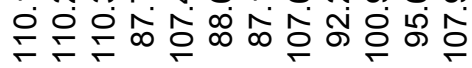

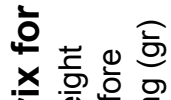

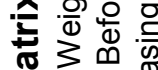

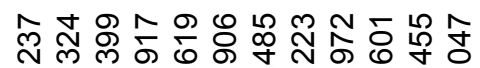
은은은

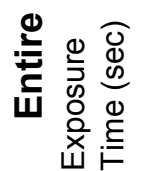

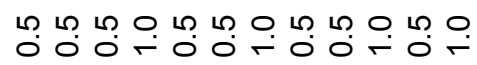

$\frac{1}{0}$
$\stackrel{\frac{1}{0}}{\frac{1}{0}}$
की

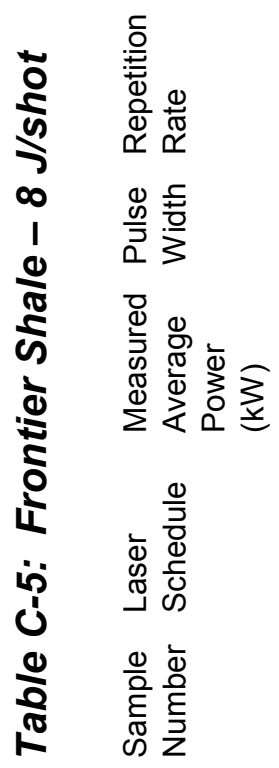

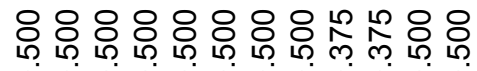
000000000000

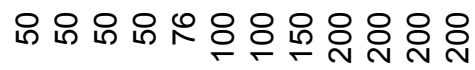

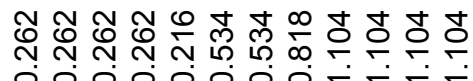
०0000000\%

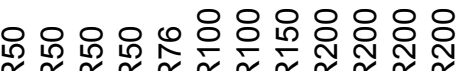

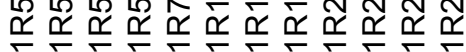

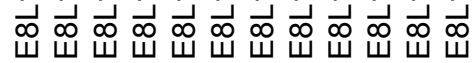

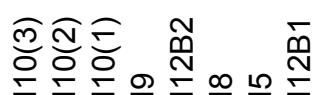

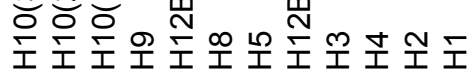

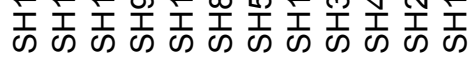




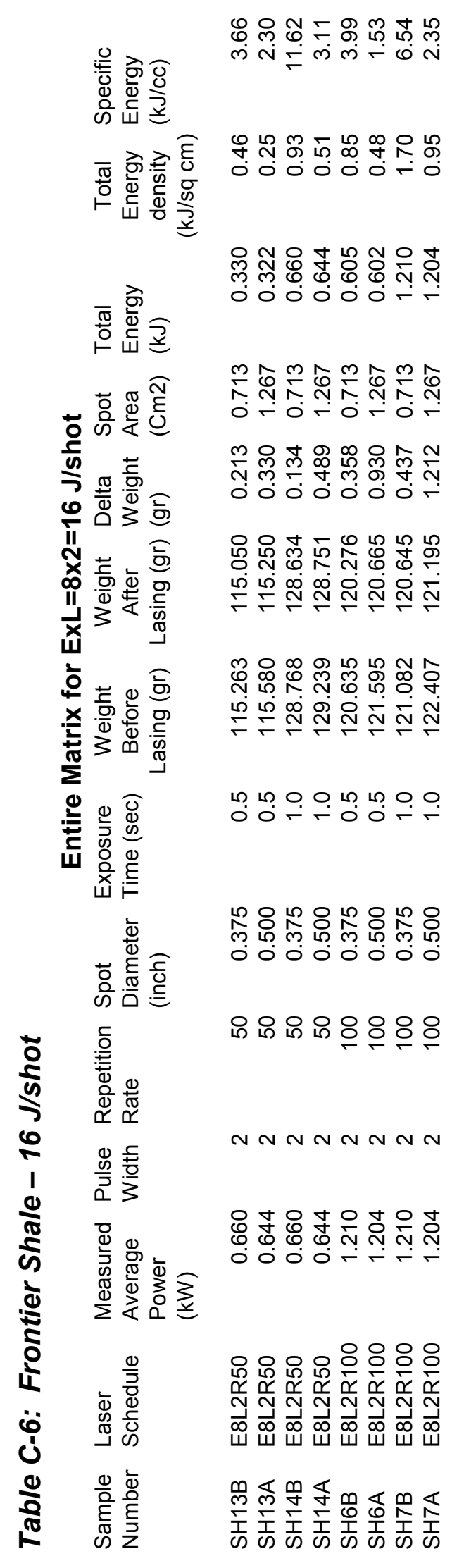




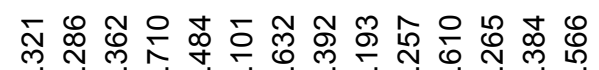

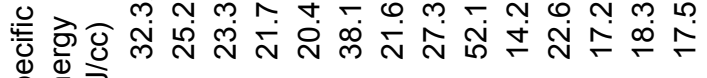
की

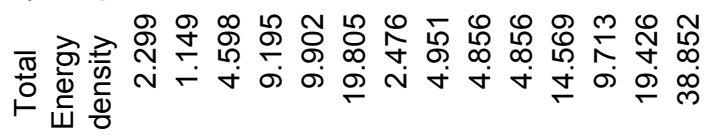

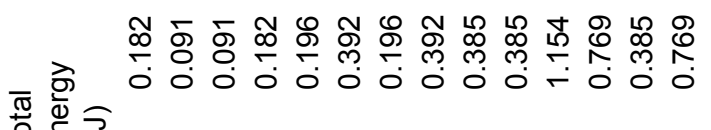
要覀

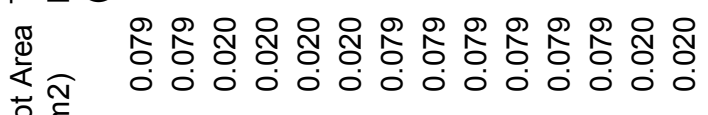
के है

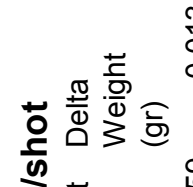

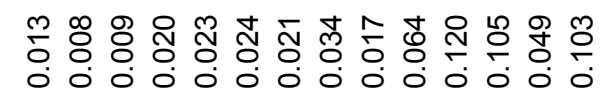

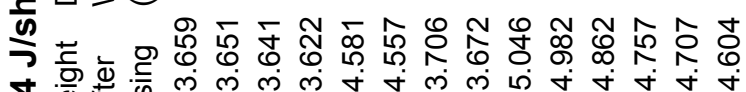

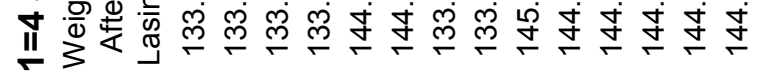

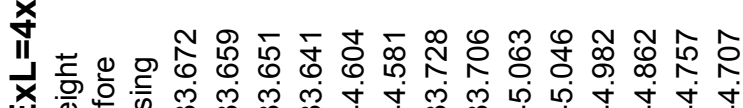

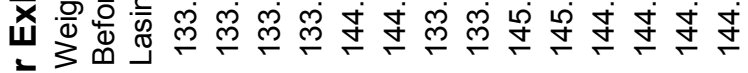
ఫे

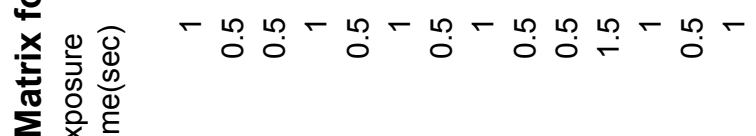
일

岌

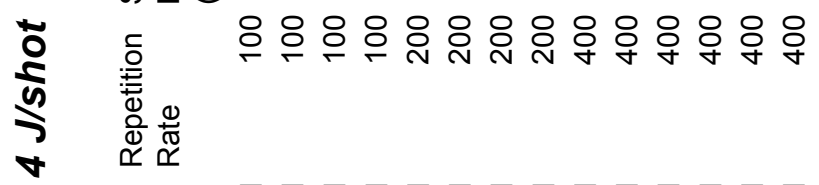

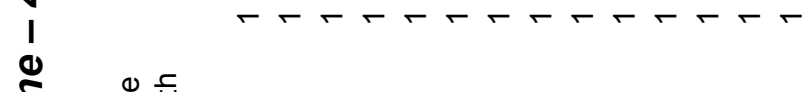

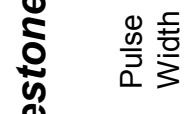

占

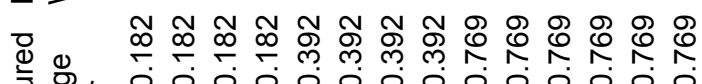

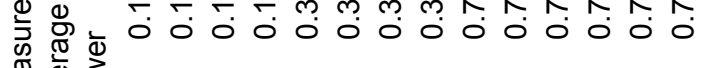
$\sum^{\infty}$

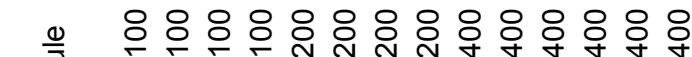

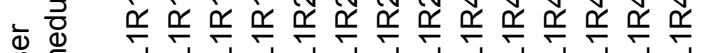

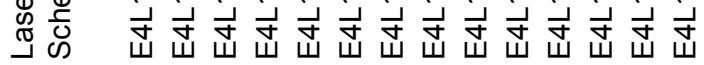

ง

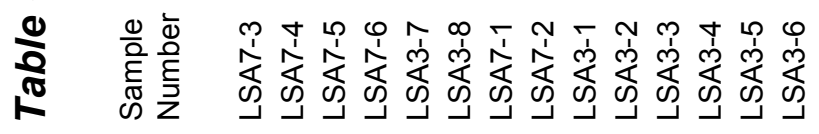




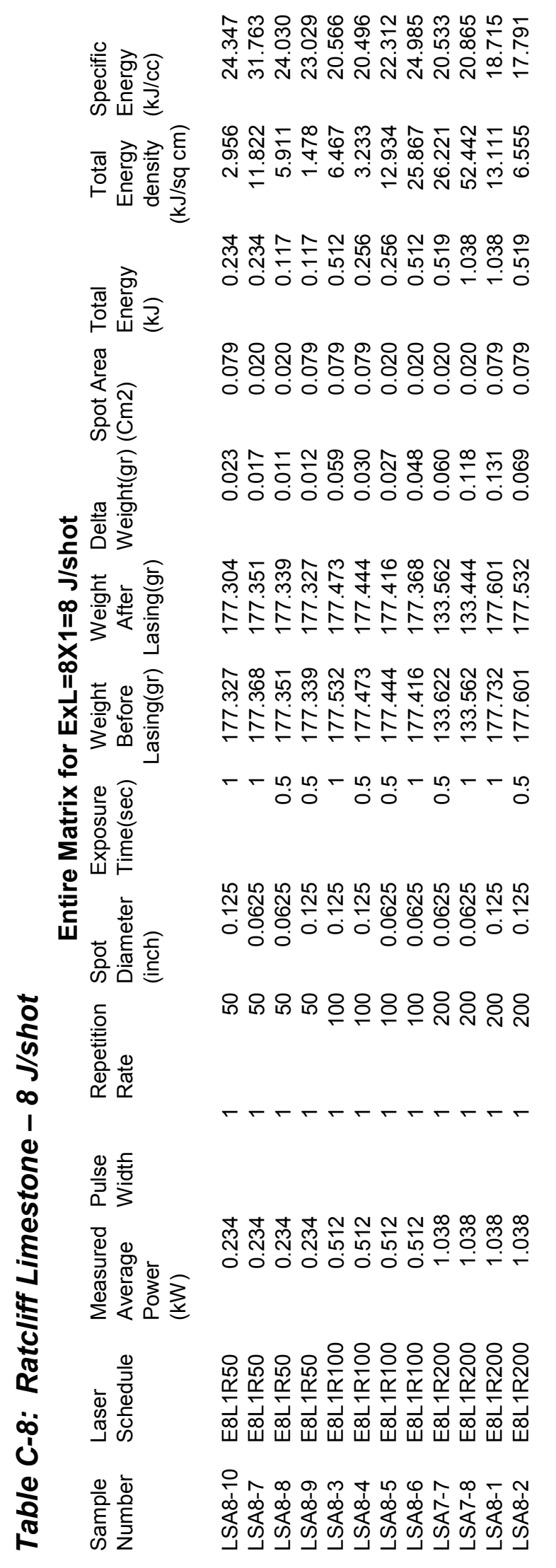




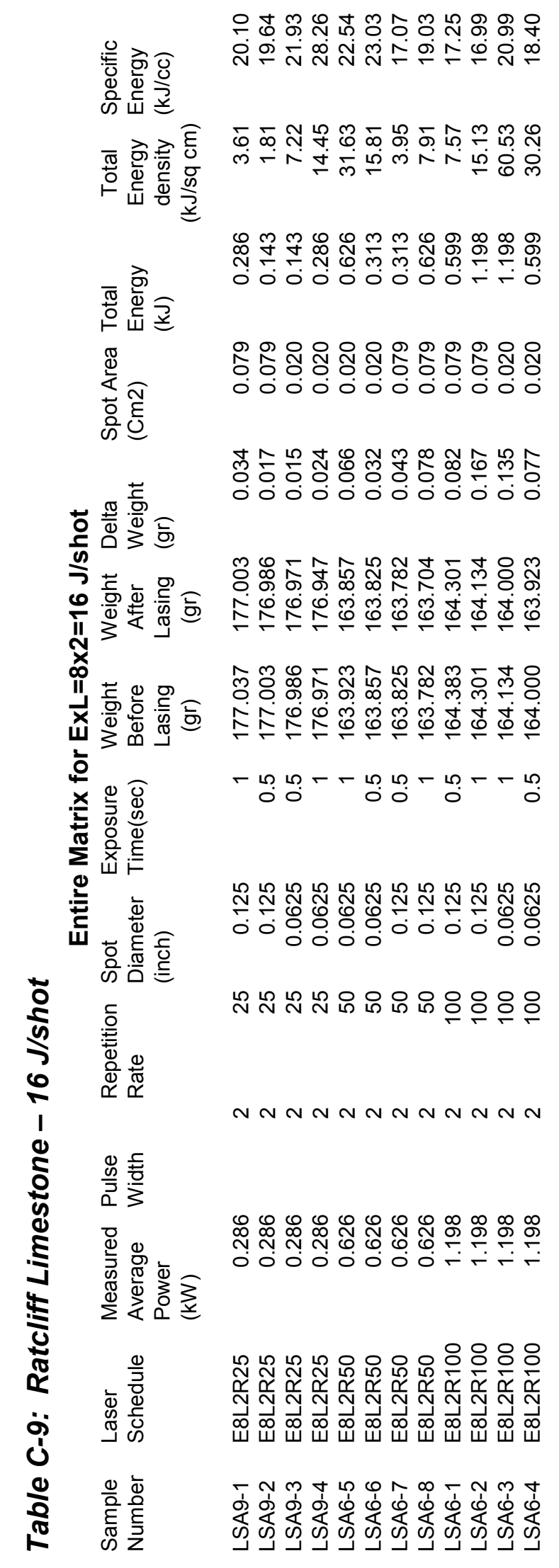




\section{D: Glossary}

Absorption: The ratio of the energy carried by absorbed wave to the energy carried by the original wave.

Beam duration: The amount of time a sample is exposed to the laser beam.

Beam intensity (Power density): The ratio of the power to the beam diameter measured in watts $/ \mathrm{cm}^{2}$.

Beam size: The diameter of the laser beam; can vary from microns to inches.

Blackbody radiation: When the rock temperature increases, the rock itself turns into an intense source of radiation; decreases rock destruction.

CAT: Computer Assisted Tomography, used to monitor the interior structure of the core.

Chipping (Spalling): Splitting off rock fragments from the rock face.

CMS-300: Core Measurement System used for permeability, porosity and bulk compressibility under stress up to 5000 psi.

COIL: Chemical Oxygen Iodine Laser.

Continuous wave $(\mathrm{CW})$ : Uninterrupted transmission of beam laser.

Differential Thermal Analysis (DTA): Used to determined melting temperature of the rocks samples.

Diffusivity: The ability of a material to conduct thermal energy compared to its ability to store energy.

Divergence: Defined as a ratio of unfocused laser radiation spot diameter (at far distance) to the distance from the laser.

Elastic moduli: Describe a material or a state of a material where strain or deformation is recoverable after a displacing stress is removed. 
Electron-microprobe (EMP): Used to determine the chemical composition of the melted material and rocks.

Plume: Gaseous effluent formed between the laser and the rock face due to heating. Results in less rock destruction.

LASER: An acronym formed from Light Amplification by Stimulation Emission of Radiation.

Laser-rock interaction: The result of exposing a rock to laser energy. Depending on the wavelength, power and duration of the exposure, the rock may break, melt or vaporize.

MIRACL: An acronym for Mid-InfraRed Advanced Chemical Laser.

PDPK-200: Pressure-decay profile permeameter, used to measure point permeability.

Plasma: The creation of an ionized cloud on the surface of the rock. It is produced by vaporization of some of the opague target surface and subsequent absorption of laser light in the vaporized materials. In this research plasma refer to as glasseous melted materials. Plasma disperses the beam, so less destruction.

Poisson's ratio: Specifies the rock's ability to deform laterally when stress is applied.

Power peak: is the pulse energy to pulse length ratio.

Pulsed lasers: Lasers that emit short, high power pulses of light.

Rate of Penetration (ROP): The speed at which the well is drilled, usually measured in feet per hour.

Reflectivity: The ratio of the energy carried by a reflected wave to the energy carried by the original wave. High reflectivity means less rock destruction.

Scattering: The irregular and diffuse dispersion of energy caused by inhomogeneities in the medium through which the energy is traveling.

SEM-EDS: Scanning electron microscope-electronic despersive system, used create 3-D images or rocks. 
Spalling (Chipping): Splitting off pieces from the rock face due to low power laser that causes the rock to break into fragments.

Specific Energy (SE): The amount of energy required to remove a volume of rock.

Thermal conductivity: Quantity of heat transmitted through a unit volume in a unit time. High thermal conductivity means high rock destruction.

Thermal stress: Stresses created with in a rock due to the non-homogeneity of the thermal expansion of different minerals making up the rock.

X-ray diffraction (XRD): Used for identify clays mineralogy.

Young's modulus: A measure of the rock's resistance to deformation. 


\section{E: Nomenclature}

\begin{tabular}{|c|c|}
\hline A & $=$ area \\
\hline BG & $=$ Berea gray sandstone \\
\hline BY & $=$ Berea yellow sandstone \\
\hline $\mathrm{C}_{\mathrm{p}}$ & $=$ heat capacity \\
\hline $\mathrm{C}$ & $=$ celcius $/$ centigrade \\
\hline cal & $=$ calorie \\
\hline$d$ & $=$ diameter \\
\hline $\mathrm{E}$ & $=$ Young's modulus \\
\hline $\mathrm{E}_{\mathrm{abs}}$ & $=$ absorbed energy \\
\hline E blackbody & $=$ blackbody energy \\
\hline $\mathrm{E}_{\mathrm{inc}}$ & $=$ incident electromagnetic wave \\
\hline $\mathrm{E}_{\mathrm{ref}}$ & $=$ reflected enery \\
\hline $\mathrm{E}_{\mathrm{sc}}$ & $=$ scattered energy \\
\hline $\mathrm{G}$ & $=$ shear modulus \\
\hline $\mathrm{g}$ & $=$ gram \\
\hline $\mathrm{H}$ & $=$ melting depth \\
\hline I & $=$ intensity (power density) \\
\hline $\mathrm{J}$ & $=$ joule \\
\hline 1 & $=$ permeability \\
\hline $\mathrm{K}_{\mathrm{b}}$ & $=$ bulk modulus \\
\hline $\mathrm{K}_{\mathrm{f}}$ & $=$ thermal conductivity \\
\hline $\mathrm{Hz}$ & $=$ hertz \\
\hline I & $=$ length \\
\hline$I_{\mathrm{s}}$ & $=$ limestone \\
\hline md & $=$ millidarcy (Permeability Unit) \\
\hline $\mathrm{P}$ & $=$ power \\
\hline $\mathrm{P}_{\mathrm{av}}$ & $=$ average power \\
\hline 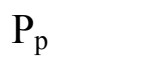 & $=$ peak power \\
\hline $\mathrm{p}$ & $=$ pressure \\
\hline $\mathrm{R}$ & $=$ repetition rate \\
\hline
\end{tabular}




$\begin{array}{ll}\mathrm{S} & =\text { seconds } \\ \mathrm{S} & =\text { shear wave. } \\ \mathrm{T} & =\text { time interval between the beginning of the laser pulses } \\ \mathrm{t} & =\text { total energy } \\ \mathrm{TE} & =\text { maximum temperature } \\ \mathrm{Tmax} & =\text { temperature cycling frequency } \\ \mathrm{Tf} & =\text { compressional wave travel time } \\ \mathrm{t}_{\mathrm{p}} & =\text { watt } \\ \mathrm{W} & =\text { pulse width } \\ \mathrm{Wp} & =\text { temperature difference } \\ \Delta \mathrm{T} & =\text { wackness coefficient } \\ \varepsilon & =\text { laser pulse length } \\ \lambda & =\text { shear stress } \\ \tau & =\text { Poisson's ratio } \\ \tau & \end{array}$


F: Figures 


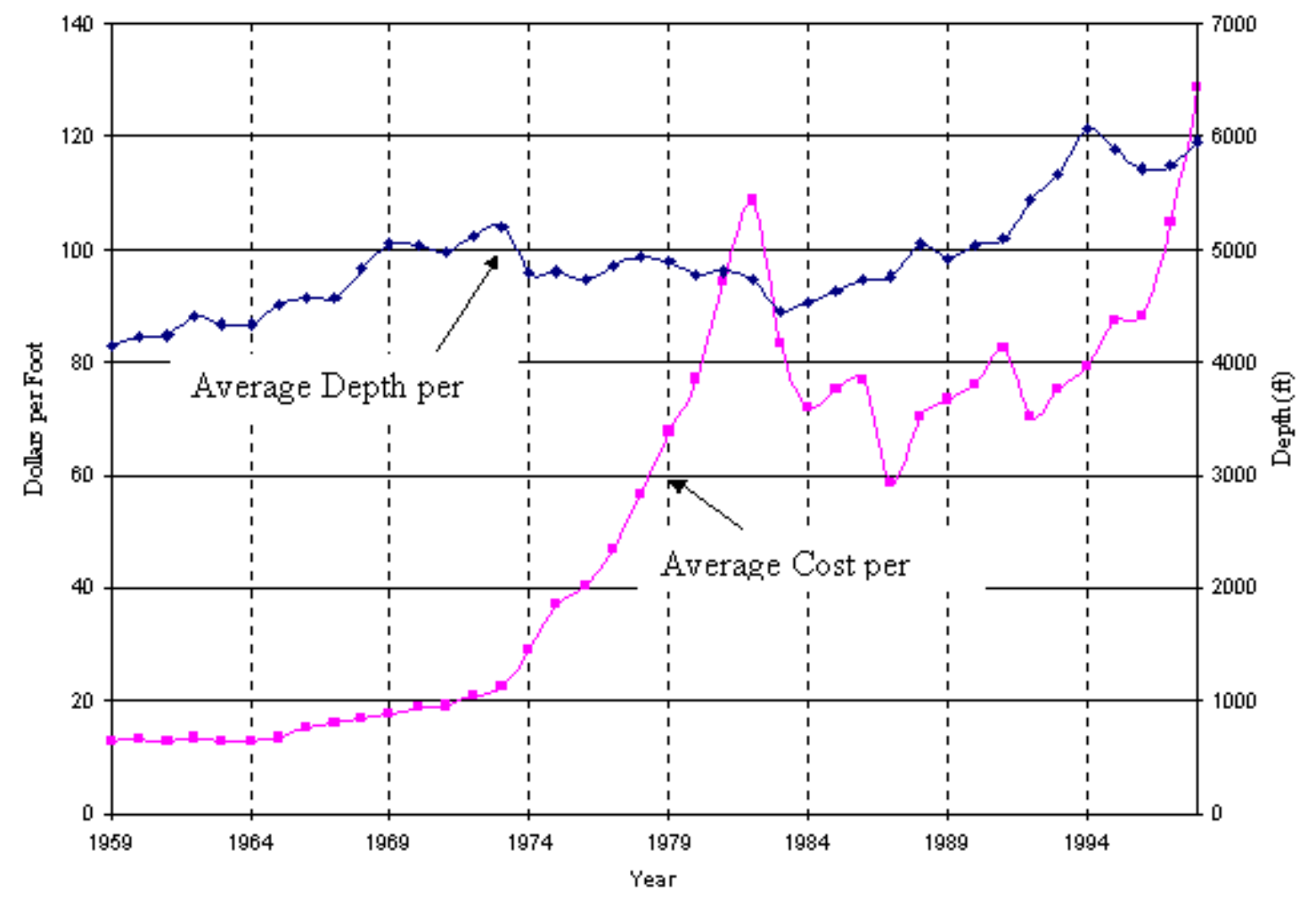

Figure 1. Estimated cost per foot and average depth per well of all wells (oil, gas and dry) drilled onshore in the U.S. from 1959 - 1999.

(DeGolyer and MacNaughton, 2000).

Nd: YAG Laser Parameters

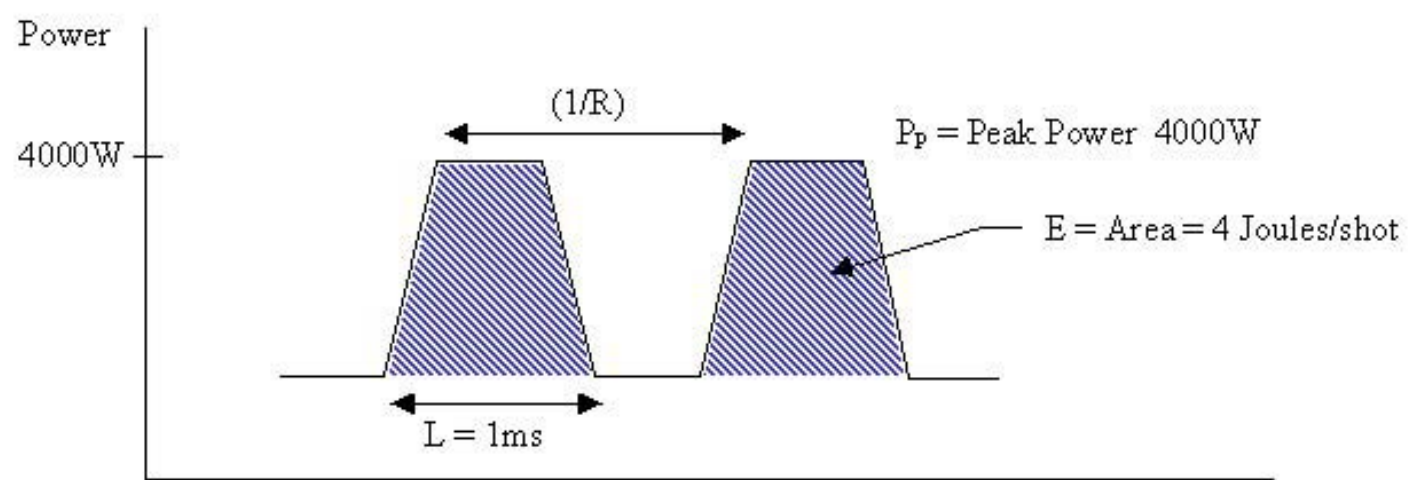

Time Duration

Figure 2. A schematic of energy (light) pulses from an Nd:YAG laser. The terms used in this report are indicated on the drawing. As a demonstration of the conflicting jargon, in the laser schedules (e.g., E4L1R400) in this report, E is also used for peak power (Pp). 


\begin{tabular}{|c|c|c|c|c|c|c|c|}
\hline Sample & $\begin{array}{l}\text { Rock } \\
\text { Type }\end{array}$ & $\begin{array}{c}\text { Porosity } \\
(\%)\end{array}$ & $\begin{array}{l}\text { Permeability } \\
\text { (md) }\end{array}$ & Mineralogy & Composition & $\%$ & $\begin{array}{l}\text { Melting } \\
\text { Temperat } \\
\text { ure }\left({ }^{0} \mathrm{C}\right)\end{array}$ \\
\hline BG & $\begin{array}{l}\text { Berea } \\
\text { Gray }\end{array}$ & 21.0 & 480 & $\begin{array}{c}\text { Quartz } \\
\text { Feldspar Opaq } \\
\text { Others }\end{array}$ & $\begin{array}{c}\mathrm{SiO}_{2} \\
\mathrm{Al}_{2} \mathrm{O}_{3} \\
\mathrm{Fe}\end{array}$ & $\begin{array}{c}85 \\
10 \\
3 \\
2\end{array}$ & $>1500$ \\
\hline LS & $\begin{array}{l}\text { Ratcliff } \\
\text { Limestone }\end{array}$ & 0.6 & 0.001 & $\begin{array}{c}\text { Calcium } \\
\text { Carbonate } \\
\text { rock fragment }\end{array}$ & $\begin{array}{c}\mathrm{CaCo}_{3} \\
\mathrm{MgO}\end{array}$ & $\begin{array}{c}85 \\
5 \\
10\end{array}$ & 1100 \\
\hline SH & $\begin{array}{l}\text { Frontier } \\
\text { Shale }\end{array}$ & 3.0 & 0.189 & $\begin{array}{c}\text { Quartz } \\
\text { Feldspar } \\
\text { fragment/clays }\end{array}$ & $\begin{array}{l}\mathrm{SioO}_{2} \\
\mathrm{Al}_{2} \mathrm{O}_{3}\end{array}$ & $\begin{array}{l}35 \\
20 \\
45\end{array}$ & $>1500$ \\
\hline
\end{tabular}

Table 1. Porosity, permeability, and microscopic properties of Berea sandstone, Radcliff limestone, and Frontier shale (modified from Graves and Batarseh, 2001a,c).

\begin{tabular}{|c|c|c|c|c|}
\hline Sample & $\begin{array}{c}\mathrm{E} \times 10^{6} \\
(\mathrm{psi})\end{array}$ & $\begin{array}{c}\mathrm{G} \times 10^{6} \\
(\mathrm{psi})\end{array}$ & $\begin{array}{c}\mathrm{K}_{\mathrm{b}} \times 10^{6} \\
(\mathrm{psi})\end{array}$ & $v$ \\
\hline BG & 5.8 & 2.1 & 5.6 & 0.33 \\
\hline LS & 10.8 & 4.3 & 7.1 & 0.25 \\
\hline SH & 8.0 & 3.1 & 5.3 & 0.25 \\
\hline
\end{tabular}

Table 2. Dynamic elastic properties of Berea sandstone, Radcliff limestone, and Frontier shale. 


\begin{tabular}{|l|l|}
\hline Range of maximum (md) & $444-683$ \\
\hline Range of average (md) & $301-472$ \\
\hline Range of minimum (md) & $117-305$ \\
\hline
\end{tabular}

\begin{tabular}{|c|c|c|c|c|c|c|c|c|}
\hline Core $^{*}$ & BG1 & BG2 & BG3 & BG4 & BG5 & BG6 & BG7 & BG8 \\
\hline Max Perm (md) & 444 & 447 & 635 & 502 & 649 & 683 & 587 & 551 \\
\hline Ave Perm (md) & 301 & 337 & 472 & 376 & 446 & 466 & 414 & 425 \\
\hline Min Perm (md) & 117 & 195 & 315 & 256 & 269 & 305 & 186 & 257 \\
\hline
\end{tabular}

Table 3. Permeability of slabbed Berea cores.

*Twins: BG1-BG2, BG3-BG4, BG5-BG6, BG7-BG8

\begin{tabular}{|c|c|c|c|c|c|c|c|}
\hline Rock & Sample & $\begin{array}{c}\text { Thermal } \\
\text { conductivity* } \mathrm{x} \\
10^{3} \\
\left(\mathrm{cal} / \mathrm{sec}^{\mathbf{3}} / \mathrm{cm}^{\mathbf{0}} \mathrm{C}\right)\end{array}$ & $\begin{array}{c}\text { Heat } \\
\text { capacity* } \\
\left(\text { cal } / \mathbf{g}^{0} \mathrm{C}\right)\end{array}$ & $\begin{array}{c}\text { Density } \\
\text { (g/cc) }\end{array}$ & Color & $\begin{array}{c}\text { Quartz } \\
(\%)\end{array}$ & $\begin{array}{c}\text { Permeability } \\
\text { (md) }\end{array}$ \\
\hline $\begin{array}{l}\text { Berea } \\
\text { Gray }\end{array}$ & $\mathrm{BG}$ & 6.2 & 0.21 & 2.64 & Gray & 85 & 500 \\
\hline Limestone & Ls & 4.8 & 0.22 & 2.71 & $\begin{array}{l}\text { White } \\
\text { to Gray }\end{array}$ & 10 & 0.02 \\
\hline Shale & $\mathrm{Sh}$ & - & - & - & Black & 46 & 0.43 \\
\hline
\end{tabular}

*After Ingersoll, 1954.

Table 4. Rock properties that affect heat transfer to rock samples; thermal conductivity, heat capacity, bulk density, color and percentage quartz. 


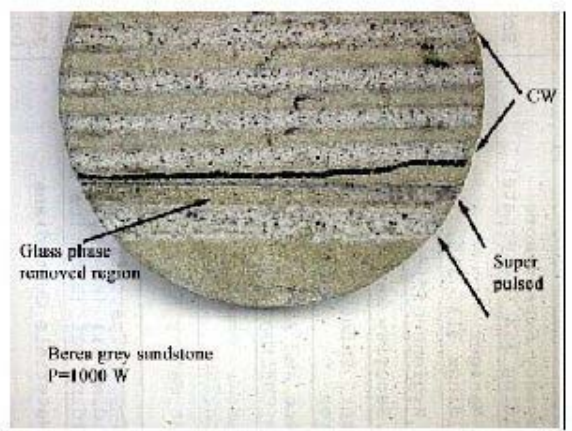

Figure 3a: Berea Grey SS exhibiting thin glass melt tracks after exposure to $6 \mathrm{~kW}$

$\mathrm{CO}_{2}$ laser in Continuous Wave (CW) and Super Pul sed Modes.

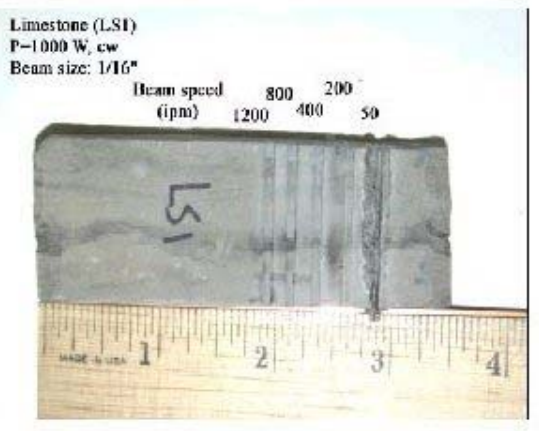

Figure 3b: Limestone (LS1) sample exhibiting tracks after exposure to $6 \mathrm{~kW}$ $\mathrm{CO}_{2}$ laser in Continuous Wave (CW) Mode

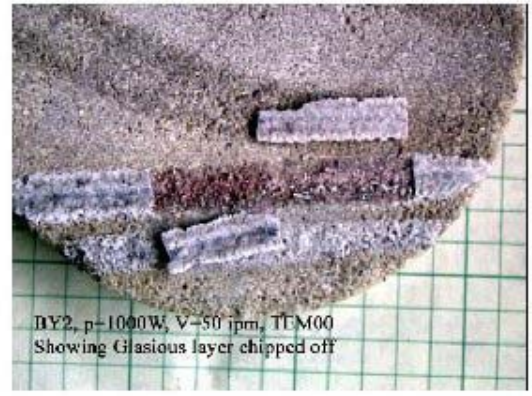

Figure 3c: Berea Yellow SS exhibiting thin gl ass melt tracks manually removed after exposure to $6 \mathrm{~kW} \mathrm{CO} 2$ laser in Super Pulsed Mode

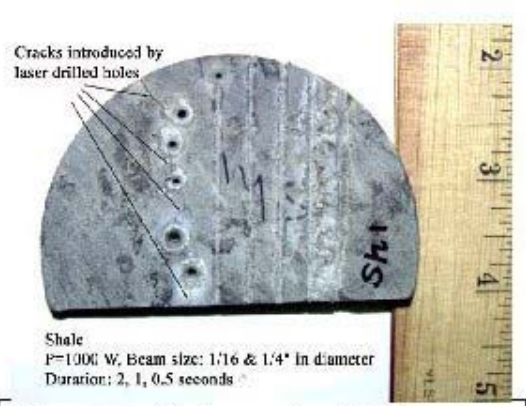

Figure 3d: Shale sample exhibiting multiple tracks and holes after initial beam size and duration changes from $6 \mathrm{~kW} \mathrm{CO}_{2}$ laser in CW Mode 

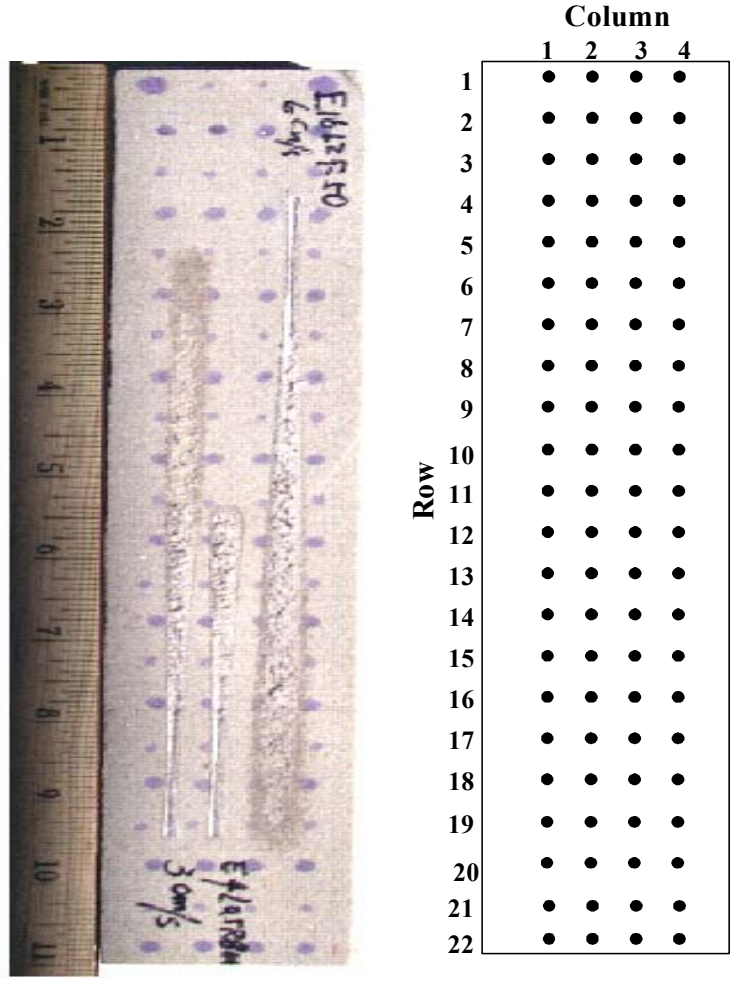

Figure 4. Point grid for measuring permeability consistency along an 11-inch Berea sandstone slab. 

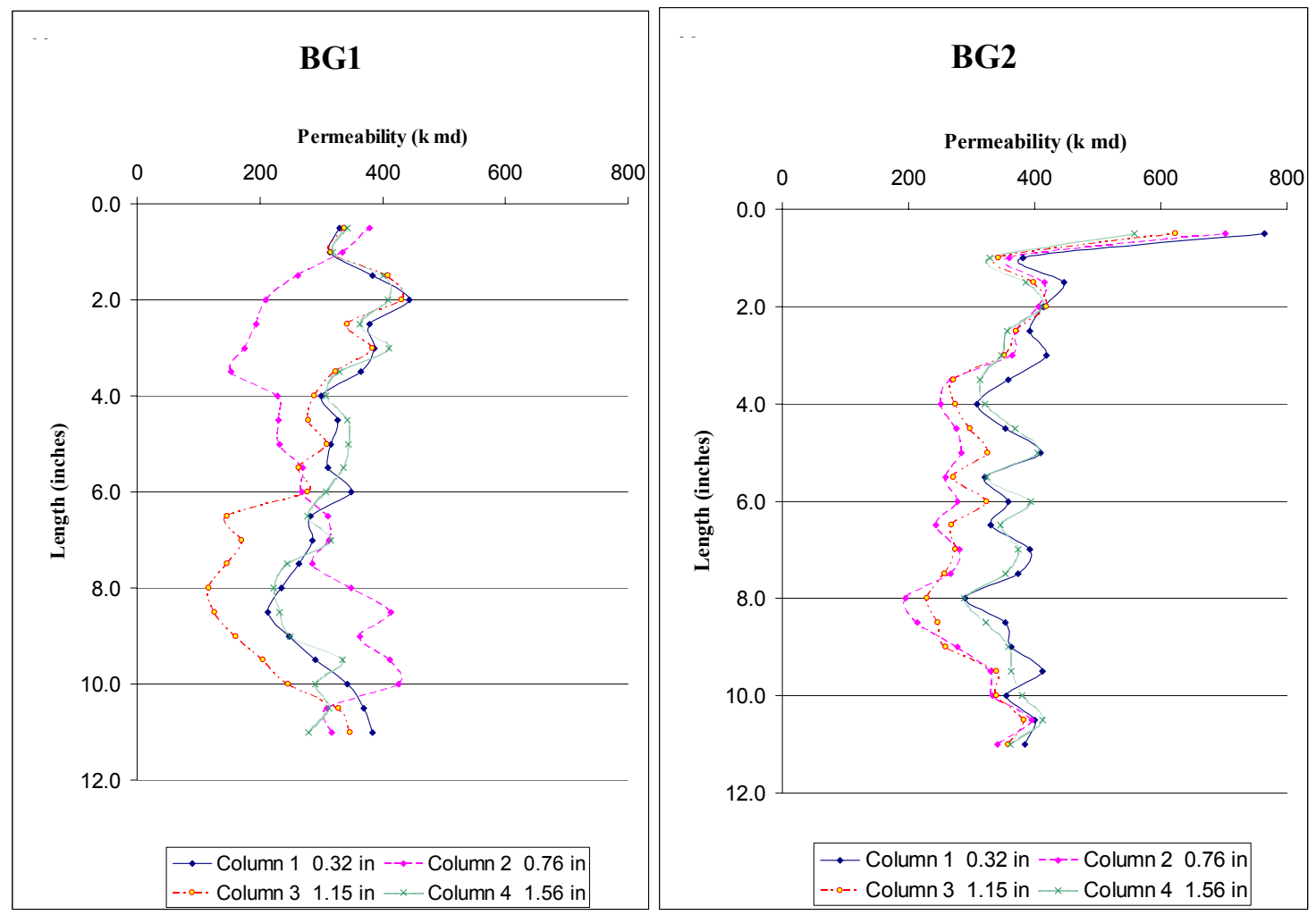

Figure 5. Permeability variation along twin Berea sandstone slabs. 


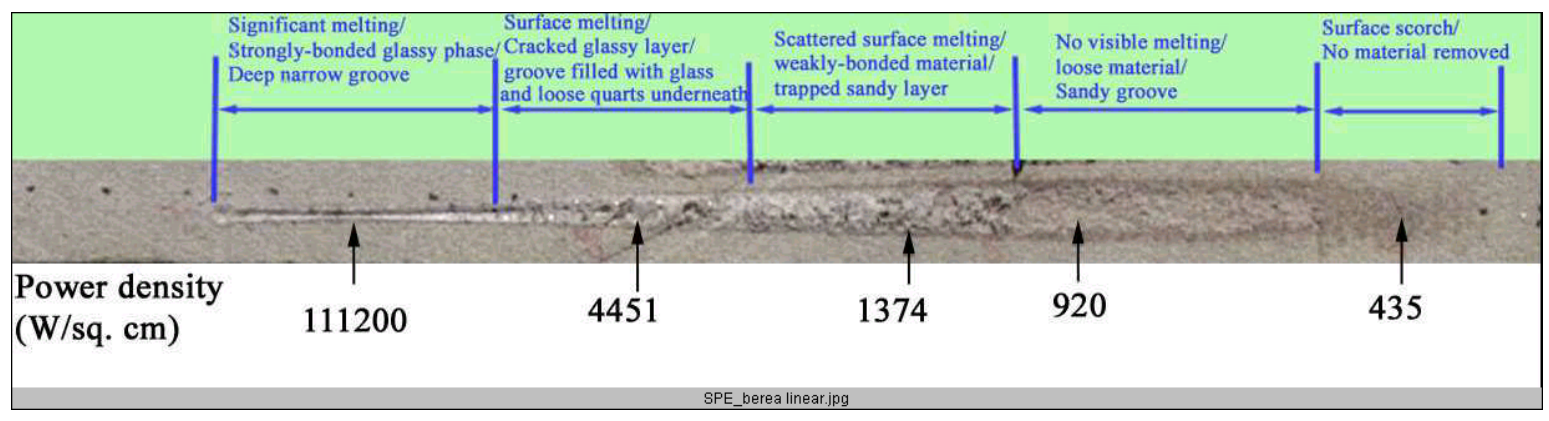

Figure 6a. Linear track test of the Berea gray sample. Power density (Irradiance) was varied by defocusing the beam as the sample was moved beneath it. Five zones of spallation and melting can be seen, as described in the figure.

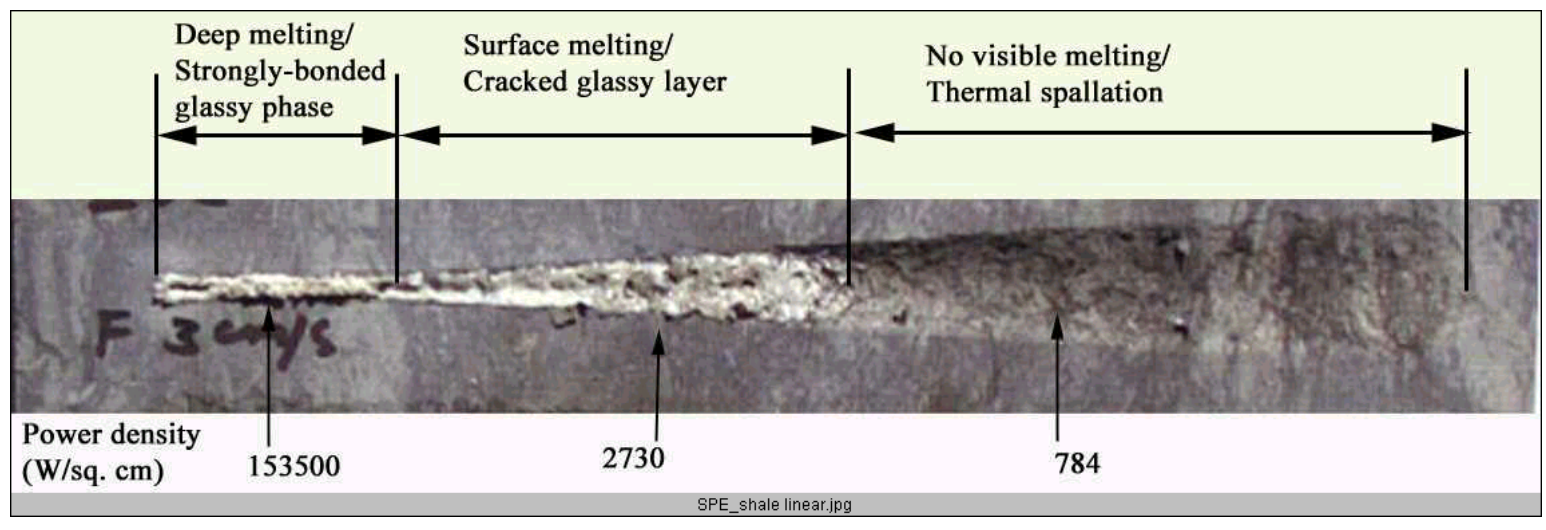

Figure 6b. Linear track test of the Frontier shale sample. Power density was varied by defocusing the beam as the sample was moved beneath it. Three distinct zones of spallation and melting were created, from which the beginning parameters for the sample matrices were developed.

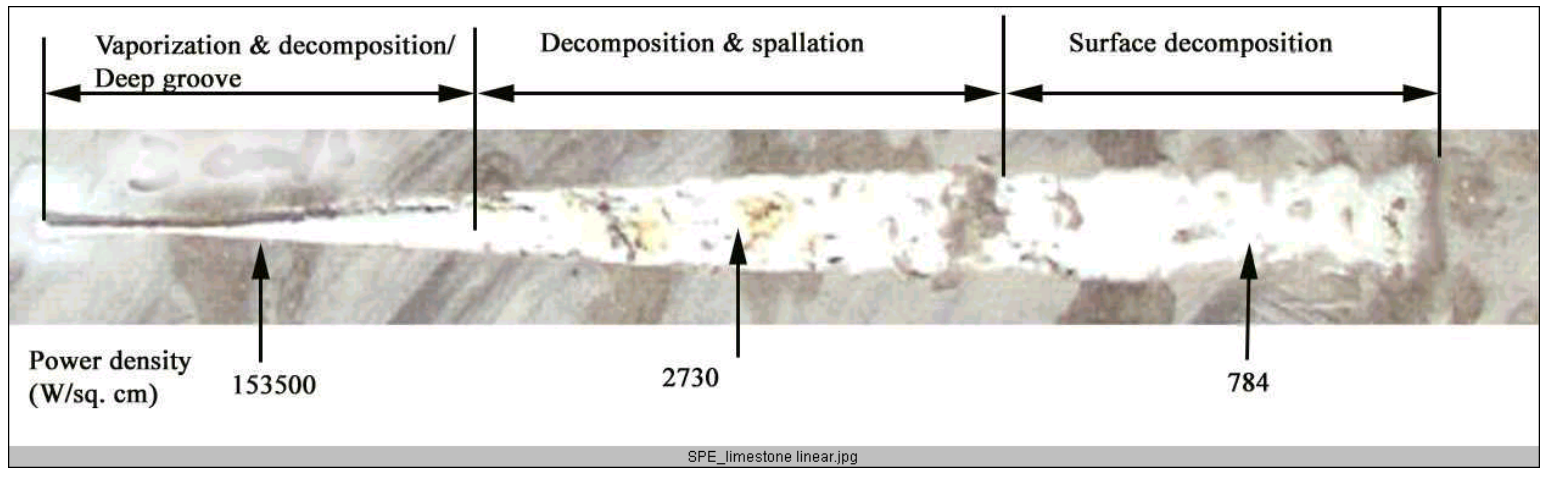

Figure 6c. Linear track test of the Ratcliff limestone. Power density (Irradiance) was varied by defocusing the beam as the sample was moved beneath it. Three distinct zones of spallation, mineral disassociation or vanorization were observed. as described in the figure. 


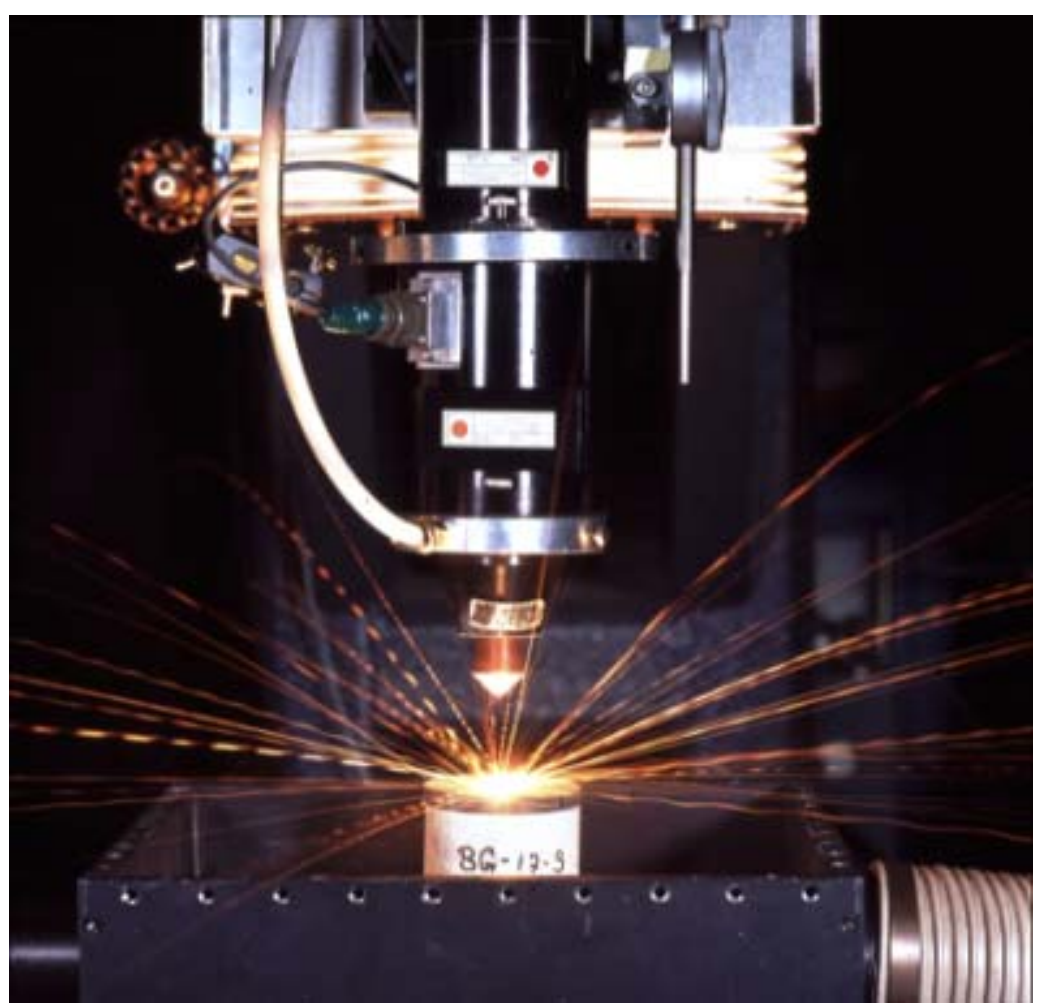

Figure 7. Nd:YAG laser drilling system in firing mode on rock sample.

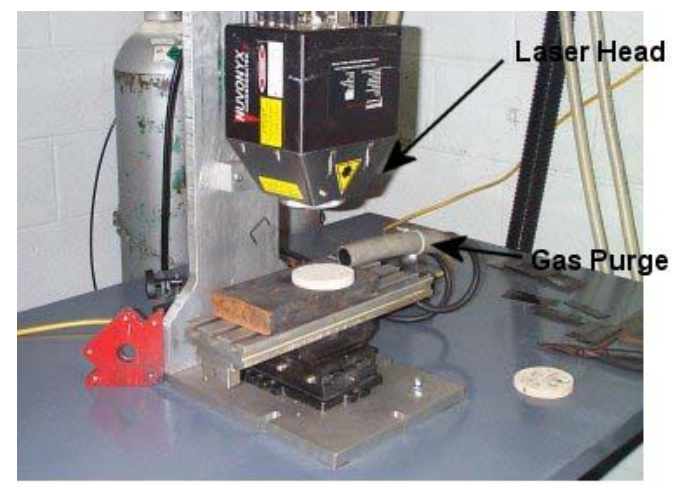

Figure 8. Nuvonyx diode laser system showing sample test configuration. 


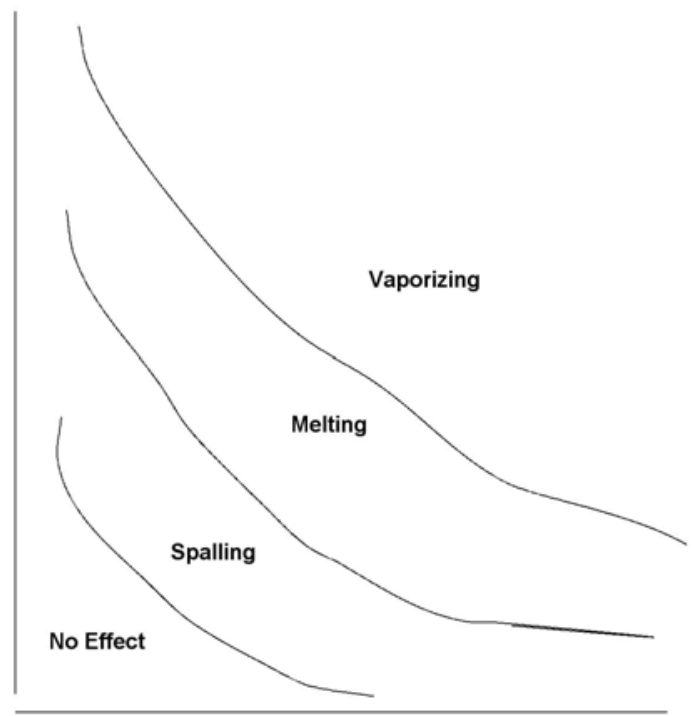

Figure 9. Schematic of relationship between lasing parameters and affect on rocks. Isoparameter lines separate zones.

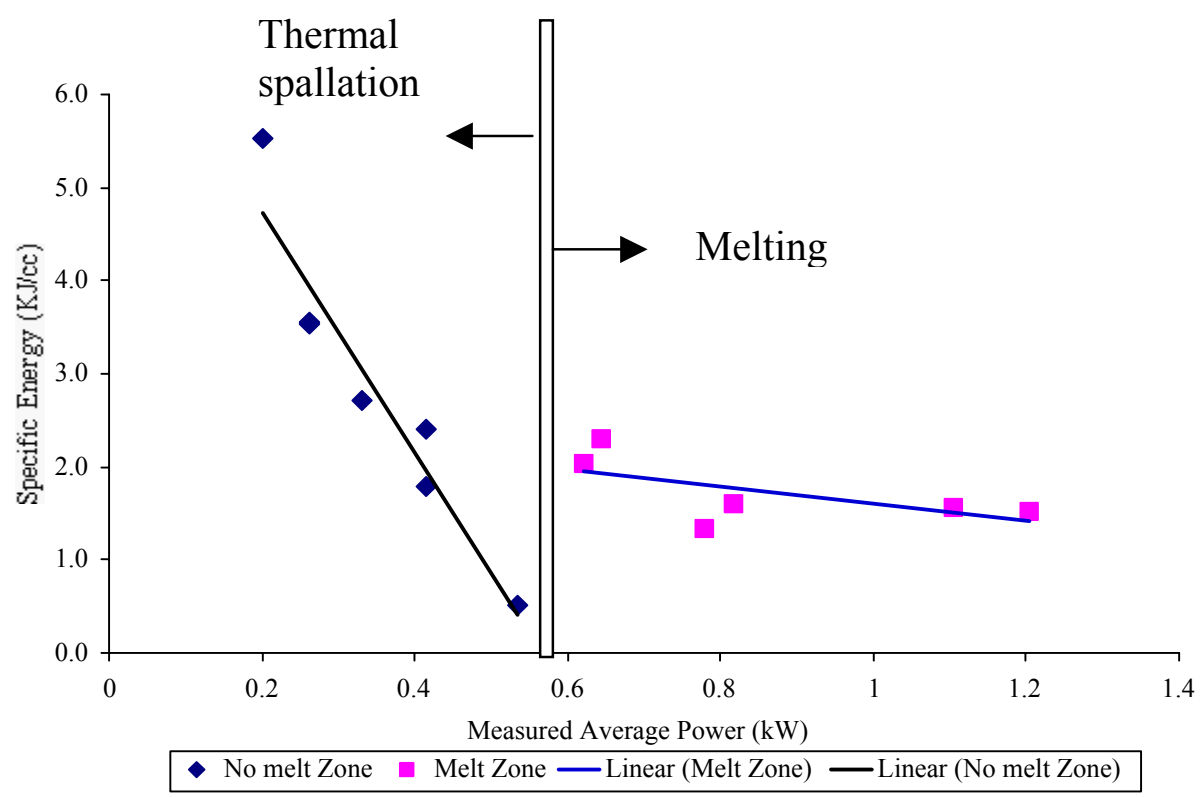

Figure 10. Specific energy as a function of laser power for Shale samples drilled at fixed beam size of 0.5 inches and exposure time of 0.5 seconds. 


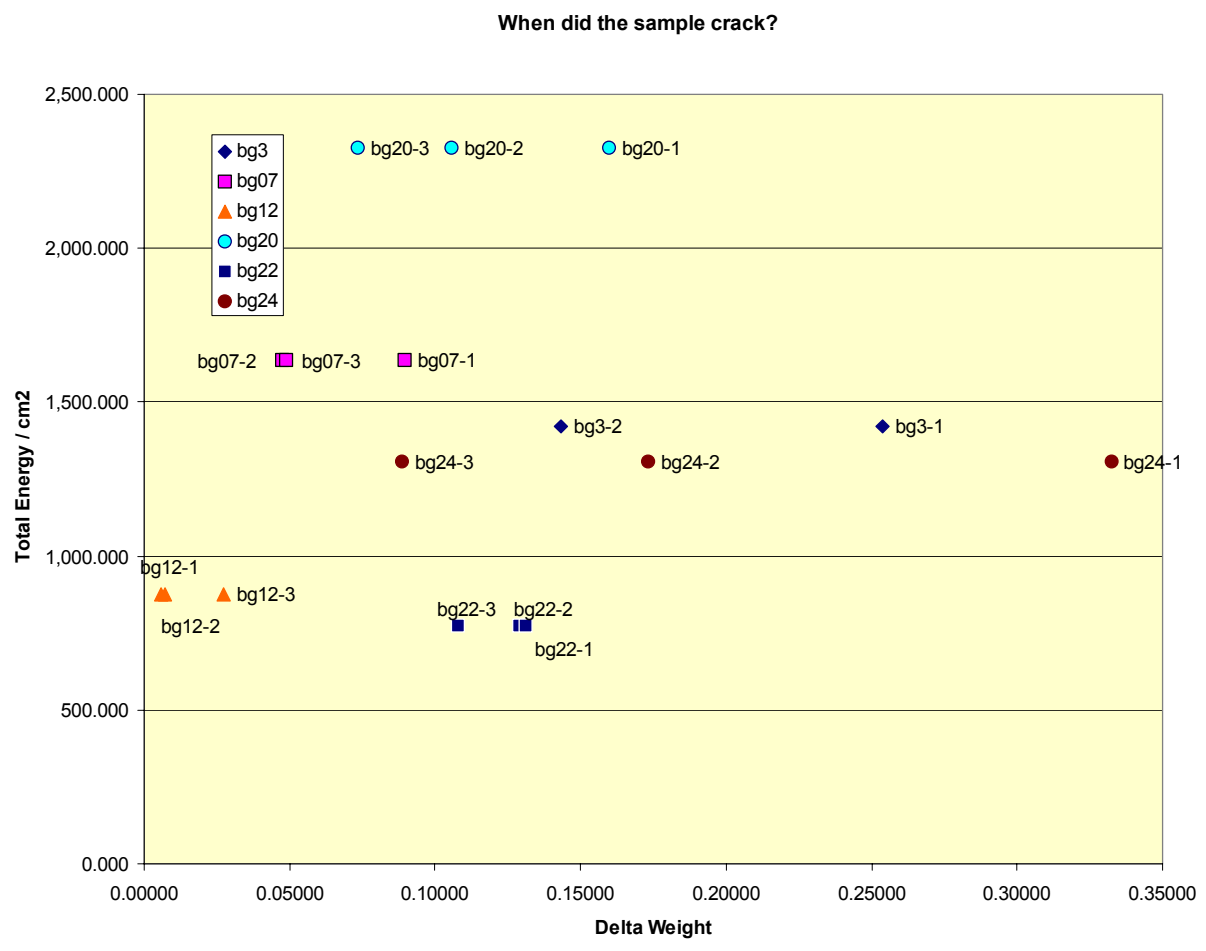

Figure 11. Sometimes the second or third spot on a sample caused a crack to form to the edge of the disk. That and subsequent calculated SE values are significantly higher than the first spot. 


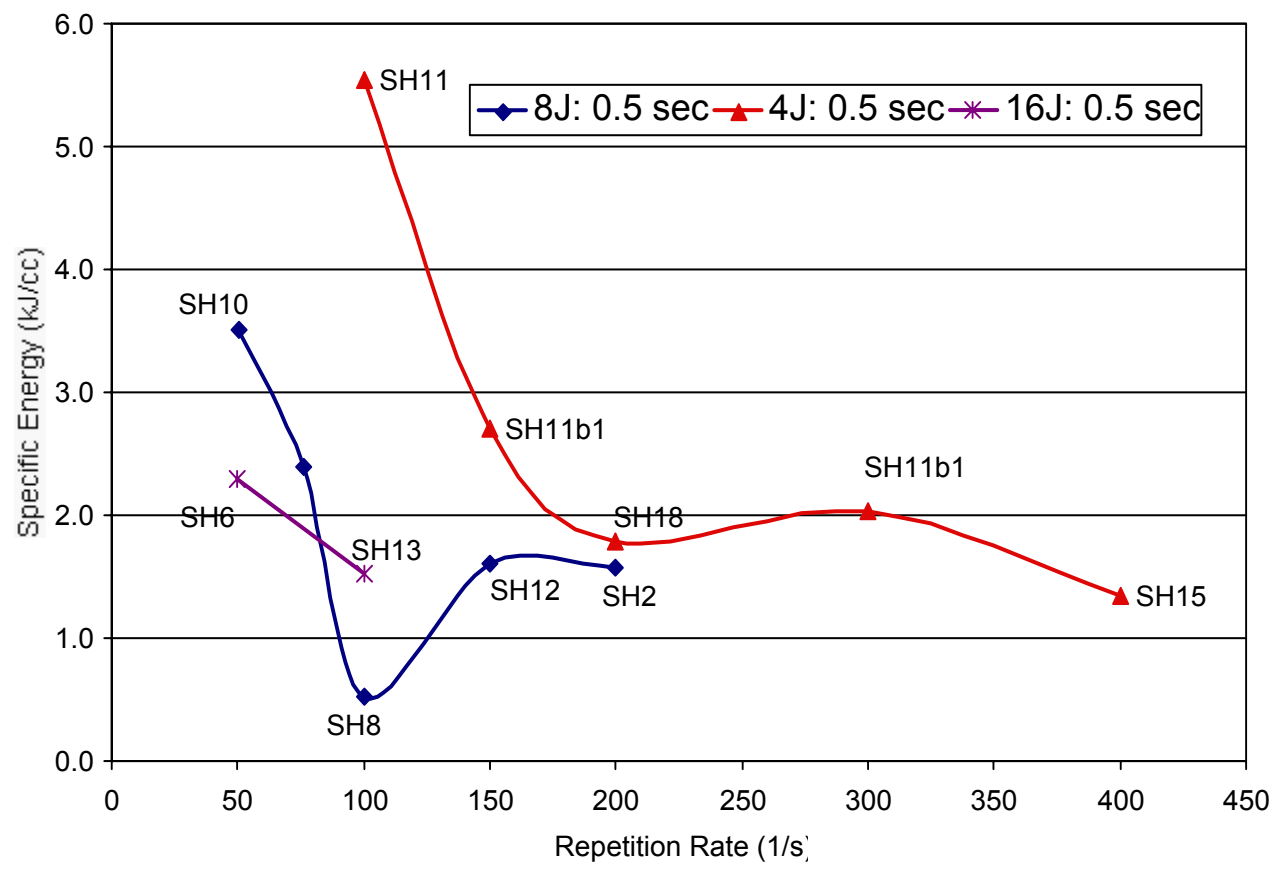

Figure 12. Graph showing relationship of SE to Repetition Rate of the pulsed lasers. Pulse energy has stronger effect than repetition rate. 


\section{Limestone by Spot Size}

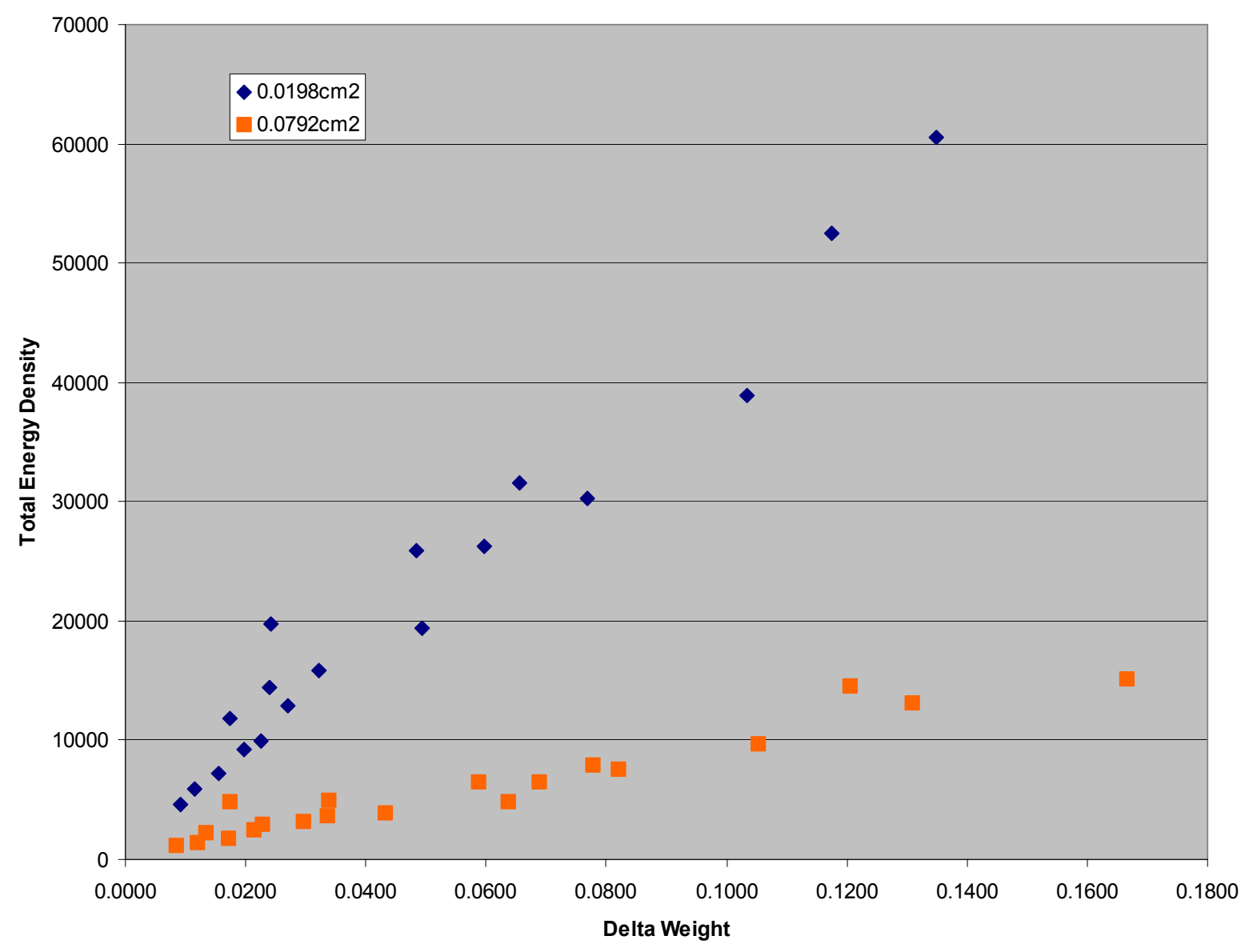

Figure 13. Limestone results show two trends that can be categorized completely by beam size. The fact that the larger beam size gives a lower SE indicates that the parameters of the test could have included even larger spot sizes. 


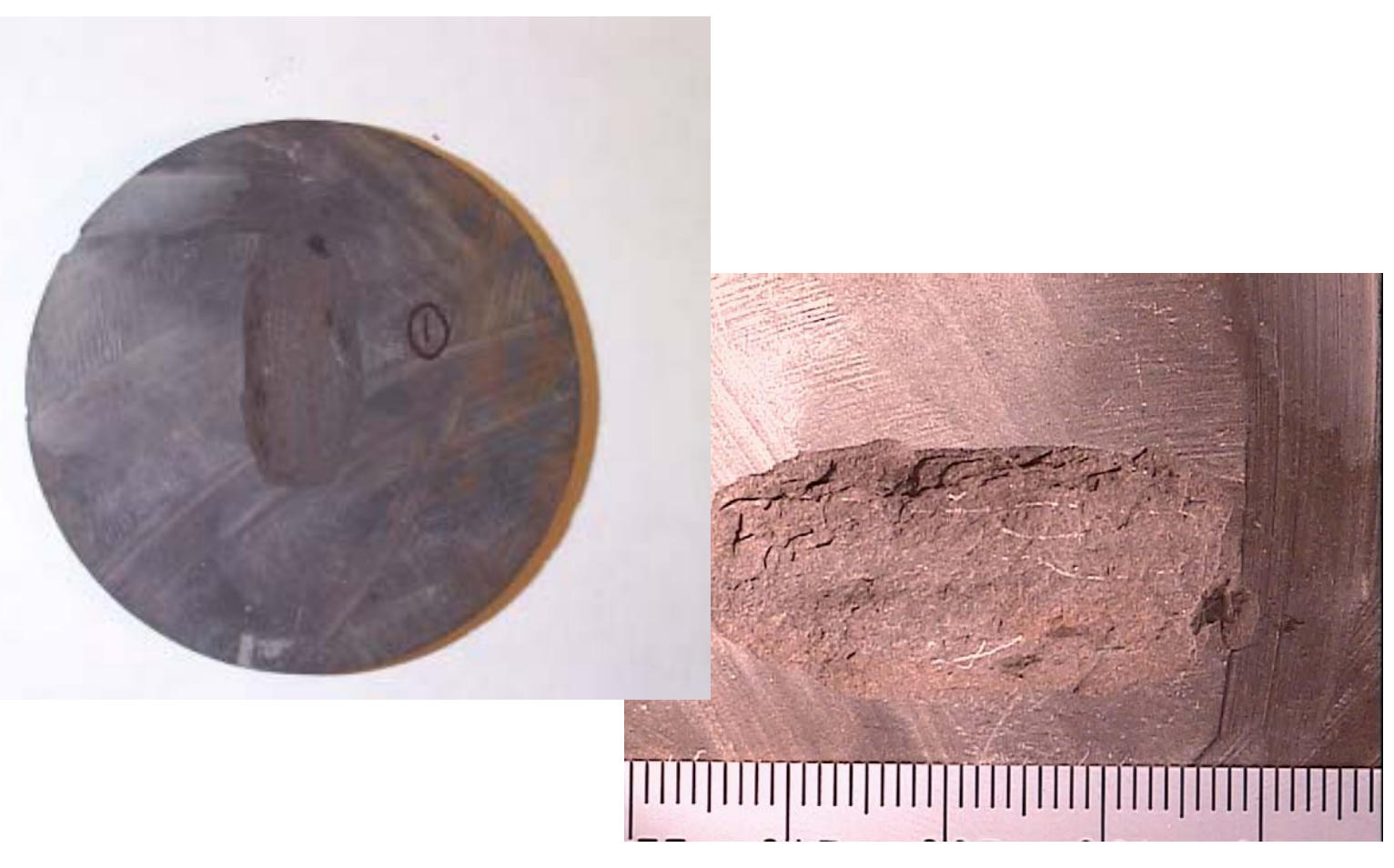

Figure 14. Two views of a shale sample exposed to the Nuvonyx diode laser. The roughly rectangular beam shape can be seen (the sample was stationary during the test). This sample is the opposite face of sample SH8, the lowest SE result of any Nd:YAG test in the dry sample series. It also was the lowest SE of the diode tests. 


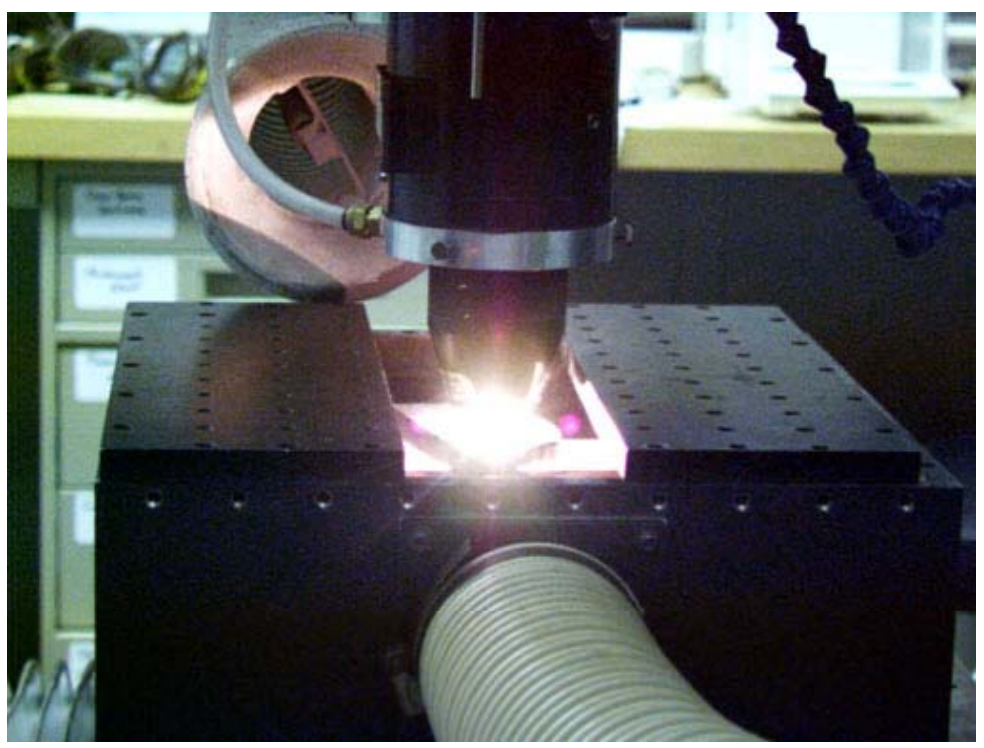

Figure 15. Setup for optically-shaped laser beam drilling wet $\mathrm{BG}$ rock

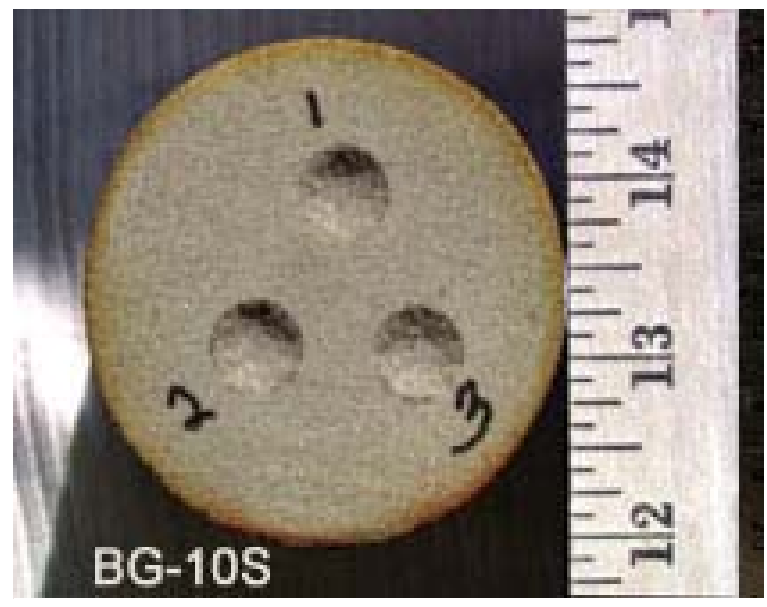

Figure 16. Three identical holes made on water-saturated Berea gray sandstone sample by a $\mathrm{Nd}$ :YAG laser. 

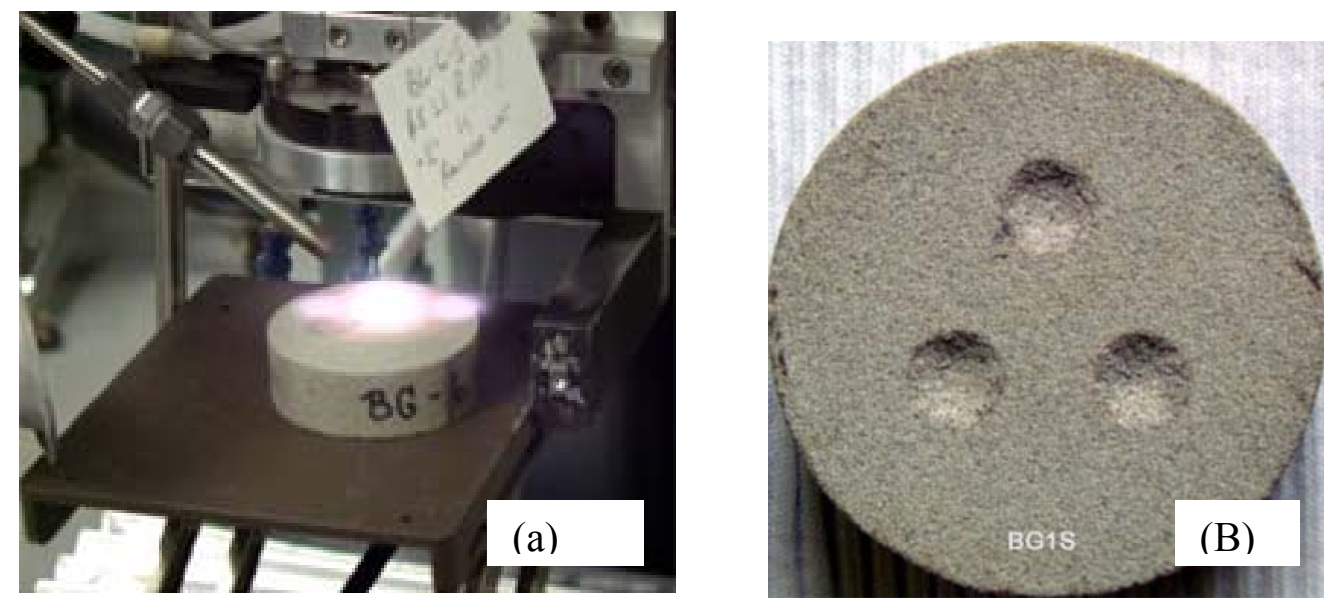

Figure 17. Raw beam out of fiberoptic cable lased on a BG rock (a) and three resulted holes (b).

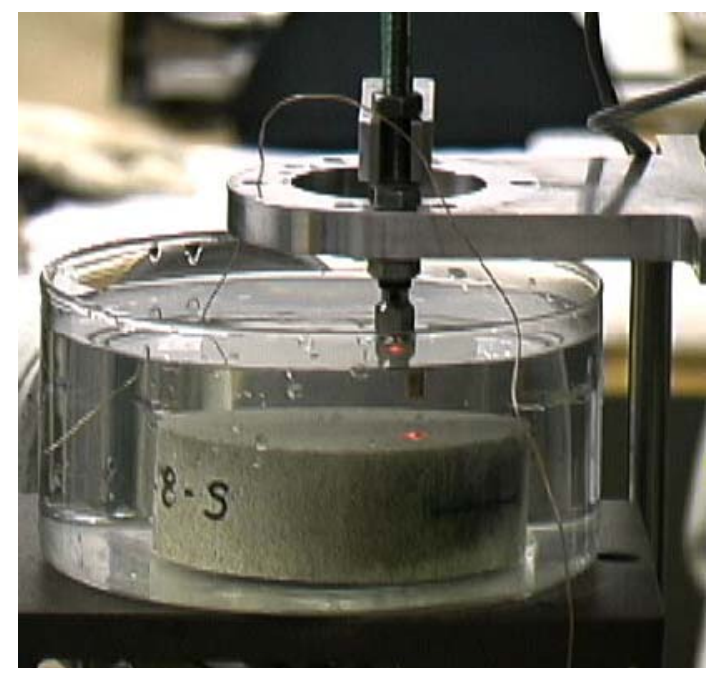

Figure 18. Photograph showing the setup for fiber underwater test. 

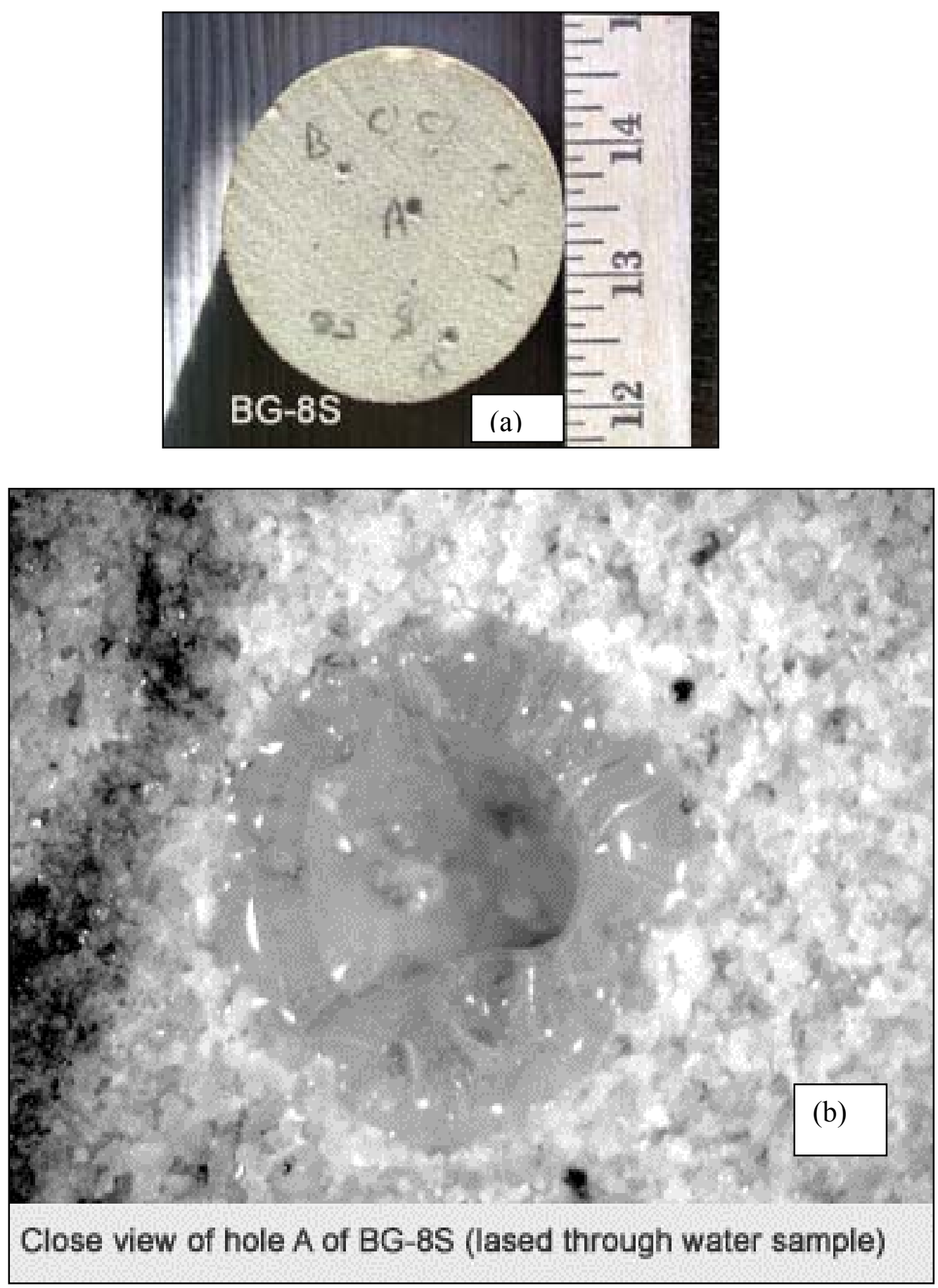

Figure 19. A hole drilled with both fiber and rock underwater at E8L2R100, distance between the fiber output end and rock $1 / 8$ " and 5 second exposure time, Hole A in (a) and (b) close view of Hole $A$ 
G: Diode Laser Report 


\author{
Report
}

\title{
Laser Removal of Rocks
}

\author{
Prepared for: \\ Gas Technology Institute
}

1700 S. Mt. Prospect Road

Des Plaines, IL 60018

Prepared by:

Native American Technologies Company

Software Systems

P.O. Box 39

Golden, Colorado 80402
1410 Ford Street

Golden, Colorado 80401

August 16, 2001

Sales and Technical Service

Research and Development

519 Cedarwood Drive 


\section{Laser Rock Removal}

\subsection{Overview}

The Petroleum Department at the School of Mines has been conducting research in the area of laser rock removal. Part of this project is to research and experiment with different lasers and find the optimum operation. This phase of the project was to study the Nuvonyx Diode Laser. Figure 1 is a photograph of the entire system. The controller unit is approximately $25 \times 30 \times 50$ inches, the head is approximately $9 \times$ $6 \times 7$ inches, and the chiller unit is approximately $19 \times 28 \times 38$ inches.

A)
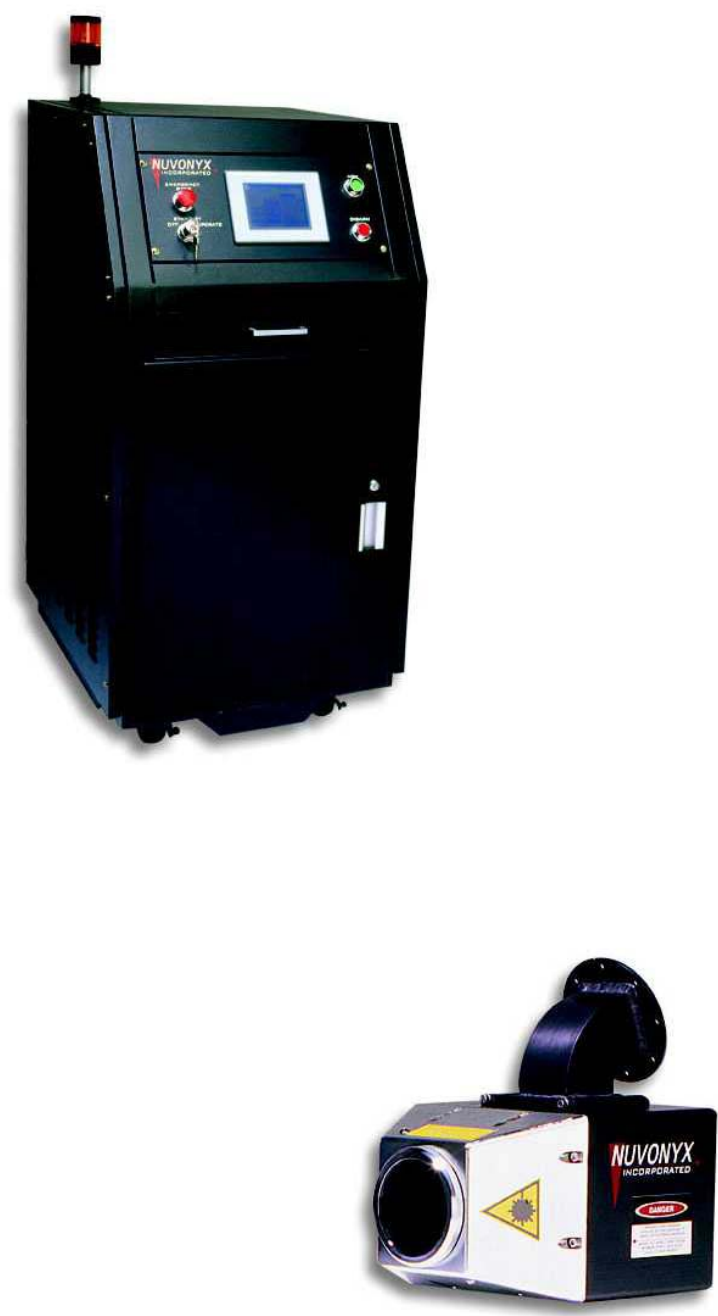

C)

Figure 1. The Nuvonyx Diode laser. A) Controlling unit with a touch screen interface B) Chiller unit which holds approximately 4 gallons of de-ionized water depending on the length of hose between chiller and laser head C) Laser head unit.
B)

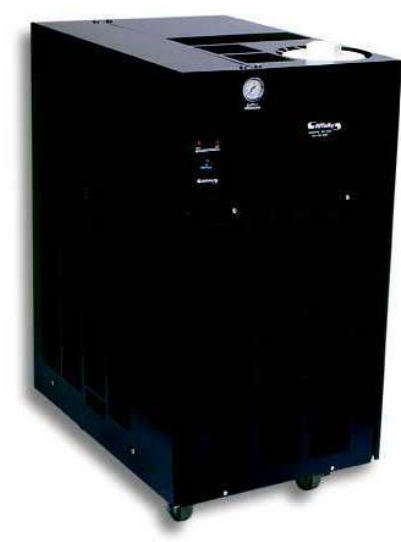




\subsection{Calculations}

\subsection{Calculating $L$}

Based on previous experiments with the Nd:YAG laser, it was decided that the area under the pulse curve should be held constant between the two lasers. See the following calculations to set the area under the curve to a specific point.

\section{Nd: YAG Laser Parameters (Assumed)}

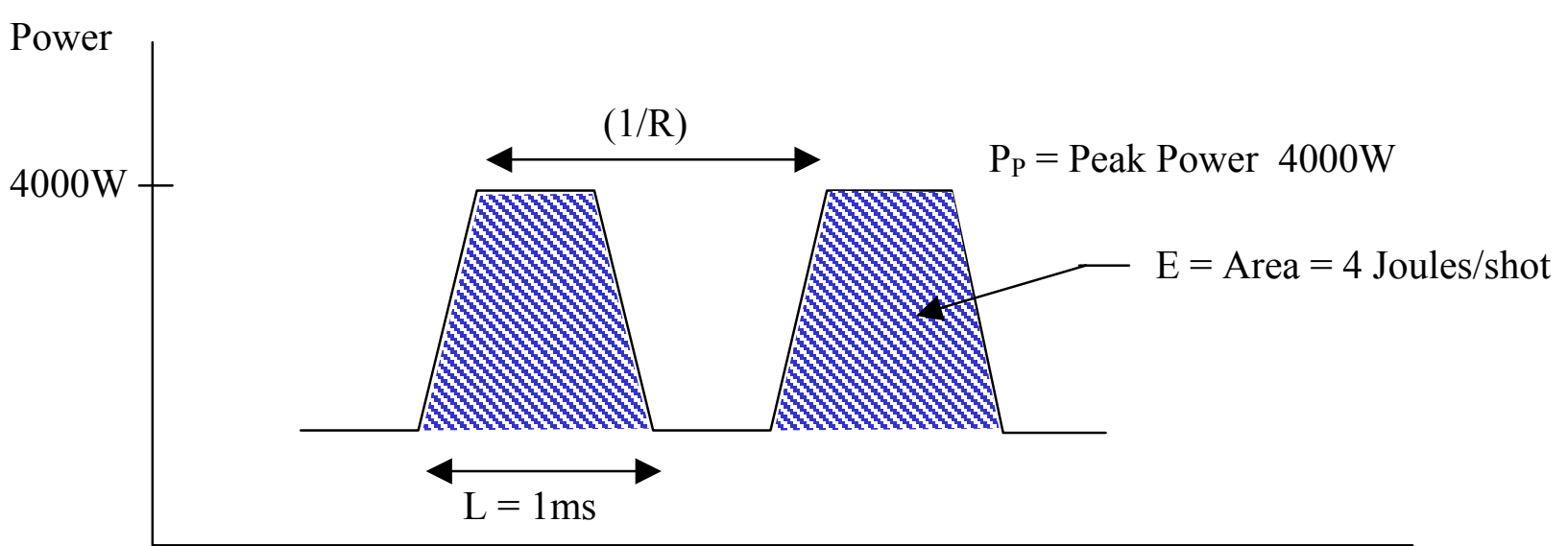

Diode Laser Parameters Used to Best Match the Nd:YAG experiments

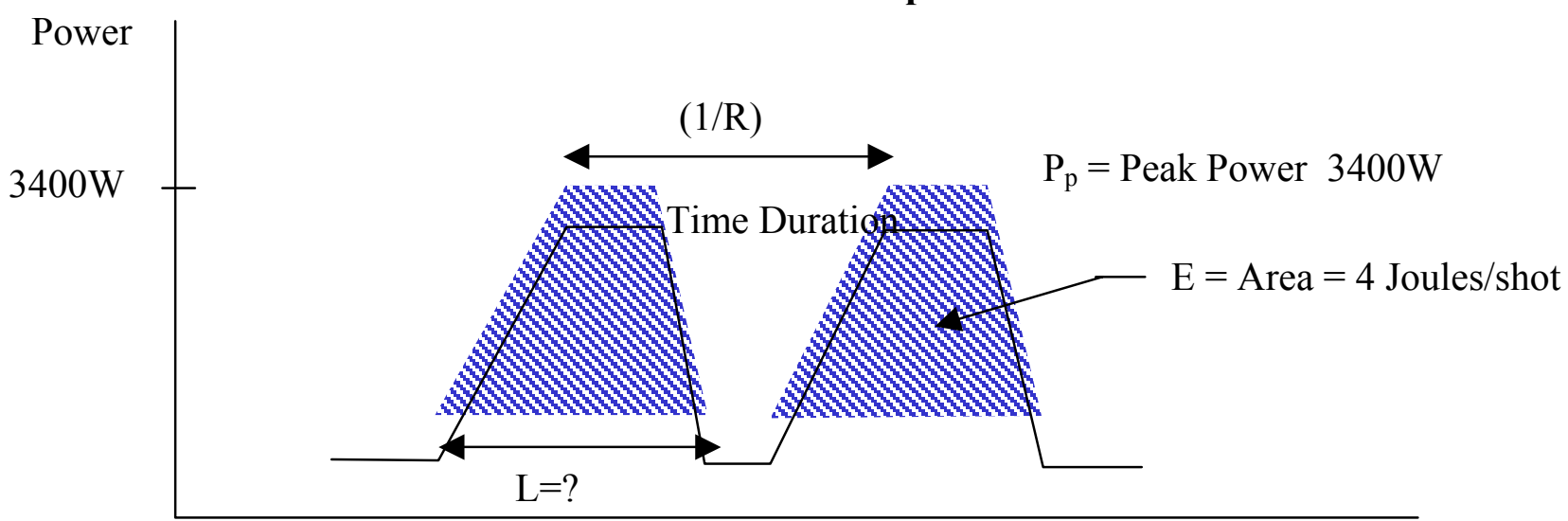

Time Duration

$\mathrm{R}=$ Repetition Rate $=$ Frequency $=50,100,200,400$

Figure 2. Calculating the same area under the curve for the Diode Laser as the $\mathrm{Nd}$ :YAG for the experiment $\mathrm{L}=1 \mathrm{~ms}, \mathrm{R}=400 \mathrm{~Hz}$, and $\mathrm{E}=4 \mathrm{~J}$ oules/shot. 
Now, the pulse width for the Diode laser must be calculated in order to achieve the same E or area under the curve. See Figure 3 for this calculation. The max power has been limited to $3400 \mathrm{~W}$ out of $4000 \mathrm{~W}$.

$$
\begin{aligned}
& \begin{array}{llll}
3400 \mathrm{~W} \\
(85 \%)
\end{array} \\
& 4=1 / 2\left(b_{1}\right)(h)+\left(b_{2}\right)(h)+1 / 2\left(b_{3}\right)(h) \\
& {\left[\frac{4(J)}{h}\right]=1 / 2\left(b_{1}\right)+\left(b_{2}\right)+1 / 2\left(b_{3}\right)} \\
& \mathbf{L}=1.505 \mathrm{~ms} \\
& A_{1}=1 / 2\left(b_{1}\right)(h) \\
& A_{2}=\left(b_{2}\right)(h) \\
& \mathrm{A}_{3}=1 / 2\left(\mathrm{~b}_{3}\right)(\mathrm{h}) \\
& b_{1}=0.185\left[\frac{85 \%}{33 \%}\right] \\
& \mathrm{b}_{3}=0.070\left[\frac{85 \%}{33 \%}\right]
\end{aligned}
$$

Figure 3. Calculation for $\mathrm{L}$ which is the pulse width. 


\subsection{Calculating Average Power}

The avergage power of a pulse can be calculated by the following equation:

$$
\begin{aligned}
& \mathrm{P}_{\mathrm{avg}}=\left(\mathrm{P}_{\text {peak }}\right)(\text { Pulse width })(\text { Repetition rate }) \\
& \mathrm{P}_{\text {peak }}=\text { Watts } \\
& \text { Pulse Width }=\mathrm{W}_{\mathrm{p}}=\text { seconds } \\
& \text { Repetition Rate }=1 / \text { seconds }
\end{aligned}
$$

For example: The sandstone example BG-A 1 had the following list of parameters:

$$
\begin{aligned}
& \mathrm{P}_{\text {peak }}=3400 \mathrm{~W} \\
& \text { Pulse Width }=0.0027 \text { seconds } \\
& \text { Repetition Rate }=200(1 / \text { seconds })
\end{aligned}
$$

Therefore:

$$
\begin{aligned}
& P_{\text {avg }}=(3400)(0.0027)(200) \\
& \mathbf{P}_{\text {avg }}=\mathbf{1 8 3 6} \mathbf{W}
\end{aligned}
$$

\subsection{Calculating Spot Size}

One of the main differences between the Diode Laser and the Nd:YAG is the spot size. The Nd:YAG has a circular spot size where the Diode Laser has a rectangular profile. The spot size calculations can be seen in Figure4. The beam size was esimated as the $12 \mathrm{~mm}$ dimension not changing, and the width changing to increase the area as the optics go passed focus. That assumption was wrong. The $12 \mathrm{~mm}$ dimension does change according to Nuvonyx. The power densities are based on the correct beam size, but the estimated area calulations were incorrect.

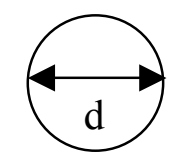

$$
12 \mathrm{~mm}=0.47 \mathrm{in}
$$

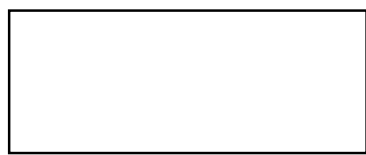

$$
\begin{aligned}
& d=0.375 \text { inches } \\
& r=0.1875 \text { inches }
\end{aligned}
$$$$
\mathrm{b}=0.47 \text { inches }
$$

$$
\begin{gathered}
\mathrm{h}=\text { ? inches } \\
\mathrm{A}=\mathrm{bh} \\
\mathrm{A}=0.110 \mathrm{in}^{2}
\end{gathered}
$$

$$
\begin{gathered}
A=r^{2} \pi \\
A=0.110 i n^{2}
\end{gathered}
$$

$$
\begin{gathered}
0.110=0.47(h) \\
h=0.23 \mathrm{in} \\
h=5.84 \mathrm{~mm}
\end{gathered}
$$

Figure 4. Spot size area calculations 


\subsection{Calculating Power Densities}

Power density is dependent on the focus of the beam. To calculate power density follow this example:

Defocus $=10 \mathrm{~mm}$

Beam Size at this focus level $=1.6 \mathrm{~cm} \times 0.4 \mathrm{~cm}$

Beam Area $=0.64 \mathrm{~cm}^{2}$

Power $=3400 \mathrm{~W}$

Power density $=($ Power $) /$ Beam area

Power density $=3400 / 0.64$

Power density $=5313 \mathrm{~W} / \mathrm{cm}^{2}$

\subsection{Calculating Specific Energy}

To calculate specific engergy, follow the example below using sample BG-A 1 again:

Specific Energy $=$ Energy input/volume of material removed

Where:

$$
\begin{aligned}
& \text { Energy input }(\mathrm{J})=\mathrm{P}_{\mathrm{avg}} * \text { Duration } \\
& \text { Energy input }=(1836 \mathrm{~W})(2.0 \text { seconds }) \\
& \text { Energy input }=3672 \mathrm{~J}
\end{aligned}
$$

Volume of material removed $=$ weight of material removed/density of sandstone

$$
\begin{aligned}
& \Delta \mathrm{V}=0.0833 / 2.61 \\
& \Delta \mathrm{V}=0.0319 \mathrm{~cm}^{3}
\end{aligned}
$$

Therefore:

Specific Energy $=3672 \mathrm{~J} / 0.0319 \mathrm{~cm}^{3}$

Specific Energy $=115110 \mathrm{~J} / \mathrm{cm}^{3}$

Specific Energy $=115.10 \mathrm{~kJ} / \mathrm{cm}^{3}$ 


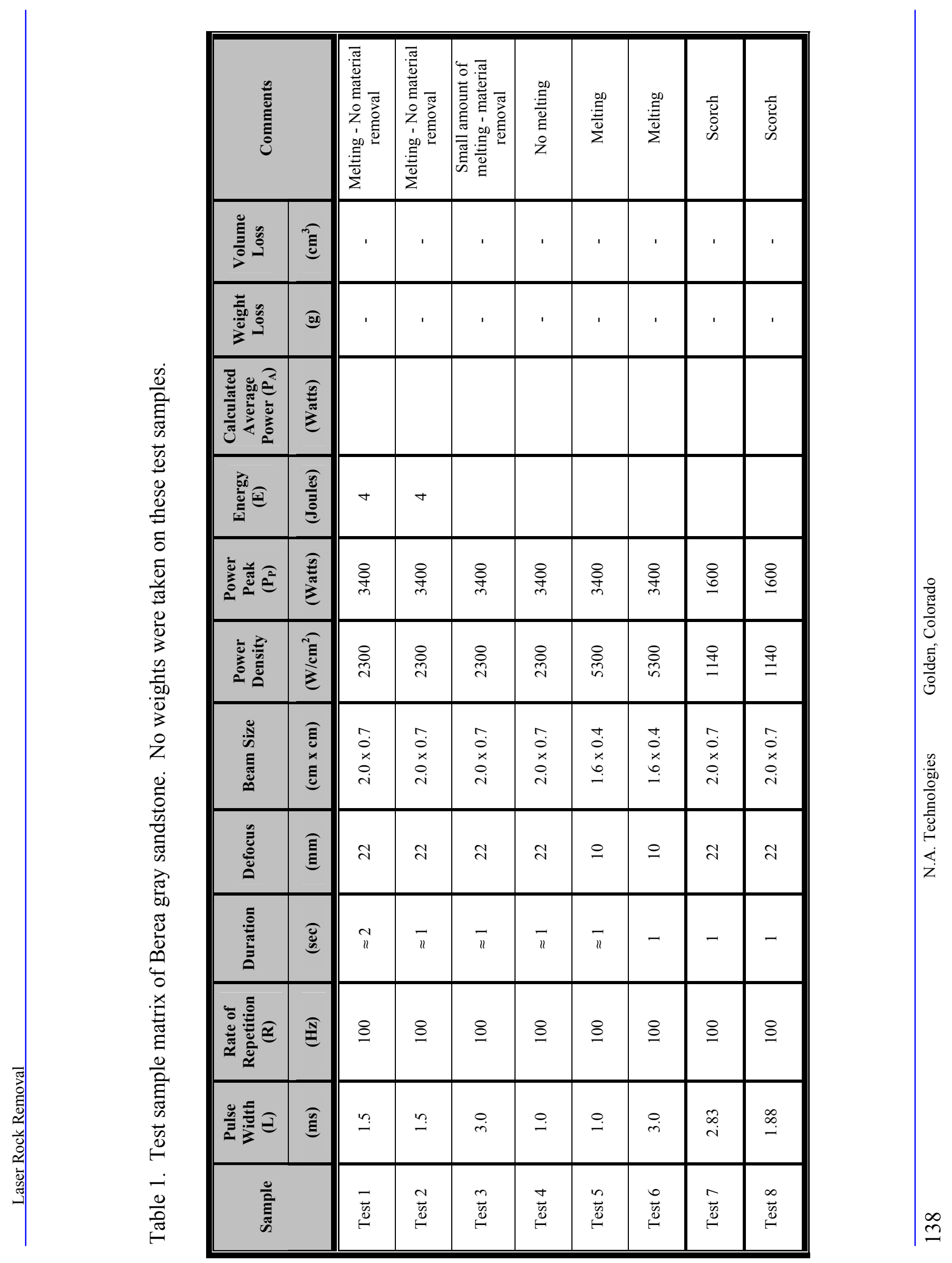




\begin{tabular}{|c|c|c|c|c|c|c|}
\hline 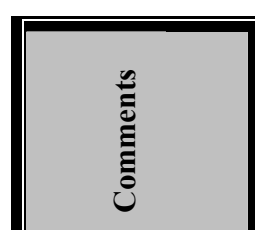 & PInIIII & & & & & $\mid$ \\
\hline 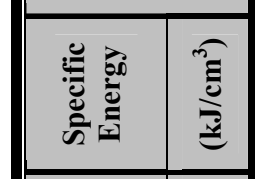 & 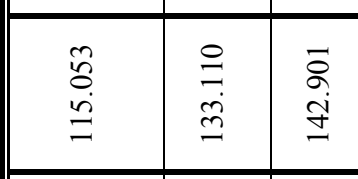 & & & 害 & & 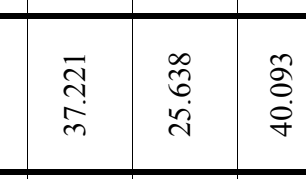 \\
\hline 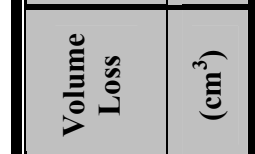 & 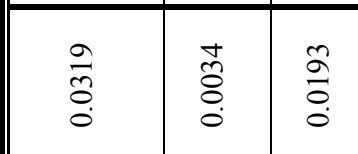 & 善 & & 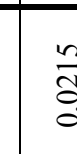 & & $\frac{2}{5}$ \\
\hline 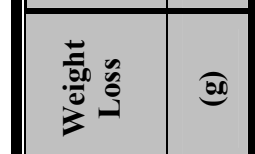 & 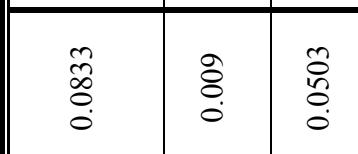 & 善 & & & & $\frac{7}{7} \frac{8}{2}$ \\
\hline $\mid$ & $\underline{z}$ & 呈 & & $g$ & & $\frac{8}{3}$ \\
\hline 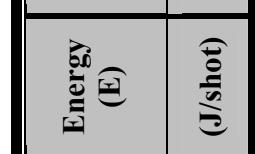 & $\cdots$ & . & & 7 & & 7. \\
\hline 15 & $\frac{18}{3}$ & 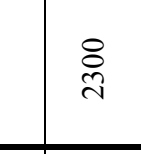 & 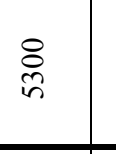 & 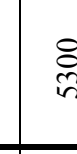 & & 888 \\
\hline $\mid \frac{2}{2}$ & $\frac{8}{g}$ & 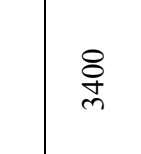 & 8 & 旅 & & 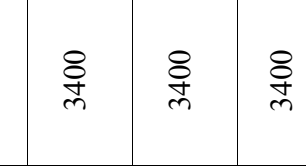 \\
\hline $\mid$ & 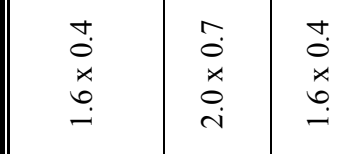 & 童 & & 8 & & 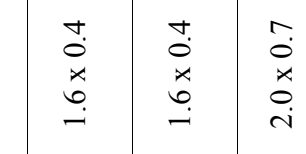 \\
\hline \begin{tabular}{|ll} 
\\
\end{tabular} & 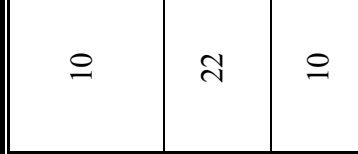 & 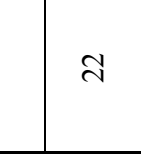 & & & & $\therefore=8$ \\
\hline 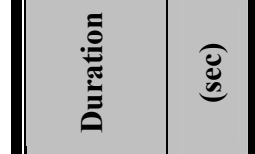 & $\therefore=$ & $=$ & & $=$ & & $::=$ \\
\hline 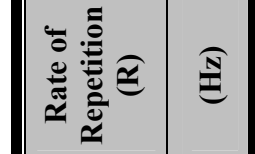 & 888 & & & & & 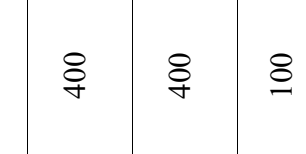 \\
\hline 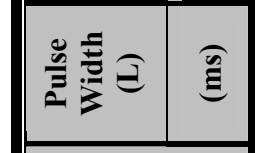 & 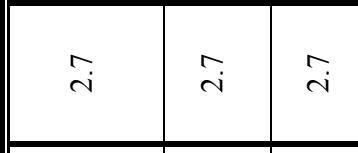 & & & $=$ & & 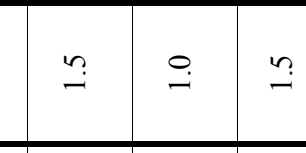 \\
\hline & & & & & & 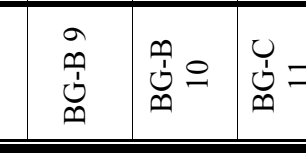 \\
\hline
\end{tabular}




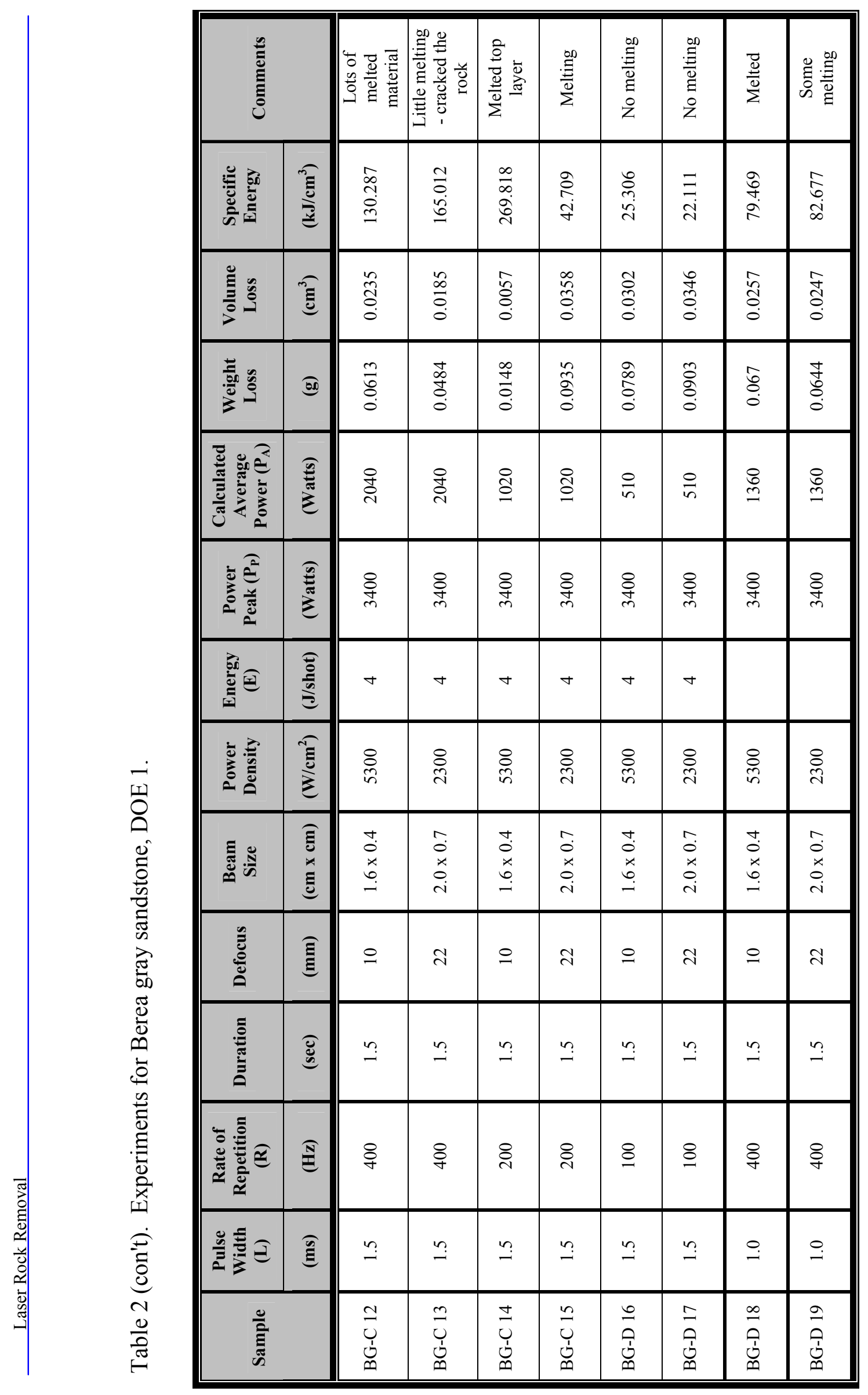




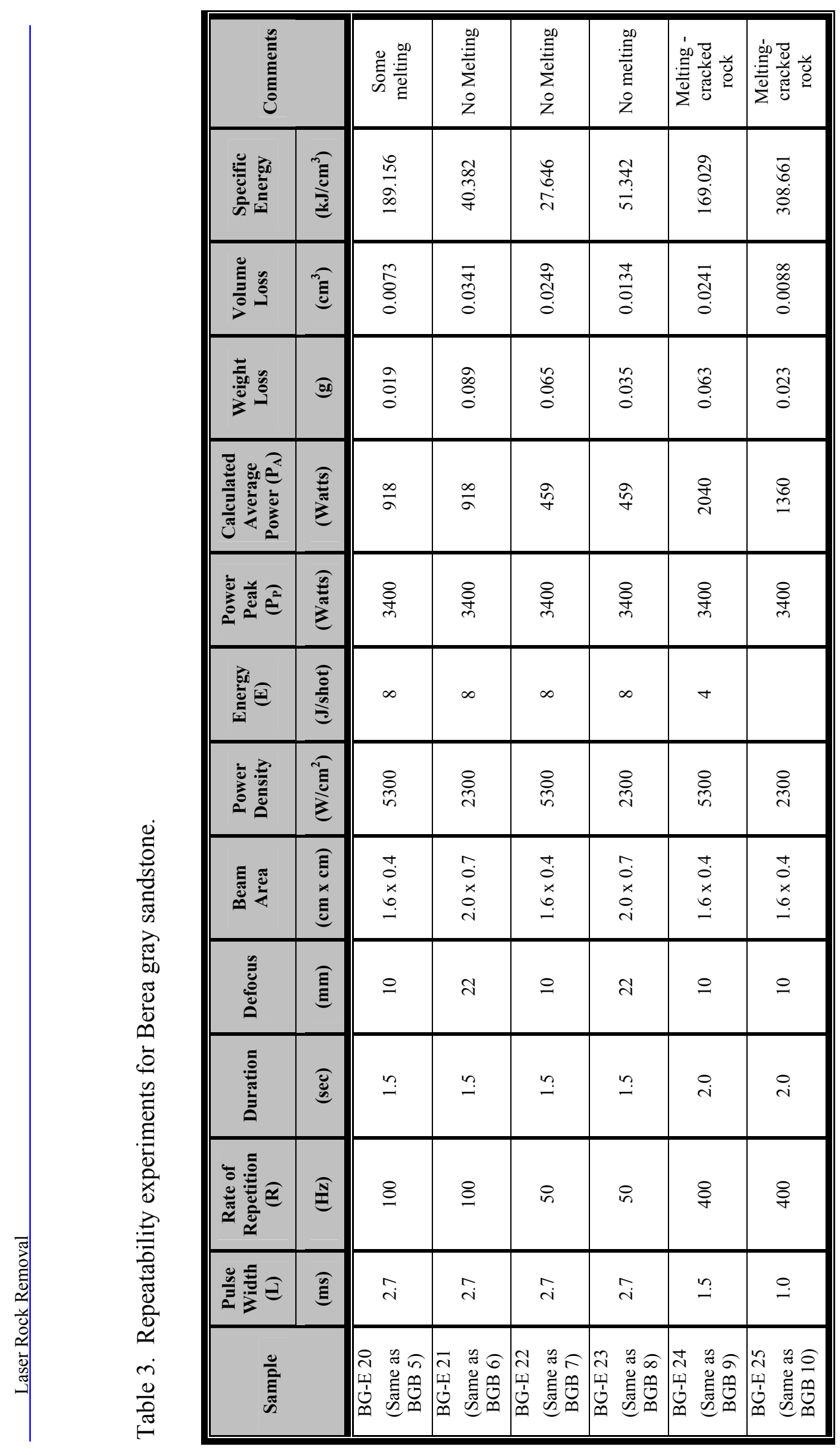

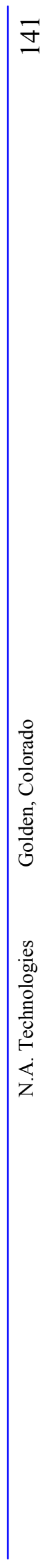




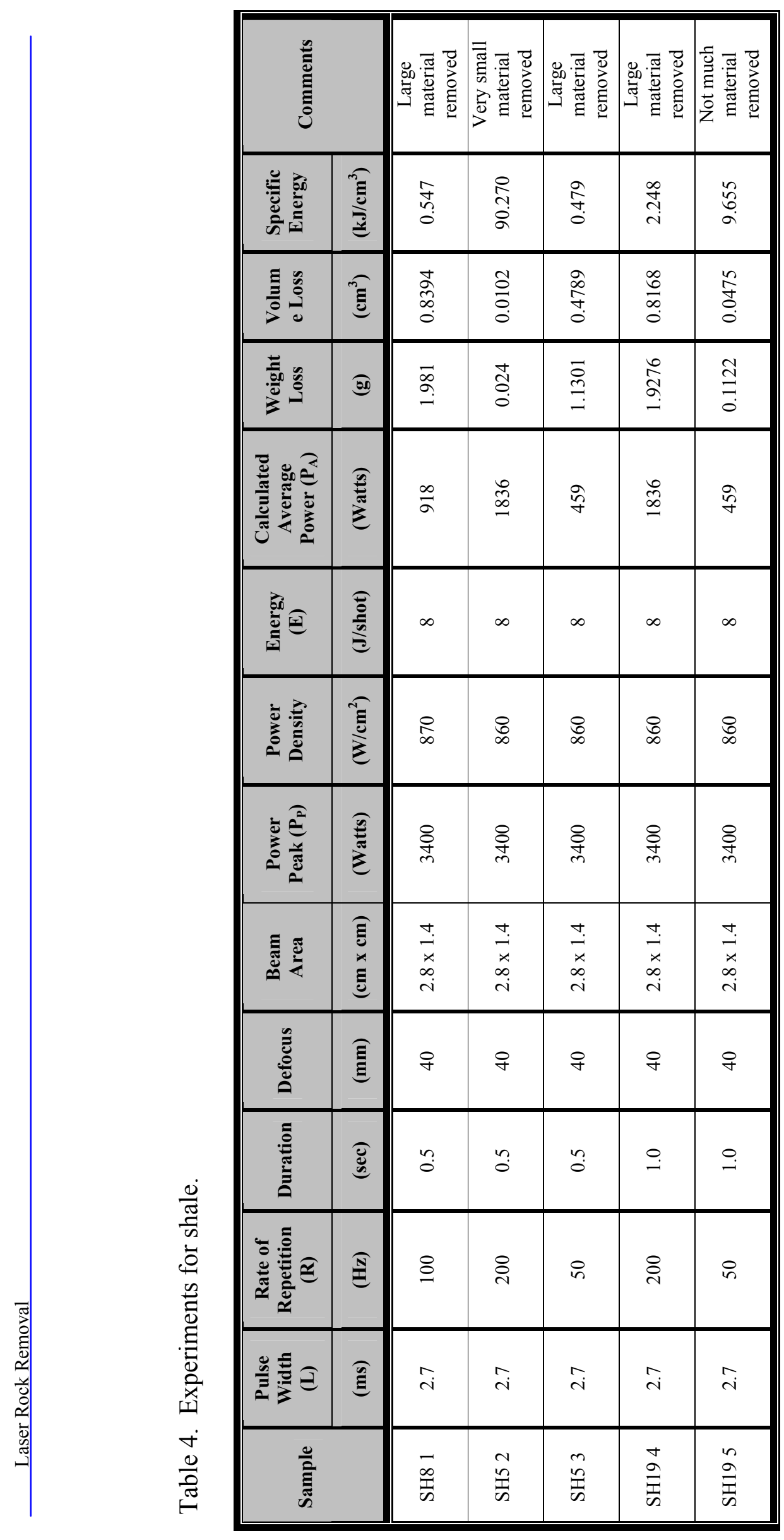




\begin{tabular}{|c|c|c|c|c|c|c|}
\hline I & & 能离 & 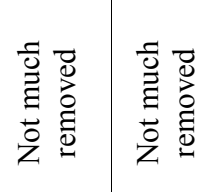 & $\underline{I n}$ & 83 & 1 \\
\hline 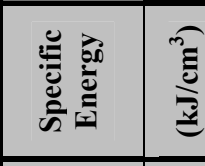 & \begin{tabular}{|l|l|} 
\\
\end{tabular} & $\frac{1}{\underline{3}}$ & 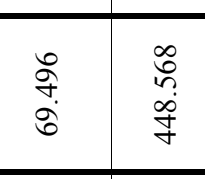 & & 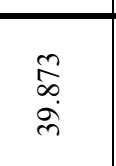 & $\frac{8}{8}$ \\
\hline 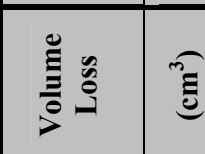 & 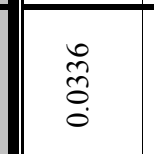 & \begin{tabular}{l|l}
$\frac{g}{\partial}$ \\
\end{tabular} & 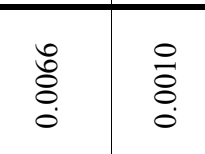 & 言 & 管 & 言 \\
\hline 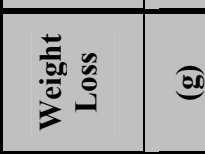 & \begin{tabular}{|l|l|}
$\frac{1}{2}$ \\
\end{tabular} & 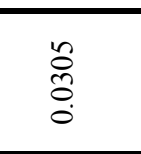 & 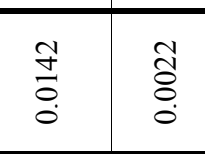 & & $\frac{8}{3}$ & 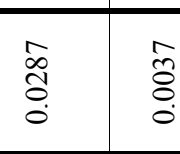 \\
\hline 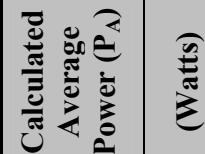 & 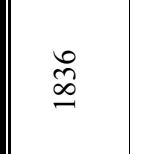 & 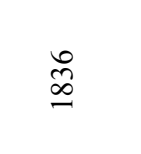 & \begin{tabular}{l|l}
$\frac{D}{\sigma}$ \\
\end{tabular} & & 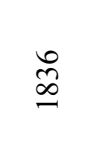 & $\frac{\partial}{\partial}$ \\
\hline 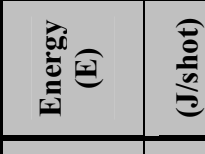 & $\infty$ & ${ }^{\circ}$ & $\cdots$ & ". & " & $\overline{.}$ \\
\hline 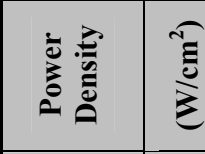 & $\frac{\rho}{\bar{B}}$ & $\bar{\Sigma}$ & 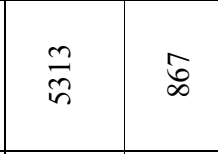 & 8 & 言 & $\bar{D}$ \\
\hline 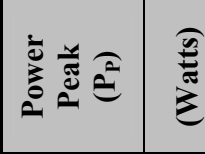 & 量 & 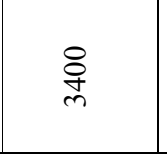 & 量量 & & 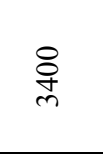 & 量等 \\
\hline $\begin{array}{lll}15 \\
\end{array}$ & 譥 & 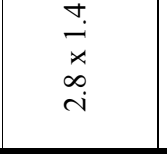 & 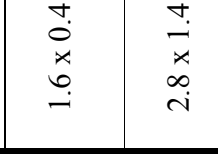 & & 资 & 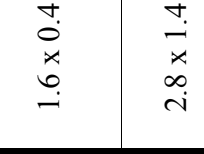 \\
\hline 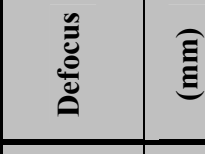 & $=$ & 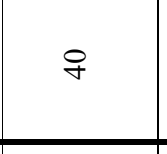 & $\because \approx$ & & $\approx$ & $=8$ \\
\hline$\overline{1}$ & $:$ & $\because$ & $\Rightarrow=$ & & $=$ & $\because \cong$ \\
\hline 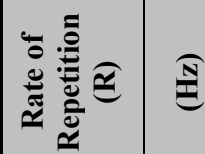 & 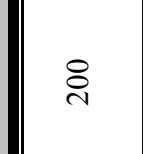 & $\frac{8}{3}$ & \begin{tabular}{|l|l}
$\underline{s}$ & $\underline{s}$
\end{tabular} & 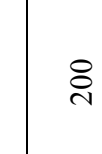 & 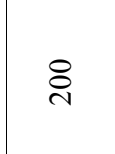 & 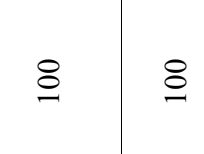 \\
\hline 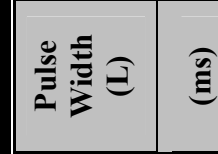 & $=$ & $\therefore$ & $\Rightarrow=$ & & & $\therefore=$ \\
\hline 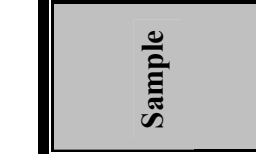 & | & & & & & 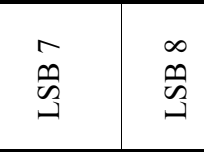 \\
\hline
\end{tabular}

